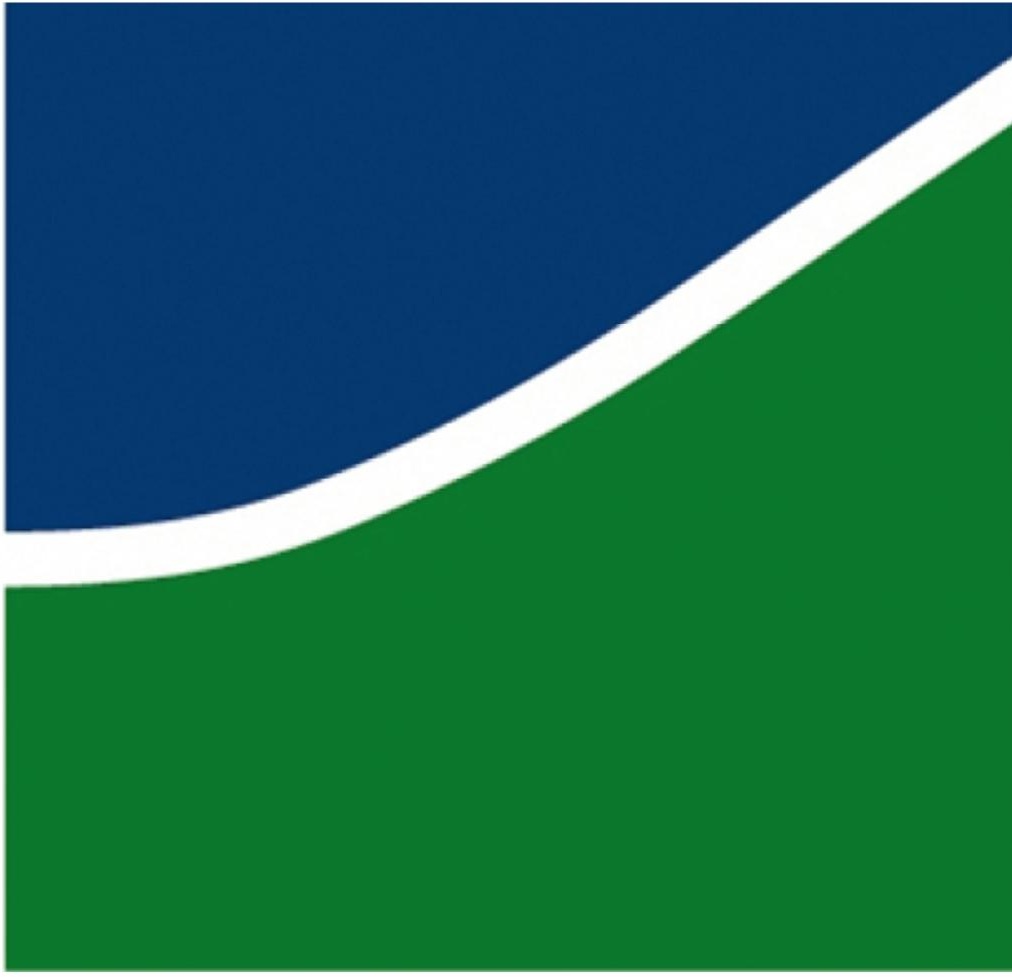

UNIVERSIDADE DE BRASÍLIA

Carolina Azevedo Guedes Ferreira

CARACTERIZAÇÃO ESTATÍSTICA DE CANAIS SEM FIO E PREDIÇÃO DE COBERTURA NA FAIXA DE 450 MHz COM APLICAÇÃO EM REDES CELULARES LTE 
Carolina Azevedo Guedes Ferreira

\section{CARACTERIZAÇÃO ESTATÍSTICA DE CANAIS SEM FIO E PREDIÇÃO DE COBERTURA NA FAIXA DE 450 MHz COM APLICAÇÃO EM REDES CELULARES LTE}

Dissertação de Mestrado submetida ao Departamento de Engenharia Elétrica da Universidade de Brasília, como parte dos requisitos necessários para a obtenção do título de Mestre em Engenharia Elétrica.

Orientador: Prof. Dr. Ugo Silva Dias

Publicação: PPGEE.DM - 596/15

Brasília/DF, Agosto de 2015 


\section{FICHA CATALOGRÁFICA}

\section{FERREIRA, CAROLINA AZEVEDO GUEDES}

Caracterização Estatística de Canais sem Fio e Predição de Cobertura na faixa de $450 \mathrm{MHz}$ com Aplicação em Redes Celulares LTE. [Distrito Federal] 2015.

88p., 210 x 297 mm (ENE/FT/UnB, Mestre, Engenharia Elétrica, 2015). Dissertação de Mestrado - Faculdade de Tecnologia. Universidade de Brasília.

Departamento de Engenharia Elétrica.

1. Futuro das Redes de Telecomunicações 2. Conceitos de LTE

3. Modelos de Canal sem fio

4. Medição de Campo

5. Planejamento de Redes Celulares
I. ENE/FT/UnB
II. Título (série)

\section{REFERÊNCIA BIBLIOGRÁFICA}

Ferreira, C. A. G. (2015). Caracterização Estatística de Canais sem Fio e Predição de Cobertura na faixa de $450 \mathrm{MHz}$ com Aplicação em Redes Celulares LTE. Dissertação de Mestrado em Engenharia Elétrica, Publicação PPGEE.DM-596/15, Departamento de Engenharia Elétrica, Faculdade de Tecnologia. Universidade de Brasília, Brasília, DF, 88p. 
UNIVERSIDADE DE BRASILLIA

FACULDADE DE TECNOLOGIA

DEPARTAMENTO DE ENGENHARIA ELÉTRICA

CARACTERIZAÇÃO ESTATÍSTICA DE CANAIS SEM FIO E PREDIÇÃO DE COBERTURA NA FAIXA DE 450 MHZ COM APLICAÇÃO EM REDES DE CELULARES LTE

\section{CAROLINA AZEVEDO GUEDES FERREIRA}

DISSERTAÇÃO DE MESTRADO SUBMETIDA AO DEPARTAMENTO DE ENGENHARIA ELÉTRICA DA FACULDADE DE TECNOLOGIA DA UNIVERSIDADE DE BRASILIA, COMO PARTE DOS REQUISITOS NECESSÁRIOS PARA A OBTENÇĀO DO GRAU DE MESTRE.

APROVADA POR:

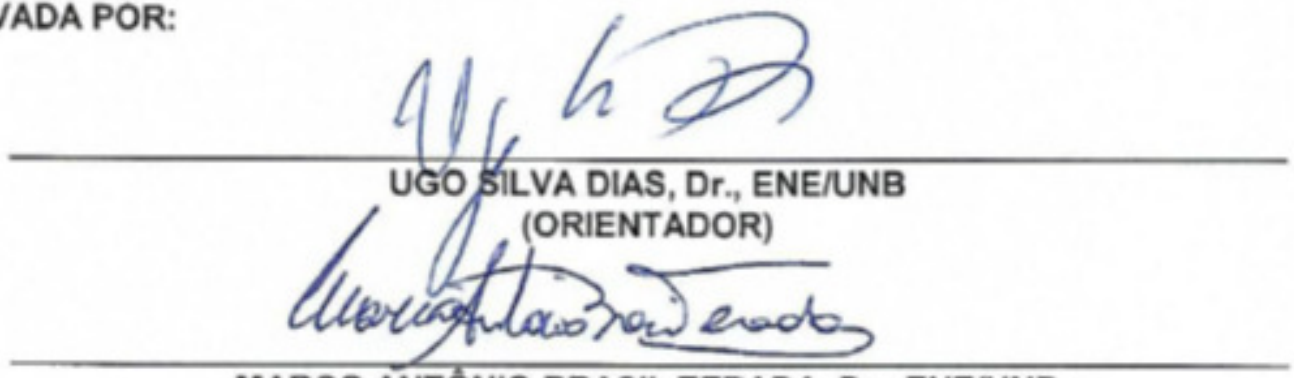

MARCO ANTÓNIO BRASIL TERADA, Dr., ENE/UNB

(EXAMINADOR INTERNO)

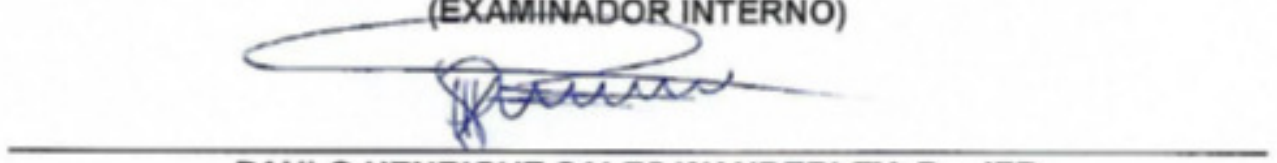

PAULO HENRIQUE SALES WANDERLEY, Dr., IFB

(EXAMINADOR EXTERNO) 


\section{Agradecimentos}

A Deus, por me permitir vivenciar esta grande e frutuosa experiência.

A minha família, pelo incentivo constante em todos os momentos. Ao meu esposo Paulo Cézar, pela paciência e companheirismo, por estar sempre ao meu lado.

Ao professor Ugo Silva Dias, pelo empenho, suporte e conhecimento compartilhado para o desenvolvimento e conclusão deste trabalho.

Aos meus amigos e todos que de forma direta ou indireta me incentivaram nesta jornada.

Carolina Azevedo Guedes Ferreira 


\section{Resumo}

Este trabalho apresenta uma investigação prática da modelagem estatística de canais sem fio utilizando a faixa de frequência de $450 \mathrm{MHz}$ com aplicação em futuras redes celulares LTE no Distrito Federal. Estatísticas de primeira e de segunda ordens, tais como PDF, CDF e função de autocorrelação dos modelos de desvanecimento $\alpha-\mu$, Nakagami- $m$, Rice e Rayleigh, são confrontadas entre si e com os dados experimentais coletados em ambientes do cerrado brasileiro. Os resultados mostram um excelente desempenho da distribuição generalizada $\alpha-\mu$, na qual apresentou o melhor ajuste aos dados experimentais, tanto nas estatísticas de primeira quanto nas de segunda ordens. Além disso, foram realizadas predições de cobertura para o sistema 4G LTE na faixa de $450 \mathrm{MHz}$ para ambientes externos e internos em áreas rurais e suburbanas do Distrito Federal com a finalidade principal de investigar a utilização da tecnologia LTE na faixa de frequência de $450 \mathrm{MHz}$ para estas áreas.

Palavras-chave: Canal sem Fio, Caracterização Estatística, Medição de Campo, LTE 450, Predição de cobertura. 


\section{Abstract}

This work presents a practical investigation of the statistical modeling of wireless channels using the frequency range $450 \mathrm{MHz}$ with application in future cellular networks LTE in the Distrito Federal. First and second orders statistics, such as PDF, CDF and autocorrelation function of $\alpha-\mu$ fading models, Nakagami-m, Rice and Rayleigh, are confronted with each other and with the experimental data collected in the Brazilian cerrado environments. The results show an excellent performance of the $\alpha-\mu$ widespread distribution, which presented the best fit to the experimental data, both in the first statistics as the second orders. In addition, coverage predictions were made for the $4 \mathrm{G}$ LTE system in the $450 \mathrm{MHz}$ band for external and internal environments in rural and suburban areas of the Federal District for the primary purpose of investigating the use of LTE technology in the $450 \mathrm{MHz}$ frequency range for these areas.

Keywords: Wireless Channel, Statistics characterization, Field measurement, LTE 450, coverage prediction. 


\section{Lista de Siglas}

$1 \mathrm{G}$

1XRTT

$2 \mathrm{G}$

$3 \mathrm{G}$

3GPP

4G

A/D

AMPS

ANATEL

$\mathrm{CDF}$

CDMA

$\mathrm{dBm}$

EDGE

eNodeB

EPC

ERB

E-UTRAN

FDD

GPRS

GSM

HSPA

HSS

IMT

IP

ITU

LNA

LEMOM

LOS

LTE
First Generation

1 x Radio Transmission Technology

Second Generation

Third Generation

Third Generation Partnership Project

Fourth Generation

Analógico/Digital

Advanced Mobile Phone System

Agência Nacional de Telecomunicações

Cumulative Distribution Function

Code Division Multiple Access

Ganho em decibel com relação a 1 miliwatt

Enhanced Data rate for GSM Evolution

Evolved Node B

Evolved Packet Core

Estação Rádio Base

Evolved UMTS Terrestrial Radio Access Network

Frequency Division Duplexing

General Packet Radio Service

Global System for Mobile Communications

High Speed Packet Acces

Home Subscription Server

Programa Internacional de Telecomunicações Móveis

Internet Protocol

International Telecommunications Union

Amplificador de Baixo Ruído (do inglês, Low Noise Amplifier)

Laboratório de Estruturas de Micro-ondas e Ondas Milimétricas

Line-of-Sight

Long-Term Evolution 


$\begin{array}{ll}\text { MAC } & \text { Medium Access Control } \\ \text { ME } & \text { Mobile Equipment } \\ \text { MME } & \text { Mobility Management Entity } \\ \text { MT } & \text { Mobile Termination } \\ \text { PCRF } & \text { Policy and Charging Resource Function } \\ \text { PDF } & \text { Probability Density Function } \\ \text { PHY } & \text { Physical Layer } \\ \text { QAM } & \text { Quadrature Amplitude Modulation } \\ \text { QoS } & \text { Quality of Service } \\ \text { QPSK } & \text { Quadrature Phase Shift Keying } \\ \text { RLC } & \text { Radio Link Control } \\ \text { SG11 } & \text { Prédio de laboratório da Universidade de Brasilia } \\ \text { SGW } & \text { Serving Gateway } \\ \text { TCP } & \text { Transmission Control Protocol } \\ \text { TDD } & \text { Time Division Duplex } \\ \text { TDMA } & \text { Time Division Multiple Access } \\ \text { TE } & \text { Termination Equipment } \\ \text { UE } & \text { User Equipment } \\ \text { UICC } & \text { Universal Integrated Circuit Card } \\ \text { UMTS } & \text { Universal Mobile Telecommunication System de Brasília } \\ \text { UnB } & \end{array}$




\section{Lista de Símbolos}

\section{Símbolos Gregos}

$\alpha$

$\sigma$

$\sigma^{2}$

$\lambda$

$\mu$

$\Gamma($.
Parâmetro de potência

Desvio Padrão

Variância

Comprimento de Onda

Número de componentes que formam o sinal. Parâmetro

inversamente proporcional à severidade do desvanecimento de curto prazo

Função Gama

\section{Símbolos Latinos}

$\begin{array}{ll}L F & \text { Perda no Espaço Livre } \\ P_{T} & \text { Potência Efetiva Isotrópica Transmitida } \\ P_{R} & \text { Potência Prevista Isotrópica Recebida } \\ G_{T}, G_{R} & \text { Ganhos das Antenas Terminais } \\ r & \text { Variável aleatória do desvanecimento de curto prazo que } \\ & \text { refere-se à envoltória do sinal } \\ \hat{r} & \text { Raiz quadrada da potência média ou valor rms da envoltória. } \\ & \text { Para a distribuição } \alpha \text { - } \mu \text {, significa a raiz } \alpha \text {-ésima da envoltória } \\ & \text { média elevada a } \alpha \\ f & \text { Frequência da Portadora } \\ c & \text { Constante de Propagação no Espaço Livre } \\ R & \text { Distância entre estação rádio base e móvel [km] } \\ I_{0} & \text { Função de Bessel de ordem o } \\ f_{R} & \text { PDF da distribuição } R \\ F_{R} & \text { CDF da distribuição } R\end{array}$




$\begin{array}{ll}E(.) & \text { Esperança } \\ \operatorname{Var}[.] & \text { Variância } \\ \rho[.] & \text { Coeficiente de autocorrelação } \\ { }_{2} F_{1}(.) & \text { Função hipergeométrica } \\ Q_{1} & \text { Marcum Function } \\ m & \text { Fator de desvanecimento, representa número de clusters } \\ & \text { multipercurso } \\ k & \text { Fator de Rice }\end{array}$




\section{Lista de Figuras}

1.1 Perspectiva de crescimento da quantidade de dispositivos móveis no mundo 2

$\begin{array}{ll}2.1 \text { Evolução da tecnologia celular. } & 7\end{array}$

2.2 Arquitetura de alto nível do LTE

2.3 Faixas de frequência designadas no Brasil 11

2.4 Relação entre frequência, raio de cobertura e número de estações rádio base 14

4.1 Amplificador de baixo ruído 26

4.2 Fonte de alimentação 26

$\begin{array}{ll}4.3 \text { Analisador de espectro } & 27\end{array}$

4.4 LabJack 28

4.5 Software LJstream 28

4.6 Analisador de Rede FieldFox 29

4.7 Antena Omnidirecional utilizada na recepção 30

4.8 Antena Omnidirecional utilizada na transmissão 30

4.9 Amplificador utilizado na transmissão 31

4.10 Diagrama de equipamentos na recepção 32

4.11 Antena acoplada ao carro $\quad 32$

4.12 Diagrama de equipamentos na transmissão 33

4.13 Sistema de transmissão 33

4.14 Prédio SG-11 UnB. Transmissor instalado no terraço 34

4.15 Vista aérea de um dos ambientes medidos 35

4.16 Via L3 35

4.17 Sinal total obtido a partir de uma das amostras coletadas $\quad 37$

4.18 Desvanecimento de longo prazo obtido a partir de uma das amostras

coletadas 38

4.19 Desvanecimento de curto prazo obtido a partir de uma das amostras coletadas 38

4.20 PDFs teórica vs. experimental em ambiente LOS rural 39

4.21 PDFs teórica vs. experimental em ambiente LOS suburbano 40

4.22 PDFs teórica vs. experimental em ambiente LOS com predominância de $\begin{array}{ll}\text { vegetações baixas } & 40\end{array}$

4.23 CDFs teórica vs. experimental em ambiente LOS rural 41 
4.25 CDFs teórica vs. experimental em ambiente LOS com predominância de vegetações baixas

4.26 Funções de autocorrelação teóricas vs. experimental em ambiente LOS suburbano

4.27 Funções de autocorrelação teóricas vs. experimental em ambiente LOS rural 43

5.1 Configurações do Rádio

5.2 Configurações de ambiente para o cenário Outdoor

5.3 Configurações do terminal para o cenário Outdoor

5.4 Cadastro das ERBs para o LTE $450 \mathrm{MHz}$ no software CelPlanner

5.5 Diagrama de irradiação da antena LPD 3805/2

5.6 Balanceamento de enlace do LTE 450 MHz pelo software CelPlanner

5.7 Sensibilidade no receptor LTE $450 \mathrm{MHz}$

5.8 Cobertura no sentido downstream para ambientes outdoors - Núcleo 1 55

5.9 Cobertura no sentido upstream para ambientes outdoors - Núcleo 1 56

5.10 Cobertura no sentido downstream para ambientes indoors - Núcleo 1 57

5.11 Cobertura no sentido upstream para ambientes indoors - Núcleo 1 58

5.12 Cobertura no sentido downstream para ambientes outdoors - Núcleo 2 59

5.13 Cobertura no sentido upstream para ambientes outdoors - Núcleo 2 59

5.14 Cobertura no sentido downstream para ambientes indoors - Núcleo 2 60

5.15 Cobertura no sentido upstream para ambientes indoors - Núcleo 2 61

5.16 Cobertura no sentido downstream para ambientes outdoors - Núcleo 3 62

5.17 Cobertura no sentido upstream para ambientes outdoors - Núcleo 3 63

5.18 Cobertura no sentido downstream para ambientes indoors - Núcleo 3 64

5.19 Cobertura no sentido upstream para ambientes indoors - Núcleo 3 


\section{Lista de Tabelas}

1.1 Números de usuários de smartphones na América Latina, por país (milhões) 2

2.1 Faixas de Frequências LTE FDD 12

2.2 Faixas de Frequências LTE TDD 12

2.3 Raio de cobertura LTE por frequência em cada tipo de ambiente (em Km) 14

$\begin{array}{ll}3.1 \text { Parâmetros para o modelo de Lee } & 18\end{array}$

4.1 Parâmetros de Desvanecimento 43

4.2 Erros médios calculados 43

5.1 Solução do fabricante WxBR para a tecnologia LTE $450 \mathrm{MHz}$ 


\section{Sumário}

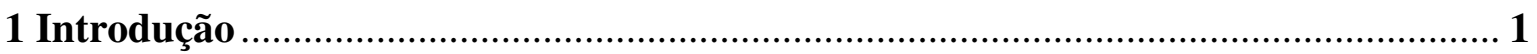

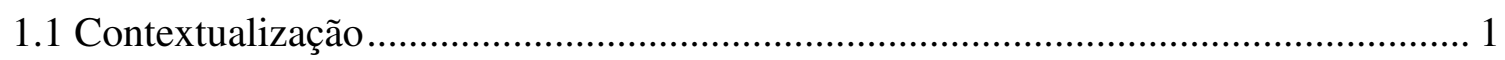

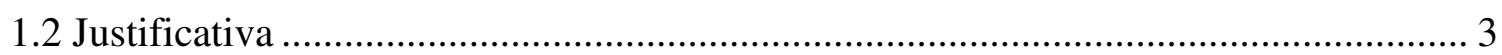

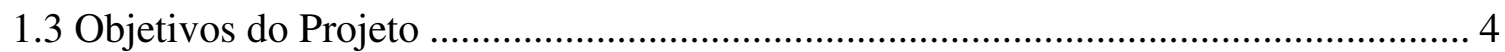

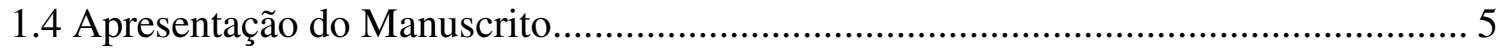

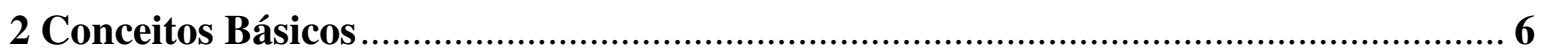

2.1 Evolução dos Sistemas de Comunicação ……............................................................ 6

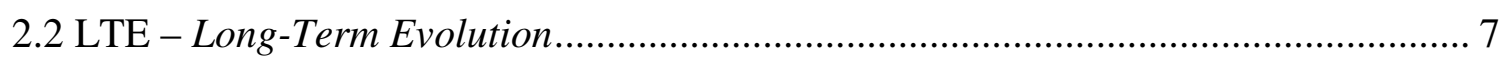

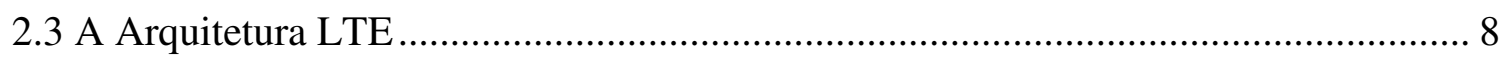

2.4 Bandas de Frequências para celular no Brasil .......................................................... 10

2.4.1 Faixas de Frequências para o LTE ............................................................................11

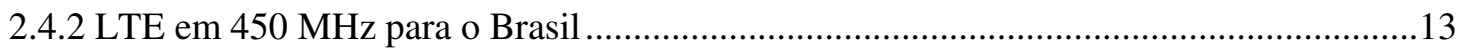

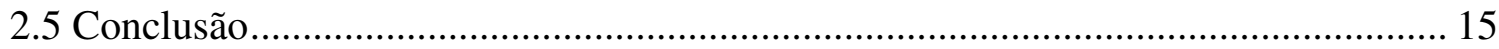

3 Modelos de Propagação com Aplicação em Redes Celulares ..................................... 16

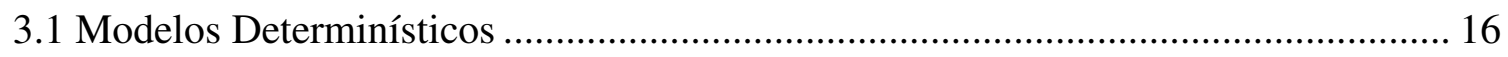

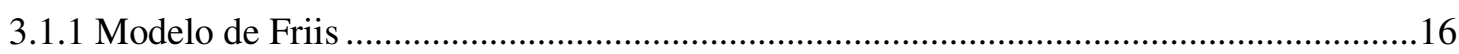

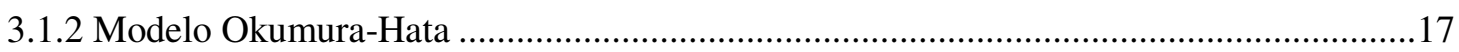

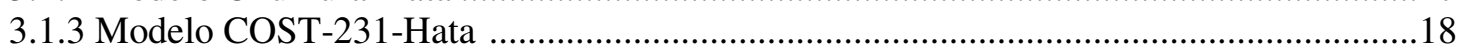

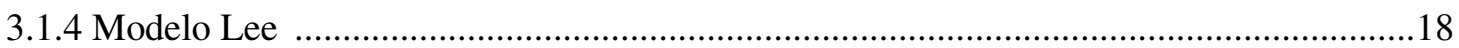

3.2 Desvanecimentos e Modelos Estatísticos ............................................................... 19

3.2.1 Desvanecimento de Longo Prazo ..................................................................................

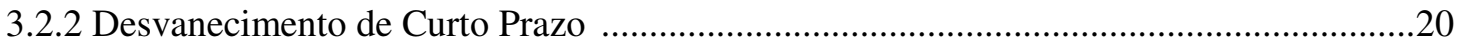

3.3 Modelos de Desvanecimento de Curto Prazo ................................................................ 20

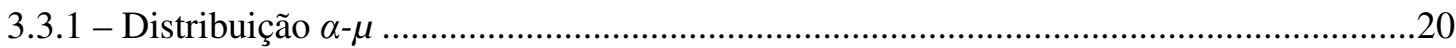

3.3.2 - Distribuições de Nakagami-m e Rayleigh .................................................................22

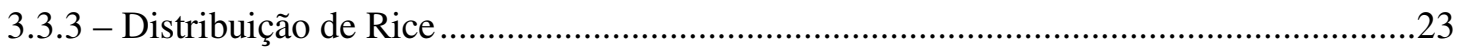

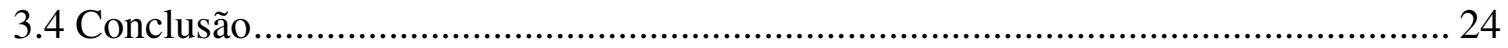

4 Medições de Campo e Caracterização Estatística .................................................... 25

4.1 Equipamentos Utilizados e sua Montagem ............................................................... 25 


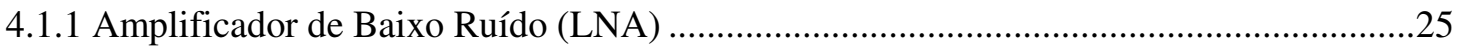

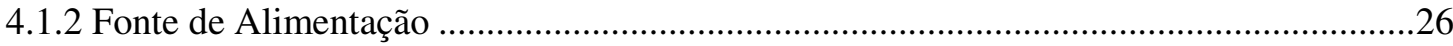

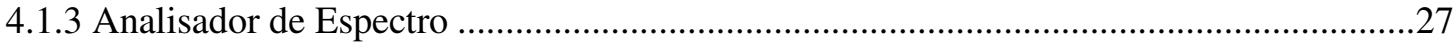

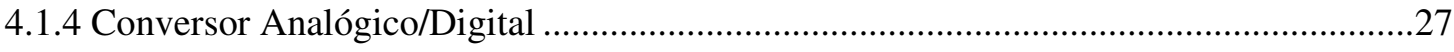

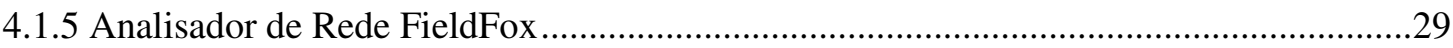

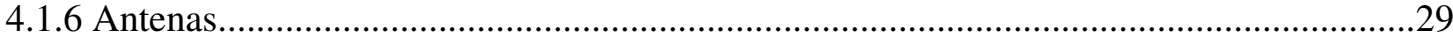

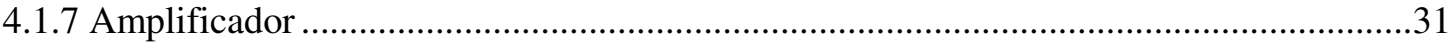

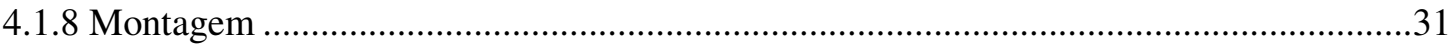

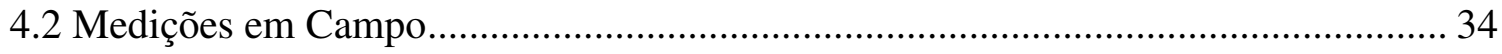

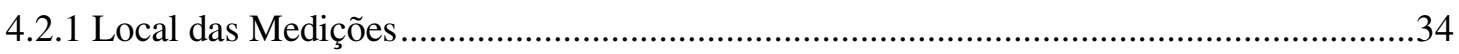

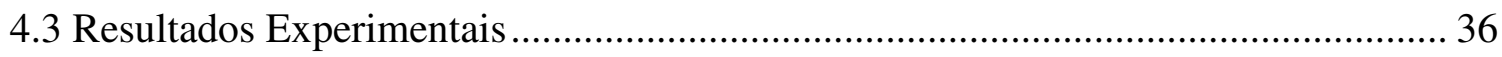

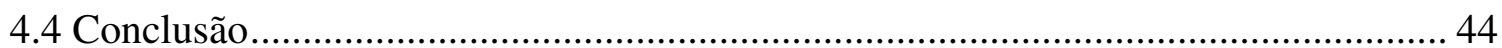

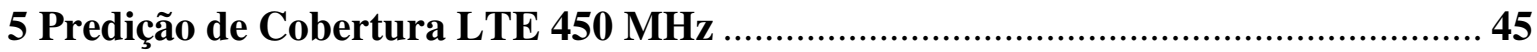

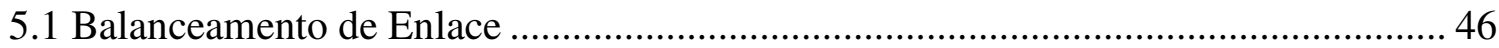

5.2 CelPlanner: Programa de Simulação ..................................................................... 46

5.2.1 Configurações realizadas para a simulação do LTE $450 \mathrm{MHz}$.......................................47

5.3 Resultados e Análises das simulações do LTE $450 \mathrm{MHz}$ em áreas rurais do Distrito

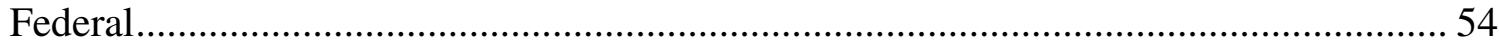

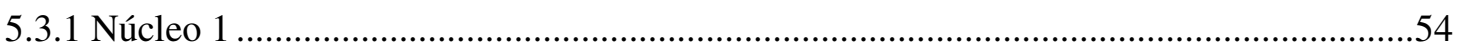

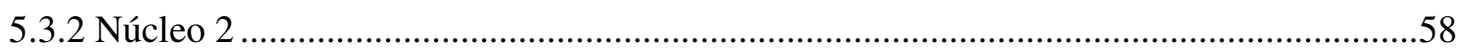

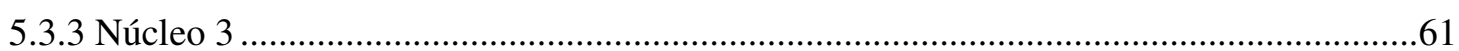

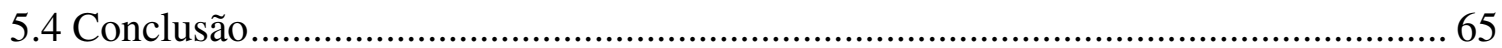

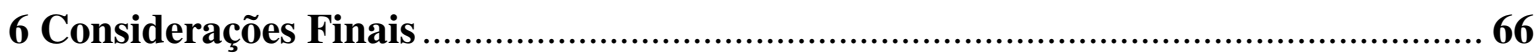

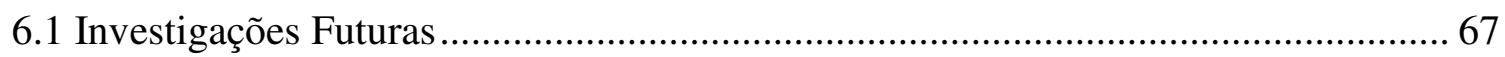

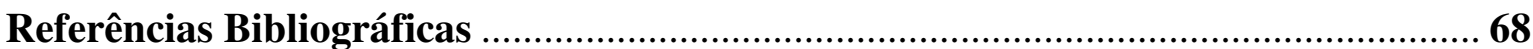




\section{Introdução}

\subsection{Contextualização}

A forma de como a sociedade em geral se comunica tem sido impactada diretamente com o decorrer do tempo. De modo especial, o surgimento dos meios de comunicação sem fio contribuiu para isto, e ainda contribui. Desde a invenção do telégrafo sem fio, por Gulielmo Marconi em 1896, as tecnologias sem fio tiveram notório destaque com avanços significativos.

Atualmente, a sociedade tem a sua disposição modos e dispositivos de comunicação mais fáceis/amigáveis e rápidos. Esta facilidade e rapidez, em grande parte, tornaram-se possível graças aos dispositivos móveis, que se tornaram, com o tempo, elementos quase que insubstituíveis para as pessoas. Esta tendência vem impulsionada pelo crescimento da indústria de comunicações móveis via rádio, que se desenvolve também a partir de melhorias na fabricação de circuitos digitais e de radiofrequência, pela integração de circuitos em larga escala, além de outras técnicas de miniaturização, transformando o mercado destes equipamentos [1].

O advento da telefonia celular é extremamente significativo para o crescimento do mercado de telefonia móvel. Desde sua origem, na década de 1940 até os dias atuais, o consumo de telefonia celular não para de crescer. Em 1990, o número de usuários era de aproximadamente 11 milhões [2]. Hoje, este número está na casa dos bilhões [2]. Segundo a UIT (União Internacional de Telecomunicações), o número de telefones móveis ao redor do mundo ultrapassou o número de telefones fixos pela primeira vez em 2002 [2]. Entretanto, os telefones móveis são apenas o início da revolução celular. A todo momento novos dispositivos são lançados, oferecendo organizadores pessoais e telefone, além de acesso a web, mensagens instantâneas, e-mail e outros serviços disponíveis na Internet.

Atualmente, o foco da indústria de tecnologia sem fio está voltado para a transmissão de dados, pois uma grande parcela do mercado utiliza a Internet a partir de dispositivos sem fio [2]. A Figura 1.1 ilustra o crescimento de vários tipos de dispositivos móveis que utilizam telefonia e dados, e seu crescimento ao longo dos últimos anos. 


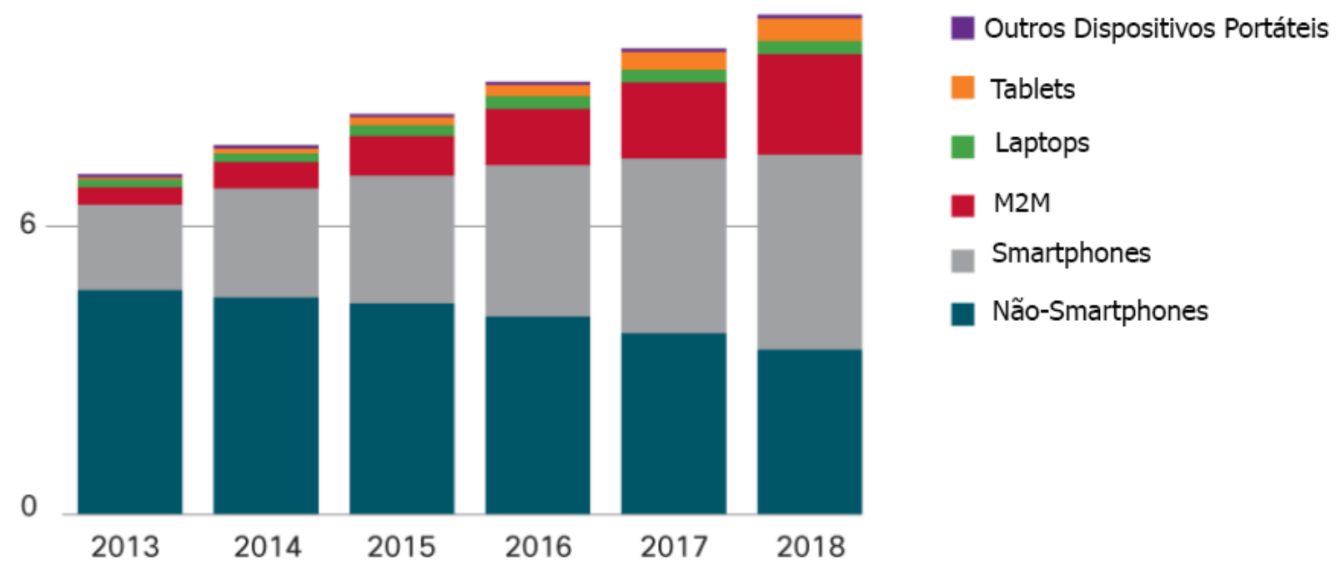

Figura 1.1: Perspectiva de crescimento da quantidade de dispositivos móveis no mundo [3].

O número de novos usuários de smartphones em 2013 na América Latina atingiu uma marca recorde, cerca de 35,4 milhões [4]. Em dezembro de 2013, o eMarketer divulgou projeções em que a taxa de crescimento de novos usuários de smartphones na América Latina continuará a crescer em taxas elevadas até 2017, como mostra a Tabela 1.1 [4].

Dessa forma, as redes de celulares precisaram evoluir em cobertura, capacidade, qualidade de serviço QoS (do inglês Quality of Service) [5], segurança da comunicação, melhor uso do espectro e aplicabilidade às situações do dia a dia moderno, sejam associadas à negócios, ao entretenimento, ou às interações interpessoais.

Tabela 1.1: Números de usuários de smartphones na América Latina, por país (milhões). Adaptado de [4].

\begin{tabular}{|c|c|c|c|c|c|c|}
\hline & $\mathbf{2 0 1 2}$ & $\mathbf{2 0 1 3}$ & $\mathbf{2 0 1 4}$ & $\mathbf{2 0 1 5}$ & $\mathbf{2 0 1 6}$ & $\mathbf{2 0 1 7}$ \\
\hline Brasil & 21,6 & 30,3 & 41,2 & 52,4 & 60,7 & 70,5 \\
\hline México & 18,4 & 27,4 & 33,3 & 40,4 & 47,3 & 54,4 \\
\hline Argentina & 8,0 & 10,4 & 12,7 & 14,8 & 16,6 & 18,4 \\
\hline Outros & 30,1 & 45,6 & 58,4 & 73,2 & 86,8 & 99,7 \\
\hline América Latina & 78,1 & 113,5 & 145,6 & 180,8 & 211,4 & 243,0 \\
\hline
\end{tabular}

No ritmo das mudanças e evolução da telefonia móvel, o Brasil começou a utilizar como tecnologia 4G, o LTE (do inglês, Long-Term Evolution).

O 4G em si encontrou vários obstáculos, como dificuldades na implantação da infraestrutura e todos os problemas envolvendo a frequência da banda a ser utilizada. Esta tecnologia chegou ao Brasil juntamente com a Copa da Confederações de 2014, com o objetivo de atender a demanda crescente de maior velocidade e alcance da internet no Brasil. 
Em 2012, através de licitação da faixa de frequência de 2500 MHz, a Anatel, Agência Nacional de Telecomunicações, disponibilizou as frequências para a implantação de redes 4G no Brasil, tendo como vencedoras desta licitação as empresas: Vivo, Tim, Claro, Oi, Sky e Sunrise. No mesmo ano, a ANATEL impôs a estas empresas, vencedoras do leilão das subfaixas 4G situadas em áreas urbanas, a implantação de redes de banda larga em áreas rurais, com as seguintes subfaixas: $451 \mathrm{MHz}$ a $458 \mathrm{MHz}$ e $461 \mathrm{MHz}$ a $468 \mathrm{MHz}$.

\subsection{Justificativa}

Historicamente, o Brasil alocou espectro de frequência abaixo de $1 \mathrm{GHz}$ para comunicações ponto-a-ponto e serviços de voz ponto-multiponto ou ponto-área, áudio e transmissão de vídeo e outros serviços especializados. A mudança de paradigma nas políticas de regulamentação do espectro começou em maio de 2010, quando o Plano Nacional de Banda Larga promoveu a banda $225-470 \mathrm{MHz}$ como uma alternativa para acomodar os serviços e aplicações de redes de altas taxas de dados no país. Logo após, ainda nesse mesmo ano, a Agência Nacional de Telecomunicações (ANATEL) iniciou esforços para criar regras de implantação de serviços de altas taxas na faixa de 450MHz. Na Resolução 558/2010 [6], a ANATEL especifica os requisitos técnicos para usar a banda 450-470 MHz, em conformidade com as recomendações da União Internacional de Telecomunicações (UIT) para a região das Américas [7].

Na sequência desse movimento, em Junho de 2012, a ANATEL leiloou licenças para as bandas de $450 \mathrm{MHz}$ e $2,5 \mathrm{GHz}$ para sistemas celulares de quarta geração (4G). Como consequência direta, a banda de $450 \mathrm{MHz}$ foi dividida em quatro áreas geográficas, cada uma atribuída a uma operadora principal que já opera no mercado brasileiro. Por meio dessa iniciativa, o governo brasileiro espera criar condições para aumentar o acesso a serviços de internet em todo o território brasileiro, em particular, para os 30 milhões de pessoas que vivem em regiões rurais, onde é provável que os titulares das licenças devam adotar a banda de $450 \mathrm{MHz}$, de modo a usufruir de suas vantagens na propagação de rádio, minimizando assim os custos com infraestrutura [8].

Apesar do LTE 450 ser uma proposta interessante, tanto sua especificação quanto sua implementação apresentam uma série de desafios práticos que poderão prejudicar seriamente o planejamento das futuras redes. De fato, o desempenho dos sistemas de comunicação sem fio nesta faixa é penalizado pela natureza estocástica do canal rádio móvel. No percurso entre transmissor e receptor, além da perda de propagação, o sinal rádio móvel 
pode ser bloqueado por obstruções físicas - o sombreamento - e sofrer múltiplas reflexões, espalhamentos e difrações - o multipercurso.

Neste contexto, se faz extremamente necessário realizar estudos de caracterização estatística na faixa de $450 \mathrm{MHz}$ que possam investigar e sugerir modelos de desvanecimento a serem utilizados no planejamento das redes LTE 450 com suas implicações práticas. Bem como, realizar a predição de cobertura para o sistema 4G LTE na faixa de $450 \mathrm{MHz}$ para ambientes externos e internos em áreas rurais do Distrito Federal com a finalidade principal de investigar a utilização da tecnologia LTE na faixa de frequência de $450 \mathrm{MHz}$ para estas áreas.

\subsection{Objetivos do Projeto}

Este projeto tem como objetivos obter e analisar com dados práticos os canais sem fio em ambientes externos na faixa de frequência de $450 \mathrm{MHz}$, bem como fazer a predição de cobertura nesta faixa de frequência em algumas áreas rurais do Distrito Federal. Tal frequência foi disponibilizada para a rede $4 \mathrm{G}$ brasileira, com uso da tecnologia LTE.

Na primeira parte do projeto são obtidos dados experimentais de transmissões na frequência estudada. Todas as medições são realizadas com equipamentos do Laboratório de Estruturas de Micro-ondas e Ondas Milimétricas (LEMOM). Essas medidas são processadas com a finalidade de cumprir alguns objetivos como: separação das componentes dos sinais sem fio na faixa de $450 \mathrm{MHz}$ - desvanecimento de longo prazo (sombreamento + perda de percurso) e desvanecimento de curto prazo (multipercurso); obtenção das densidades de probabilidades das envoltórias medidas dos sinais sem fio em desvanecimento de curto prazo; obtenção das PDFs dos modelos tradicionais (Rayleigh, Rice, Nakagami-m e $\alpha-\mu)$ e comparação com as medidas experimentais; obtenção das CDFs dos modelos tradicionais (Rayleigh, Rice, Nakagami-m e $\alpha-\mu$ ) e comparação com as medidas experimentais; obtenção das funções de autocorrelação experimentais e comparação com modelos teóricos.

$\mathrm{Na}$ segunda parte do projeto, através do programa computacional de simulação CelPlanner é possível realizar a predição de cobertura para o sistema 4G LTE na faixa de $450 \mathrm{MHz}$ para ambientes externos e internos em áreas rurais do Distrito Federal com a finalidade principal de investigar a utilização da tecnologia LTE na faixa de frequência de 450MHz para estas áreas. 


\subsection{Apresentação do Manuscrito}

O trabalho se organiza de maneira a permitir ao leitor acompanhar o desenvolvimento deste projeto.

No Capítulo 2, são abordados os sistemas de quarta geração LTE assim como sua arquitetura e suas bandas de frequência.

No Capítulo 3, serão abordados Modelos para investigação de redes celulares através de Modelagens estatísticas de desvanecimento, como Rayleigh, Rice, Nakagami- $m$ e $\alpha-\mu$, além de apresentar conceito de autocorrelação.

No Capítulo 4, é exposto o processo de montagem para obtenção dos dados práticos, bem como a apresentação dos equipamentos, percursos e parâmetros utilizados. Além disso, apresenta as estatísticas dos canais estudados e realiza comparações entre os dados práticos e os obtidos através dos modelos teóricos. Para a autocorrelação, a comparação é feita apenas com a função de autocorrelação $\alpha-\mu$.

A seguir, o Capítulo 5, descreve o programa computacional CelPlanner utilizado para realizar as predições de cobertura e os cálculos de balanceamento de enlace das estações rádio base de interesse neste projeto, assim como, os parâmetros utilizados nas configurações das simulações. Além disso, pode ser visto os resultados obtidos através dessas simulações e as análises de cada cenário estudado neste projeto.

Finalizando, o Capítulo 6, apresenta as considerações finais e propõe a realização de trabalhos futuros. 


\section{Conceitos Básicos}

\subsection{Evolução dos Sistemas de Comunicação}

Em 1970, a AT\&T propôs o primeiro sistema telefônico celular de alta capacidade que ficou conhecido como AMPS (do inglês Advanced Mobile Phone System) e em 1983, o primeiro sistema celular entrava em operação comercial nos EUA, utilizando o que se chamou de primeira geração (1G). A tecnologia de primeira geração utilizada no Brasil também foi o AMPS.

Esta primeira geração (1G) utilizava técnicas analógicas de comunicação, as células eram grandes, o espectro era mal utilizado e apresentava uma capacidade muito baixa.

Devido a pressão de demanda, especialmente nos EUA, onde o sistema analógico havia atingido o limite de sua capacidade nas maiores áreas metropolitanas e devido à necessidade de padronização do sistema celular europeu, iniciou-se uma nova geração de sistema celular com base em sistemas digitais, a segunda geração (2G).

Com a chegada dos sistemas de segunda geração (2G) no início dos anos 90 as comunicações móveis tornaram-se populares. A utilização de tecnologia digital permitiu melhor uso do espectro, diminuição no tamanho dos aparelhos e também dos custos. $\mathrm{O}$ TDMA (do inglês Time Division Multiple Access) surgiu como uma opção que mantinha a compatibilidade com a arquitetura e canalização utilizada pelos sistemas AMPS.

O sistema mais popular 2G foi GSM (do inglês Global System for Mobile). Outro sistema importante foi o IS-95, o primeiro padrão digital baseado em CDMA (do inglês Code Division Multiple Access).

Simultaneamente ao grande sucesso do sistema de comunicação de segunda geração, ocorreu a popularização da internet. Assim, as duas tecnologias começaram a se unir, e os usuários começaram a baixar dados a partir de seus dispositivos celulares. Neste contexto, as tecnologias $2 \mathrm{G}$ evoluíram para 2,5G com o advento do comutador de pacote de núcleo de rede e com a modificação da interface aérea, tornando possível a transmissão de voz e dados. O GSM surgiu com o GPRS e o CDMA com o 1xRTT.

A primeira evolução realmente experimentada pelo usuário do GSM foi o EDGE, sendo seguido pelo $3 \mathrm{G}$ nos anos 2000. Os sistemas de terceira geração utilizam técnicas diferentes de transmissão e recepção do que o $2 \mathrm{G}$, obtendo um aumento de velocidade e 
eficiência espectral. O sistema $3 \mathrm{G}$ dominante no mundo é UMTS e foi desenvolvido a partir do GSM. Para a família do CDMA a evolução para o 3G foi o CDMA EVDO.

Mais tarde, o sistema UMTS foi melhorado para aplicações de dados, com a introdução das tecnologias de 3,5G chamadas HSDPA (do inglês high speed downlink packet access) e HSUPA (do inglês high speed uplink packet access), que juntas formam o HSPA (do inglês high speed packet access).

A Figura 2.1, mostra a evolução dos sistemas de comunicação segundo as duas principais famílias, o GSM e o CDMA.

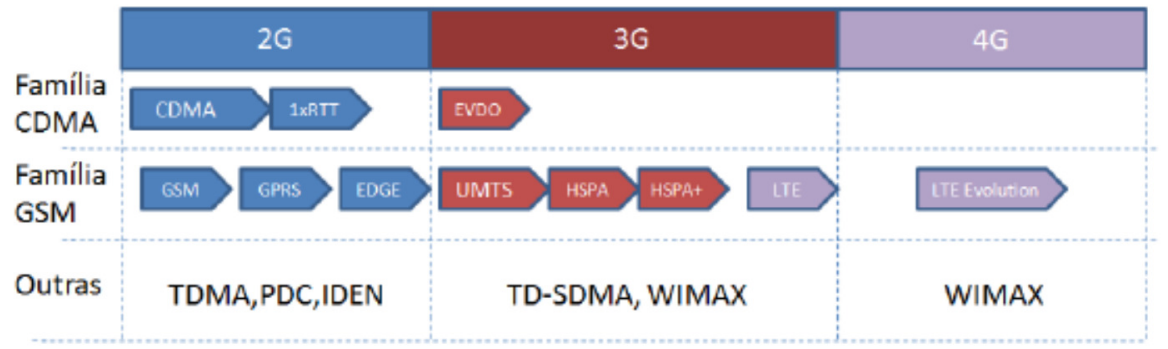

Figura 2.1: Evolução da tecnologia celular. Adaptado de [9]

\subsection{LTE - Long-Term Evolution}

Buscando-se soluções para tornar a transmissão de dados mais eficiente, ao mesmo tempo em que o volume desse tráfego encontra-se em ascensão, o padrão LTE (Evolução de Longo Prazo, do inglês Long Term Evolution) foi proposto como o próximo passo rumo ao sistema móvel de $4^{\mathrm{a}}$ Geração (4G), precedido pelas redes $2 \mathrm{G}$ e $3 \mathrm{G}$.

O sistema LTE foi concebido por uma colaboração de padronização de telecomunicações conhecido como Projeto de Parceria de Terceira Geração (3GPP, do inglês Third Generation Partnership Project). O LTE é uma evolução do UMTS (Sistema de Telecomunicações de Móvel Universal, do inglês Universal Mobile Telecomunication System).

O desenvolvimento do LTE começou em 2004 (release 8) com a definição de suas metas. A partir das discussões dos requisitos fundamentais para o novo sistema LTE, foi criado um estudo no 3GPP com a finalidade específico de evolução da tecnologia de acesso rádio 3GPP para garantir a competitividade ao longo de 10 anos [10]. Os requisitos para o LTE foram refinados, e finalizados em junho de 2005. Em resumo: 
- Redução de atrasos, tanto em termos de estabelecimento de conexão e latência de transmissão, a fim de melhorar o desempenho do usuário final;

- Aumento das taxas de dados dos usuários;

- Aumento da taxa de dados na borda da célula, para a uniformidade da prestação dos serviços;

- Reduzir o custo por bit, implicando melhora na eficiência espectral;

- Maior flexibilidade na utilização do espectro, em ambas as bandas novas e préexistentes;

- Arquitetura da rede simplificada;

- Mobilidade total, inclusive entre diferentes tecnologias de acesso de rádio;

- Consumo de energia razoável para o terminal móvel para permitir mais o uso de aplicações multimídia sem recarregar a bateria.

A compatibilidade com os sistemas anteriores é uma das exigências para uma tecnologia em termos de telefonia. Por esse aspecto, o LTE é compatível com as redes previamente estabelecidas, tanto as padronizadas pelo 3GPP como as demais.

\subsection{A Arquitetura LTE}

O LTE, por ser a evolução de sistemas anteriores, tem sua arquitetura desenvolvida a partir da arquitetura dos sistemas de terceira geração UMTS (do inglês Universal Mobile Telecommunication System). Esta nova arquitetura é simplificada em relação às gerações anteriores, sendo composta por três elementos principais: o equipamento do usuário (UE, do inglês User Equipament), a rede de acesso terrestre $3 \mathrm{G}$ a rádio evoluída (E-UTRAN, do inglês Evolved UMTS terrestrial Radio Access Network) e o núcleo evoluído de pacotes (EPC, do inglês Evolved Packet Core). A Figura 2.2 ilustra o sistema de arquitetura utilizada no LTE. 


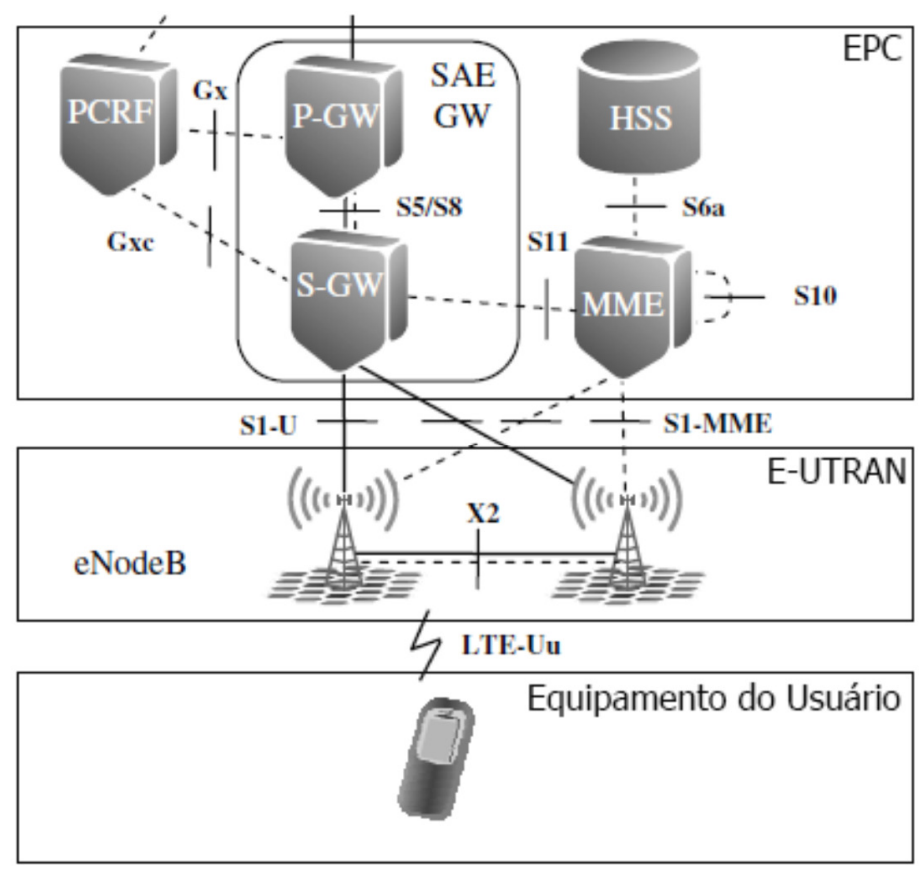

Figura 2.2: Arquitetura de alto nível do LTE [11].

O Equipamento do Usuário (UE) é composto da mesma arquitetura dos equipamentos de gerações anteriores (UMTS e GSM). Suas principais funções são criação, manutenção e remoção da comunicação com usuário final, além de fornecer a interface necessária para este usuário. Ele possui dois principais componentes, descritos a seguir:

- Um dispositivo de comunicação chamado de Equipamento Móvel (ME, do inglês Mobile Equipament), que pode ser dividido em Terminal Móvel (MT, do inglês Mobile Termination) e Equipamento Terminal (TE, do inglês Termination Equipament);

- Um cartão inteligente (UICC, do inglês Universal Integrated Circuit Card), coloquialmente chamado de SIM Card, com o objetivo de armazenar dados específicos do usuário e efetuar cálculos de segurança.

O UE assegura que parte do equipamento móvel e cada SIM card em circulação possam ser configurados para atender as necessidades do assinante.

A E-UTRAN é responsável pela comunicação entre o móvel e o EPC. Consiste de um único componente, conhecido como eNodeB ou eNB (do inglês Evolved Node B). As eNodeBs geralmente são distribuídas em toda a área de cobertura de redes, exercendo o controle das funções de rádio relacionadas a parte fixa do sistema. É composta pelas camadas física (PHY), controle de acesso ao meio (MAC), controle de enlace via rádio (RLC), além 
de funções como gestão de recursos de rádio, controle de qualidade de serviço, criptografia, compressão e descompressão de cabeçalhos de pacotes, entre outras.

O EPC é o elemento da arquitetura responsável por conectar a rede de dados com serviços externos. Entre as suas funções estão autenticação, segurança, gerenciamento de mobilidade, gerenciamento de perfil do usuário, conexão e autorização de serviços. Um grande diferencial deste núcleo é que ele não contém um domínio de comutação de circuitos, sendo equivalente ao domínio de comutação de pacotes das outras redes 3GPP existentes, apesar de sua arquitetura ser completamente nova [11]. O EPC possui os seguintes componentes principais:

- MME - Entidade de Gerenciamento de Mobilidade: é o principal elemento de controle do núcleo EPC. Possui funções de autenticação e segurança, gerenciamento de mobilidade e gerenciamento de serviços de conectividade.

- SGW - Gateway de Serviço: sua principal função é o roteamento e o encaminhamento de pacotes de dados. Além disso, atua na mobilidade de usuários durante handovers e mobilidade entre o sistema LTE e outras tecnologias (como $2 \mathrm{G}$ e 3G) [12].

- PGW - Gateway de Pacote de Dados: é o roteador de borda entre o núcleo e as redes de pacotes externas. Desempenha funções de propagação e filtragem de tráfego, conforme exigido por determinado serviço. Além disso, atua na mobilidade entre tecnologias 3GPP e tecnologias não-3GPP $[11,12]$.

- PCRF - Função de Política e Carregamento de Recursos: é o elemento da rede responsável pela determinação de políticas de controle. Toma decisões sobre como lidar com serviços em termos de QoS.

- HSS - Servidor de Assinatura Local: é um banco de dados central para todos os dados de usuários permanentes.

\subsection{Bandas de Frequências para celular no Brasil}

No Brasil, estão disponíveis atualmente as frequências nas bandas de:

- $850 \mathrm{MHz}$, antigas bandas A e B;

- $900 \mathrm{MHz}$, bandas de extensão utilizadas pelo GSM;

- 1700 e $1800 \mathrm{MHz}$, bandas D, E e subfaixas de extensão utilizadas pelo GSM;

- 1900 e $2100 \mathrm{MHz}$, destinadas na sua maior parte para sistemas 3G. 
No Brasil, a tecnologia padrão para $4 \mathrm{G}$ é o LTE, sendo adotado por todas as operadoras [13].

A Figura 2.3, mostra como estão designadas as frequências no Brasil.

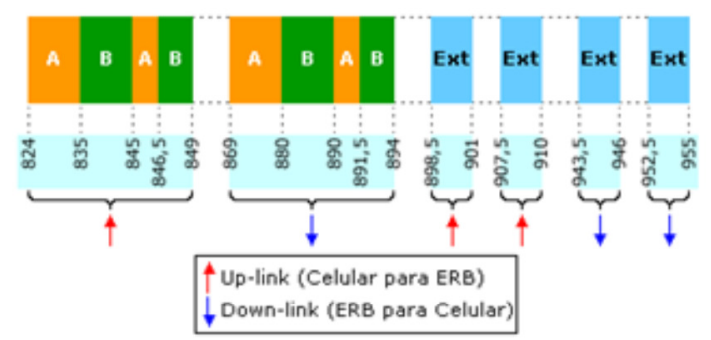

$850 \mathrm{MHz}$ e $900 \mathrm{MHz}$

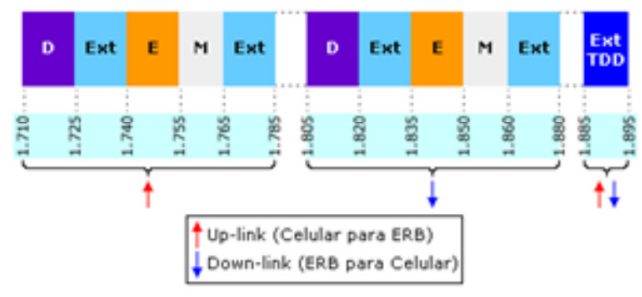

$1700 \mathrm{MHz}$ e $1800 \mathrm{MHz}$

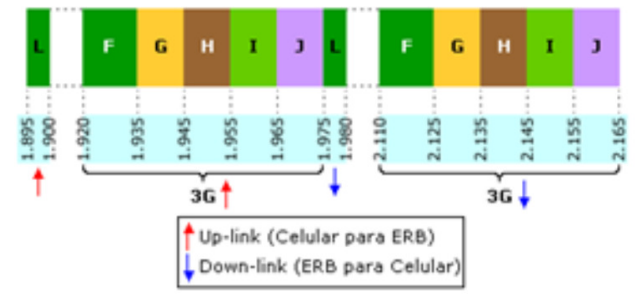

$1900 \mathrm{MHz}$ e $2100 \mathrm{MHz}$

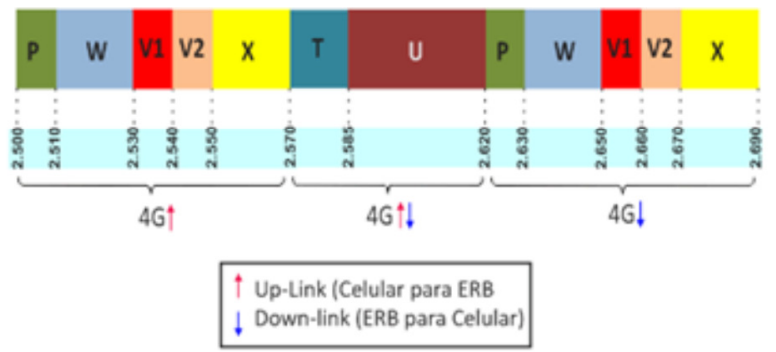

$2500 \mathrm{MHz}$

Figura 2.3: Faixas de frequência designadas no Brasil [14].

\subsubsection{Faixas de Frequências para o LTE}

As redes LTE utilizam em sua maioria um par de canais separados para transmissão e recepção (FDD, do inglês Frequency Division Duplex), embora existam também redes em que a transmissão e recepção compartilhem o mesmo canal (TDD, do inglês Time-Division Duplex).

As Tabelas 2.1 e 2.2 mostram a distribuição padronizada da canalização LTE operando em FDD e TDD, respectivamente. 
Tabela 2.1: Faixas de Frequências LTE FDD.

\begin{tabular}{|c|c|c|c|}
\hline \multicolumn{4}{|c|}{ LTE FDD } \\
\hline Banda LTE $\left(\mathbf{N}^{\circ}\right)$ & Uplink (MHz) & Downlink (MHz) & Largura de Banda (MHz) \\
\hline 1 & $1920-1980$ & $2110-2170$ & 60 \\
\hline 2 & $1850-1910$ & $1930-1990$ & 60 \\
\hline 3 & $1710-1785$ & $1805-1880$ & 75 \\
\hline 4 & $1710-1755$ & $2110-2155$ & 45 \\
\hline 5 & $824-849$ & $869-894$ & 25 \\
\hline 6 & $830-840$ & $875-885$ & 10 \\
\hline 7 & $2500-2570$ & $2620-2690$ & 70 \\
\hline 8 & $880-915$ & $925-960$ & 35 \\
\hline 9 & $1749,9-1784,9$ & $1844,9-1879,9$ & 35 \\
\hline 10 & $1710-1770$ & $2110-2170$ & 60 \\
\hline 11 & $1427,9-1452,9$ & $1475,9-1500,9$ & 20 \\
\hline 12 & $698-716$ & $728-746$ & 18 \\
\hline 13 & $777-878$ & $746-756$ & 10 \\
\hline 14 & $788-798$ & $758-768$ & 10 \\
\hline 15 & $1900-1920$ & $2600-2620$ & 20 \\
\hline 16 & $2010-2025$ & $2585-2600$ & 15 \\
\hline 17 & $704-716$ & $734-746$ & 12 \\
\hline 18 & $815-830$ & $860-875$ & 15 \\
\hline 19 & $830-845$ & $875-890$ & 15 \\
\hline 20 & $832-862$ & $791-821$ & 30 \\
\hline 21 & $1447,9-1462,9$ & $1495,5-1510,9$ & 15 \\
\hline 22 & $3410-3500$ & $3510-3600$ & 90 \\
\hline 23 & $2000-2020$ & $2180-2200$ & 20 \\
\hline 24 & $1625,5-1660,5$ & $1525-1559$ & 34 \\
\hline 25 & $1850-1915$ & 1930-1995 & 65 \\
\hline
\end{tabular}

Tabela 2.2: Faixas de Frequências LTE TDD

\begin{tabular}{|c|c|c|}
\hline \multicolumn{3}{|c|}{ LTE TDD } \\
\hline Banda LTE $\left.\mathbf{( N}^{\circ}\right)$ & Alocação (MHz) & Largura de Banda (MHz) \\
\hline 33 & $1900-1920$ & 20 \\
\hline 34 & $2010-2025$ & 15 \\
\hline 35 & $1850-1910$ & 60 \\
\hline 36 & $1930-1990$ & 60 \\
\hline 37 & $1910-1930$ & 20 \\
\hline 38 & $2570-2620$ & 50 \\
\hline 39 & $1880-1920$ & 40 \\
\hline 40 & $2300-2400$ & 100 \\
\hline 41 & $2496-2690$ & 194 \\
\hline 42 & $3400-3600$ & 200 \\
\hline 43 & $3600-3800$ & 200 \\
\hline
\end{tabular}




\subsubsection{LTE em 450 MHz para o Brasil}

Em 2007, a ITU-R World Radiocommunication Conference (WRC-07) identificou um novo espectro para o IMT (do inglês, Internacional Mobile Telecommunication), buscando tanto bandas mais baixas (maior cobertura) e bandas mais altas (maior capacidade). A subbanda 450- $470 \mathrm{MHz}$ foi identificada globalmente, mas não era esperado estar amplamente disponível [15]. Os estudos do 3GPP incluíram a banda de $450 \mathrm{MHz}$, recentemente. Assim, foi aprovada junto a 3GPP, para o Brasil, a especificação para o LTE operar nesta banda de frequência.

O grande desafio, no Brasil, é a prestação de serviços de banda larga em áreas rurais e suburbanas. A solução proposta, LTE $450 \mathrm{MHz}$, tem como premissa aumentar a cobertura e oferecer altas taxas de dados (até $25 \mathrm{Mbps}$ para enlace direto e até 12,5 Mbps para enlace reverso), consistindo-se de uma arquitetura totalmente baseada em IP, baixa latência e melhor performance, quando comparada com a tecnologia de terceira geração (3G) [13]. O $\mathrm{CPqD}$, Centro de Pesquisa e Desenvolvimento em Telecomunicações, iniciou o desenvolvimento desta solução em 2011, com o apoio do Fundo para o Desenvolvimento Tecnológico das Telecomunicações (FUNTTEL), do Ministério das Comunicações e da Financiadora de Estudos e Projetos (Finep) [15].

A propagação da onda no espaço livre é tal que se mantendo constante a potência da antena de transmissão assim como os ganhos e as alturas das antenas transmissoras e receptoras, a potência recebida é inversamente proporcional à frequência e à distância. Dada esta relação entre frequência e cobertura, podemos perceber que o uso de frequências mais baixas, como $450 \mathrm{MHz}$, aumenta a área de cobertura. Esta é a base do conceito de utilização de frequências mais baixas para obter maior cobertura. A Tabela 2.3 ilustra a cobertura de algumas faixas de frequências em ambientes distintos. Em áreas com alta densidade populacional, com consequentemente maior número de assinantes, é exigido maior tráfego e taxa de dados. Dessa forma, são utilizadas mais estações rádio base para servir mais usuário, sendo possível aumentar a frequência e reduzir a área de cobertura. Em áreas com baixa densidade demográfica, como ambiente rural e suburbano, o número de usuários é menor, exigindo menor número de estações rádio base de atendimento. Para melhor explorar o investimento nesta ERB, aumenta-se a área de cobertura diminuindo a frequência. Usando menos estações rádio base para cobrir a mesma área, podem-se reduzir substancialmente os custos de capital e os custos operacionais da rede [16]. A Figura 2.4 ilustra a relação entre o valor de frequência e o número de estações rádio base exigida. 
Tabela 2.3: Raio de cobertura LTE por frequência em cada tipo de ambiente (em Km) [17]

\begin{tabular}{|c|c|c|c|c|}
\hline $\begin{array}{c}\text { Downlink } \\
@ 1 \mathrm{Mbps}\end{array}$ & $\begin{array}{c}\text { Urbano } \\
\text { Denso }\end{array}$ & Urbano & $\begin{array}{c}\text { Sub } \\
\text { urbano }\end{array}$ & Rural \\
\hline $450 \mathrm{MHz}$ & 1.47 & 2.72 & 9.18 & 20.47 \\
\hline $700 \mathrm{MHz}$ & 0.99 & 1.82 & 6.13 & 13.58 \\
\hline $1.8 \mathrm{GHz}$ & 0.49 & 0.88 & 2.93 & 6.40 \\
\hline $2.6 \mathrm{GHz}$ & 0.31 & 0.56 & 1.86 & 4.31 \\
\hline
\end{tabular}

\begin{tabular}{|c|c|c|c|c|}
\hline $\begin{array}{c}\text { Uplink @ } \\
256 \mathrm{Kbps}\end{array}$ & $\begin{array}{c}\text { Urbano } \\
\text { Denso }\end{array}$ & Urbano & $\begin{array}{c}\text { Sub } \\
\text { urbano }\end{array}$ & Rural \\
\hline $450 \mathrm{MHz}$ & 1.07 & 1.96 & 6.59 & 14.64 \\
\hline $700 \mathrm{MHz}$ & 0.71 & 1.29 & 4.32 & 9.55 \\
\hline $1.8 \mathrm{GHz}$ & 0.38 & 0.68 & 2.24 & 4.89 \\
\hline $2.6 \mathrm{GHz}$ & 0.24 & 0.42 & 1.40 & 3.23 \\
\hline
\end{tabular}

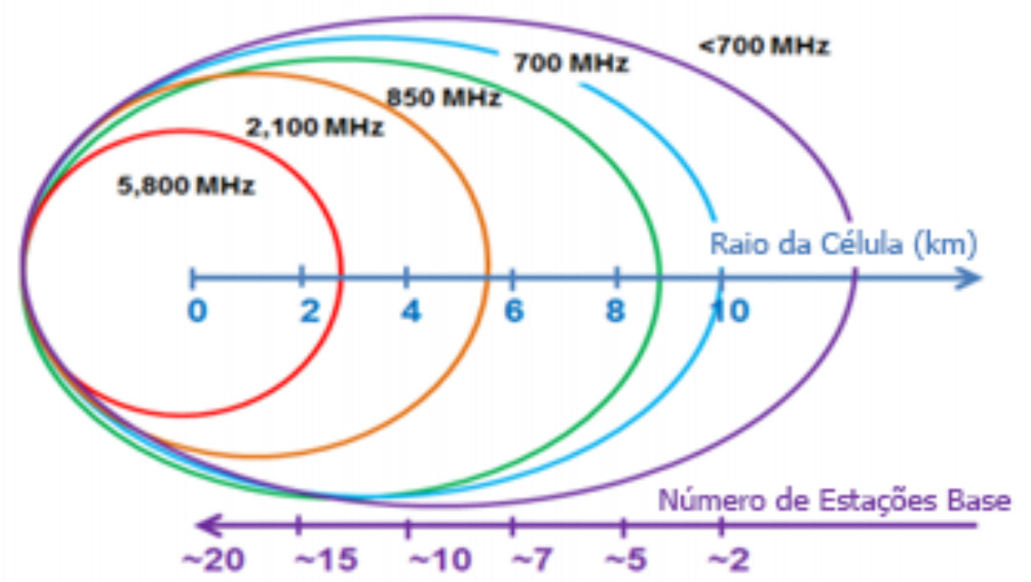

Figura 2.4: Relação entre frequência, raio de cobertura e número de estações rádio base [17].

Para facilitar o fornecimento de cobertura para as áreas de baixa densidade populacional, a ANATEL aprovou a resolução 558 em 20 de dezembro de 2010 que define o Regulamento de Canalização e Condições de Uso do Espectro na banda de 450 - $470 \mathrm{MHz}$. Nos termos deste regulamento, a faixa de 450 - $470 \mathrm{MHz}$ seria esvaziada e alocada para fornecer serviços de telefonia fixa e móvel, incluindo toda a gama de serviços IMT (Programa Internacional de Telecomunicações Móveis) em todo o Brasil. Usuários efetivos 
desta banda seriam migrados para um espectro alternativo de forma a evitar interferências [18].

Ainda em 2012, a ANATEL promoveu a licitação da faixa de $450 \mathrm{MHz}$, concedendo o uso das subfaixas de radiofrequência de 451 a $458 \mathrm{MHz}$ e de 461 a $468 \mathrm{MHz}$. Para as empresas vencedoras, foram exigidos os compromissos de cobertura em $30 \%$ dos municípios até dezembro de 2013, em 60\% até dezembro de 2014, e em 100\% até dezembro de 2015. Em dezembro de 2017 deverão ser ofertadas conexões de dados com as características mínimas de taxa de transmissão para enlace direto de $1 \mathrm{Mbps}$, para enlace reverso de 256 Kbps e franquia mensal mínima de 500MB [19].

Em julho de 2013, o 3GPP especificou os requisitos técnicos para implantação o LTE na banda de $450 \mathrm{MHz}$ no Brasil, composto dos requisitos de radiofrequência, requisitos de desempenho e testes de conformidade com as especificações.

\subsection{Conclusão}

Neste capítulo foi apresentada uma breve descrição do atual cenário das tecnologias de telefonia móvel, dando foco na forma como são utilizadas as frequências disponíveis e suas respectivas tecnologias. Os conceitos tratados neste capítulo motivam o estudo estatístico que seguirá no próximo capítulo. 


\section{Modelos de Propagação com aplicação em Redes}

\section{Celulares}

Os sistemas de comunicação sem fio apresentam limitações fundamentais impostas pelo canal de rádio móvel. O caminho do sinal entre o transmissor e receptor pode variar desde a simples linha de visão até um que seja seriamente obstruído por prédios, montanhas e folhagens. Os canais de rádio são aleatórios e não oferecem uma análise fácil, diferentemente de canais estacionários e previsíveis.

A modelagem do canal de rádio é, historicamente, uma das partes mais complexas do projeto do sistema de rádio móvel, e normalmente, é feita de uma forma estatística, com base em medições realizadas no cenário de interesse.

Este capítulo trará uma breve explicação sobre os conceitos necessários para a análise proposta neste trabalho.

\subsection{Modelos Determinísticos}

\subsubsection{Modelo de Friis}

Para um sinal transmitido no espaço livre a um receptor que está localizado a uma distância $d$ do transmissor, assumindo que não haja obstáculos estre o transmissor e o receptor e que o sinal se propaga ao longo de uma linha reta entre os dois, o modelo de canal, que caracteriza a perda de percurso, para o cenário definido como cenário em linha-de-visada (Line-Of-Sight-LOS), é implementado segundo o modelo de Friis [20], através de

$$
\frac{P_{R}}{P_{T}}=G_{T} G_{R}\left(\frac{\lambda}{4 \pi d}\right)^{2}
$$

em que d é a distância entre transmissor e receptor; $\lambda$ é o comprimento de onda; a perda com a distância é representada por $L_{d}=P_{R} / P_{T}$ e, $G_{T}$ e $G_{R}$ são os ganhos das antenas transmissora e receptora, respectivamente [21]. 
Com o modelo de Friis é possível fazer ajustes empíricos para modelar ambientes diversificados. Como em ambientes urbanos que existem fortes efeitos de multipercurso e em que não há uma linha de visada disponível, a formula pode ser generalizada e utilizada para estimar a razão media entre potência recebida e a transmitida no enlace de comunicação, como em

$$
\frac{P_{R}}{P_{T}} \approx G_{T} G_{R}\left(\frac{\lambda}{4 \pi d}\right)^{n}
$$

em que $n$ é o expoente de perda e varia, tipicamente, entre 2 e 5.

\subsubsection{Modelo Okumura-Hata}

Este método empírico divide a área de predição em três categorias: áreas abertas, áreas suburbanas e áreas urbanas. A área urbana é utilizada como referência e são aplicados fatores de correção na conversão para as outras categorias. O modelo é válido apenas para as seguintes características [20]:

- Faixa de frequência: $150 \mathrm{MHz}$ a $1500 \mathrm{MHz}$;

- Faixa de altura da antena da estação rádio base (antena transmissora): $30 \mathrm{~m}$ a $200 \mathrm{~m}$;

- Faixa de altura da antena do dispositivo móvel (antena receptora): $1 \mathrm{~m}$ a 10 m;

- Raio de distância entre estação base e dispositivo móvel: maior que 1 km.

A expressão para a perda de propagação é dada por

$$
\begin{gathered}
L_{d B}=A+B \log R-E(\text { para áreas urbanas) } \\
L_{d B}=A+B \log R-C \text { (para áreas suburbanas) } \\
L_{d B}=A+B \log R-D \text { (para áreas abertas) }
\end{gathered}
$$

em que

$$
\begin{aligned}
& A=69,55+26,16 \log f_{c}-13,82 \log h_{b}, \\
& B=44,9-6,55 \log h_{b}, \\
& C=2\left(\log \left(f_{c} / 28\right)\right)^{2}+5,4, \\
& D=4,78\left(\log f_{c}\right)^{2}-18,33 \log f_{c}+40,94, \\
& E=3,2\left(\log \left(11,75 h_{m}\right)\right)^{2}-4,97, \text { para cidades grandes, } f_{c}>300 \mathrm{MHz},
\end{aligned}
$$




$$
\begin{aligned}
& E=8,29\left(\log \left(1,54 h_{m}\right)\right)^{2}-1,1, \text { para cidades grandes, } f_{c}<300 \mathrm{MHz}, \\
& E=\left(1,1 \log f_{c}-0,7\right) h_{m}-\left(1,56 \log f_{c}-0,8\right), \text { para cidades médias a pequenas. }
\end{aligned}
$$

\subsubsection{Modelo COST 231-Hata}

O modelo Okumura-Hata para cidades médias e pequenas foi estendido para cobrir a banda entre $1500 \mathrm{MHz}$ a $2000 \mathrm{MHz}$. A expressão é dada por [20]

$$
L_{d B}=F+B \log R-E+G,
$$

em que

$$
F=46,3+33,9 \log f_{c}-13,82 \log h_{b}
$$

$E$ foi definido anteriormente para cidades médias a pequenas e

$\mathrm{G}=0 \mathrm{~dB}$ para cidades médias e áreas suburbanas ou $3 \mathrm{~dB}$ para áreas metropolitanas.

\subsubsection{Modelo Lee}

A expressão do modelo de Lee pode ser escrita em sua forma simplificada como

$$
L=10 n \log R-20 \log h_{b(e f f)}-P_{0}-10 \log h_{m}+29,
$$

em que $n$ e $P_{0}$ são medidas realizadas e determinadas pela Tabela 3.1. Todas as medidas foram realizadas para a frequência de $900 \mathrm{MHz}$, em que fatores de correção podem ser aplicados para outras frequências [20].

Tabela 3.1: Parâmetros para o modelo de Lee [20].

\begin{tabular}{|llcc|}
\hline Ambiente & & $\boldsymbol{N}$ & $\boldsymbol{P}_{\mathbf{0}}$ \\
\hline Espaço Livre & & 2 & -45 \\
Área aberta & & 4,35 & -49 \\
Suburbano & & 3,84 & $-61,7$ \\
Urbano & Filadélfia & 3,68 & -70 \\
& Newark & 4,31 & -64 \\
& Tokyo & 3,05 & -84 \\
& Nova York & 4,8 & -77 \\
\hline
\end{tabular}




\subsection{Desvanecimentos e Modelos Estatísticos}

Em sua maioria as ondas de rádio passam direto pela maioria dos objetos em seu caminho durante a transmissão, mas ainda assim esses objetos causam influências no sinal. O resultado é um problema comum denominado desvanecimento. Em outras palavras, o canal de propagação de um sinal de RF, entre dois pontos, tem suas características variando continuamente no tempo, de tal forma que, no destino, o nível do sinal recebido também varia no tempo, mesmo que, no emissor, a potência transmitida permaneça constante.

Dependendo da relação entre os parâmetros de sinal (banda, período de símbolo, entre outros) e os parâmetros de canal (espalhamento temporal ${ }^{1}$, espalhamento Doppler ${ }^{2}$, entre outros), os sinais transmitidos podem sofrer diferentes tipos de desvanecimento. Eles podem ser classificados como desvanecimento de longo prazo ou desvanecimento de curto prazo [22].

\subsubsection{Desvanecimento de Longo Prazo}

Também conhecido como desvanecimento em larga escala, lento ou sombreamento. Ocorre quando a amplitude do sinal do rádio sofre atenuações devido ao efeito da degradação do sinal provocado por obstáculos existentes em seu caminho, fatores ligados a distância percorrida pelo sinal em relação ao ponto de partida. Esta perda de percurso pode causar variações da ordem de $150 \mathrm{~dB}$ sobre uma área de cobertura [20].

Aliado à perda de percurso, o desvanecimento de longo prazo também considera o efeito do sombreamento, causado pelos edifícios e outros obstáculos presentes no ambiente de propagação, causando variações lentas na amplitude do sinal e apresenta uma distribuição log-normal [23].

A ocorrência de precipitações atmosféricas tais como chuva, granizo e neve além de oscilações do índice de refração atmosférico que provocam a diminuição do raio efetivo da terra e maximizam obstáculos, também contribuem para este tipo de desvanecimento.

Em um canal com desvanecimento de longo prazo, a resposta ao impulso muda a uma taxa mais lenta que o período de símbolo. Isto é, o tempo de coerência do canal é muito

\footnotetext{
${ }^{1} \mathrm{O}$ espalhamento temporal é um fenômeno natural causado pela reflexão e dispersão dos percursos de propagação do canal e expressa a dispersão temporal do sinal transmitido.

${ }^{2} \mathrm{O}$ espalhamento Doppler é uma medida do alargamento espectral causado pela taxa temporal de variação do canal de rádio móvel e é definido como a faixa de frequências sobre a qual o espectro Doppler recebido é essencialmente diferente de zero. [22]
} 
maior que o período de símbolo do sinal transmitido. Nesse caso, o canal pode ser considerado constante por um ou vários intervalos de símbolo.

\subsubsection{Desvanecimento de Curto Prazo}

Também conhecido como desvanecimento em pequena escala. É causado pelas reflexões dos múltiplos percursos de uma onda transmitida nos dispersores, como casas e prédios. Esses componentes chegam ao receptor em tempos diferentes e geram variações de amplitude e de fase do sinal quando combinados [23].

No desvanecimento de curto prazo, a resposta ao impulso do canal muda a uma taxa mais rápida do que o período do símbolo. Isto é, o tempo de coerência do canal é menor que o período de símbolo do sinal transmitido [22].

\subsection{Modelos de Desvanecimento de Curto Prazo}

Em comunicações sem fio, a envoltória e a fase do sinal variam de maneira aleatória devido ao fenômeno do multipercurso. O bom conhecimento dos fenômenos que afetam o canal de propagação e dos parâmetros do sinal propagado tem um impacto direto na qualidade e na confiabilidade do projeto de um sistema de comunicações. Consequentemente, uma boa caracterização estatística da envoltória torna a análise de qualquer técnica de comunicação bem mais precisa.

Esta seção apresenta as distribuições investigadas neste trabalho. A distribuição generalizada $\alpha-\mu$ contém os modelos de Nakagami- $m$ e Rayleigh como casos particulares. Em seguida, a distribuição de Rice será exibida.

\subsubsection{Distribuição $\alpha-\mu$}

A distribuição $\alpha-\mu$ considera um sinal composto de clusters de ondas de multipercurso propagando-se em um meio ambiente não-homogêneo. Ela pode ser utilizada para caracterizar as variações de pequena escala do sinal sem fio em desvanecimento em cenários que podem não apresentar linha de visada [24]. Como seu nome sugere, a distribuição $\alpha-\mu$ é escrita em função de dois parâmetros físicos. O parâmetro de potência $\alpha>0$ é relacionado com as não linearidades do meio de propagação, enquanto que o parâmetro $\mu>0$ está associado ao número de clusters de multipercurso. 
Para um sinal em desvanecimento generalizado $\alpha-\mu$ com envoltória R, um parâmetro arbitrário $\alpha>0, \operatorname{com} \hat{r}=\sqrt[\alpha]{E\left(R^{\alpha}\right)}$, em que $E(\cdot)$ é o operador esperança, a PDF (função densidade de probabilidade) da envoltória $\alpha-\mu, f_{R}(r)$, é escrita como [24]

$$
f_{R}(r)=\frac{\alpha \mu^{\mu} r^{\alpha \mu-1}}{\hat{r}^{\alpha \mu} \Gamma(\mu)} \exp \left(-\mu \frac{r^{\alpha}}{\hat{r}^{\alpha}}\right)
$$

em que $\mu>0$ é o inverso da variância normalizada de $R^{\alpha}$,

$$
\mu=\frac{E^{2}\left(R^{\alpha}\right)}{V\left(R^{\alpha}\right)}
$$

em que $\Gamma(\cdot)$ é a função Gamma [25, Eq. 6.1.1] e $V(\cdot)$ denota o operador variância.

A CDF (função de distribuição acumulada) da envoltória da distribuição $\alpha-\mu, F_{R}(r)$, é dada por [24]

$$
F_{R}(r)=\frac{\Gamma\left(\mu, \mu r^{\alpha} / \hat{r}^{\alpha}\right)}{\Gamma(\mu)}
$$

em que $\Gamma(\because$,$) é a função Gamma incompleta [25, Eq. 6.5.1].$

Os momentos da envoltória $\alpha-\mu$ são descritos em [24] como $E\left(R^{k}\right)=\frac{\hat{r}^{k} \Gamma(\mu+k / \alpha)}{\mu^{k / \alpha} \Gamma(\mu)}$. A partir deles, uma igualdade pode ser definida e que é útil para a estimação de parâmetros práticos da distribuição $\alpha-\mu$. Essencialmente [24],

$$
\frac{E^{2}\left(R^{\beta}\right)}{E\left(R^{2 \beta}\right)-E^{2}\left(R^{\beta}\right)}=\frac{\Gamma^{2}(\mu+\beta / \alpha)}{\Gamma(\mu) \Gamma(\mu+2 \beta / \alpha)-\Gamma^{2}(\mu+\beta / \alpha)}
$$

em que $\beta$ pode ser escolhido arbitrariamente. Para dois valores distintos de $\beta$, duas equações são obtidas tais que os parâmetros físicos $\alpha$ e $\mu$ são encontrados. Para o caso particular em que $\beta=1$ e $\beta=2$, Eq. (3.12) fornece um estimador em termos de primeiro e segundo momentos. Obviamente, a partir da Eq. (3.12), outros estimadores baseados em momentos podem ser obtidos.

A função de autocorrelação, $A_{r}(d)$, da envoltória $\alpha-\mu$ pode ser obtida a partir de seus momentos conjuntos generalizados [26], como 


$$
A_{R}(d)=\frac{\hat{r}^{2} \Gamma^{2}\left(\mu+\frac{1}{\alpha}\right){ }_{2} F_{1}\left(-\frac{1}{\alpha},-\frac{1}{\alpha} ; \mu ; \rho(d)\right)}{\mu^{\frac{2}{\alpha}} \Gamma^{2}(\mu)}
$$

em que ${ }_{2} F_{1}(\cdot, ; ;)$ é a função hipergeométrica [25, Eq. 15.1.1] e $\rho(d)$ é o coeficiente de autocorrelação espacial.

Neste trabalho, o caso geral de cenários em desvanecimento sob efeito de anisotropia/isotropia é investigado, tal que a distribuição do ângulo de chegada (AoA) das ondas de multipercurso são não-uniforme/uniforme. Um modelo amplamente utilizado para AoA é a distribuição paramétrica de Von Mises (Tikhunov) [27]. Para este modelo, o coeficiente de autocorrelação espacial pode ser obtido como na Eq. (3.14), em que $0<\zeta<1$ indica a diretividade no receptor, $I_{0}(\cdot)$ é a função de Bessel modificada de primeiro tipo e ordem zero [25, Eq. 9.6.16], $\varphi \in[-\pi, \pi)$ representa a direção média de AoA, e b $\geq 0$ controla a largura do feixe. Em particular, para $\zeta=0$, o modelo composto anisotrópico/isotrópico reduz-se ao cenário isotrópico com AoA uniforme, tal que $\rho(d)=$ $J_{0}^{2}(2 \pi d / \lambda)$.

$$
\rho(d)=\left|\frac{\zeta I_{0}\left(\sqrt{b^{2}-(2 \pi d / \lambda)^{2}+j 4 \pi b d \cos (\varphi) / \lambda}\right)+(1-\zeta) J_{0}(2 \pi d / \lambda) I_{0}(b)}{I_{0}(b)}\right|^{2}
$$

\subsubsection{Distribuições de Nakagami-m e Rayleigh}

Os modelos tradicionais de desvanecimento de Nakagami- $m$ [28] e de Rayleigh [29] apresentam-se como casos particulares da distribuição $\alpha-\mu$. Para se obter as suas estatísticas, basta admitir, nas Equações de (3.9) a (3.14), $\alpha=2$ e $\mu=$ m para reduzi-las à Nakagami- $m$, e $\alpha=2$ e $\mu=1$ para reduzi-las à Rayleigh. Nota-se que Rayleigh considera um ambiente composto por apenas um cluster de multipercurso.

Quando não existem sinais com linha de visada, ou seja, não há um sinal com potência predominante, a distribuição de Rayleigh modela muito bem o canal.

E a distribuição de Nakagami- $m$ é uma distribuição mais flexível, podendo se aproximar ou até se igualar à maioria das distribuições. Esta distribuição caracteriza melhor o desvanecimento de curto prazo em propagação de sinais de alta frequência, e em longas 
distâncias. É também empregada para modelar ambientes de microcélulas em presença de multipercurso.

\subsubsection{Distribuição de Rice}

O modelo de Rice pode ser usado para representar a variação em pequena escala do sinal em desvanecimento imerso em condições de linha de visada. Essa distribuição se ajusta a ambientes onde, além das componentes de multipercurso, tem-se um sinal direto, com potência superior, devido à existência de visada direta entre transmissor e receptor (LOS, do inglês line-of-sight). A distribuição de Rice é escrita em função do parâmetro k que consiste na razão entre a potência das componentes dominantes e a potência das ondas espalhadas [30], [31].

A PDF do modelo de Rice

$$
f_{R}(r)=\left(\frac{2(k+1) r}{\Omega}\right) \exp \left[-k-\frac{(k+1) r^{2}}{\Omega}\right] I_{0}\left(2 \sqrt{\frac{k(k+1)}{\Omega} r}\right)
$$

em que $\Omega$ é a potência média do sinal. O parâmetro de desvanecimento k de Rice pode ser estimado por

$$
k=\frac{\sqrt{1-\gamma}}{1-\sqrt{1-\gamma}}
$$

em que $\gamma=V\left(R^{2}\right) / E^{2}\left[R^{2}\right]$.

A CDF da envoltória de Rice é definida por

$$
F_{R}(r)=1-Q_{1}\left(\sqrt{2 k}, \sqrt{\frac{2(k+1)}{\Omega}} r\right)
$$

em que $Q_{1}(\cdot, \cdot)$ é a função Marcum-q de ordem unitária [25]. 


\subsection{Conclusão}

Neste capítulo foram apresentados os conceitos estatísticos utilizados na análise dos sinais medidos neste trabalho. No próximo capítulo serão explicados o sistema de medição onde foram coletados os dados e apresentados os resultados das medições. 


\section{Medições de Campo e Caracterização Estatística}

Foram realizadas medições de campo para que se pudesse obter e analisar o comportamento dos sinais propagados na frequência de $450 \mathrm{MHz}$. Essas medições ocorreram de modo a obter os mais variados fenômenos de propagação para análise.

Este capitulo foi dividido em três partes para melhor explicar a forma como foram realizadas as medições: equipamentos utilizados e montagem dos equipamentos; medições em campo; e resultados obtidos.

\subsection{Equipamentos Utilizados e sua Montagem}

Para a realização das medições, vários equipamentos foram necessários durante o processo. A maior parte foi cedida pelo Laboratório de Estruturas de Micro-ondas e Ondas Milimétricas e o restante foi cedido pelo Laboratório de Antenas, ambos localizados no prédio SG 11 na Universidade de Brasília - UnB.

Os equipamentos mais relevantes ao objetivo deste trabalho são apresentados a seguir.

\subsubsection{Amplificador de Baixo Ruído (LNA)}

Um amplificador de baixo ruído é um amplificador eletrônico, normalmente utilizado na recepção do sistema de transmissão, posicionado bem próximo à antena para reduzir as perdas de cabo.

Pela fórmula de Friss sabemos que um sistema pode apresentar várias figuras de ruído, onde os primeiros estágios numa cascata são os mais críticos na performance de ruído uma vez que a fórmula de Friss mostra que o ruído adicionado por cada estágio diminui na medida em que o ganho dos estágios anteriores aumenta [32]. Então, o LNA ideal deve apresentar a menor figura de ruído e o maior ganho possível. A Figura 4.1 mostra o LNA utilizado nas medições deste trabalho, sua marca é Mini-Circuits e modelo ZHL-1724HLN [33], podendo ser alimentado pelas potências de 12, 15 ou 16 volts. 


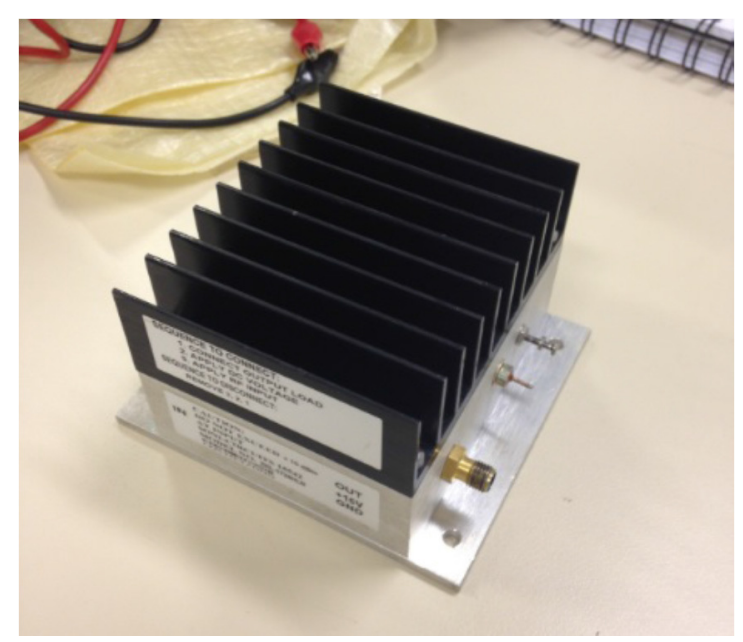

Figura 4.1: Amplificador de baixo ruído

\subsubsection{Fonte de Alimentação}

Para a realização das medições a presença do LNA é primordial, e para isso é necessária uma alimentação para o mesmo. Nas medições realizadas, foram utilizadas baterias de 12 volts, como mostrado na Figura 4.2, para alimentar o LNA e outros equipamentos que precisavam de energia. As medições foram realizadas no carro e o esquema de recepção será exibido mais à frente.

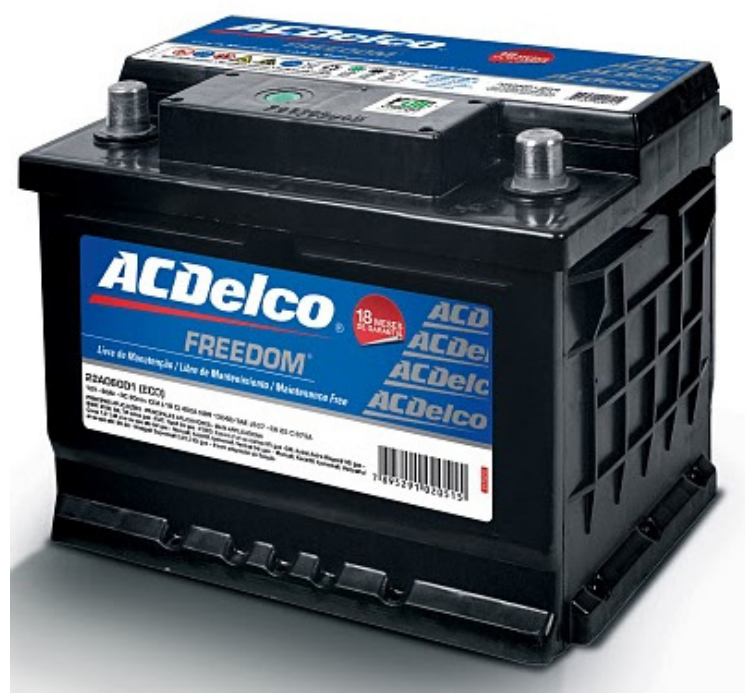

Figura 4.2: Fonte de alimentação. 


\subsubsection{Analisador de Espectro}

O analisador de espectro é essencialmente um receptor de rádio passivo, com uma interface gráfica (display) para a análise e medida do sinal no domínio da frequência. $\mathrm{O}$ analisador indica geralmente a informação contida no sinal de forma direta, tais como a tensão, a potência, o período e a frequência.

$\mathrm{O}$ analisador de espectro foi utilizado a fim de visualizar a potência recebida e também para a aquisição de dados junto com o LabJack, que será visto mais detalhadamente nas próximas subseções. $\mathrm{O}$ analisador utilizado nas medições é mostrado na Figura 4.3. O modelo é o HP8593E Spectrum Analyzer [35].

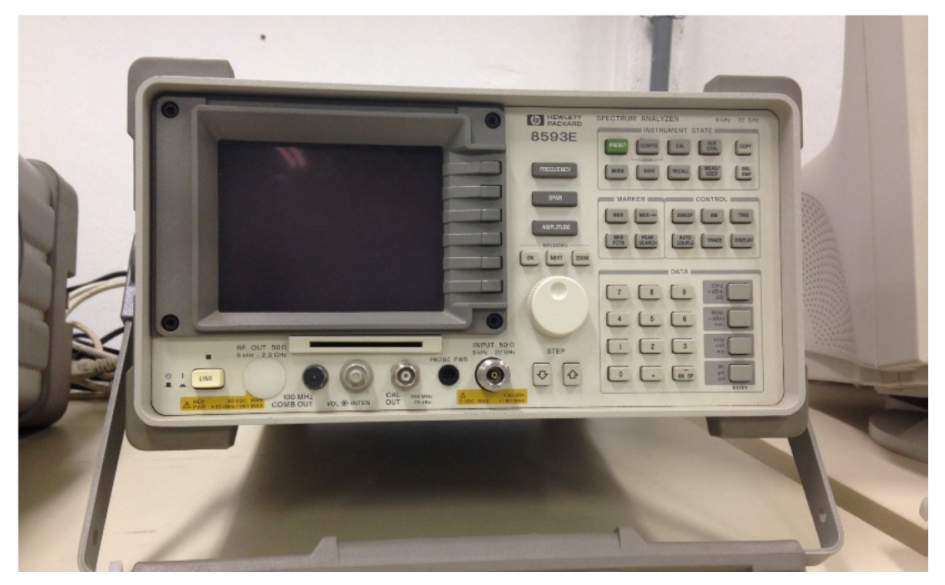

Figura 4.3: Analisador de espectro.

\subsubsection{Conversor Analógico/Digital}

Para a aquisição de dados foi utilizado o conversor A/D LabJack U12 [36], mostrado na Figura 4.4. Juntamente com um software instalado no computador que acompanha as medições, mostrado na Figura 4.5, ele é capaz de obter os dados de potência durante as medições através de uma conexão com analisador de espectro, com capacidade de gerar 300 amostras por segundo. $\mathrm{O}$ analisador de espectro realiza as medidas e o LabJack as grava em um arquivo .dat que será analisado posteriormente. 


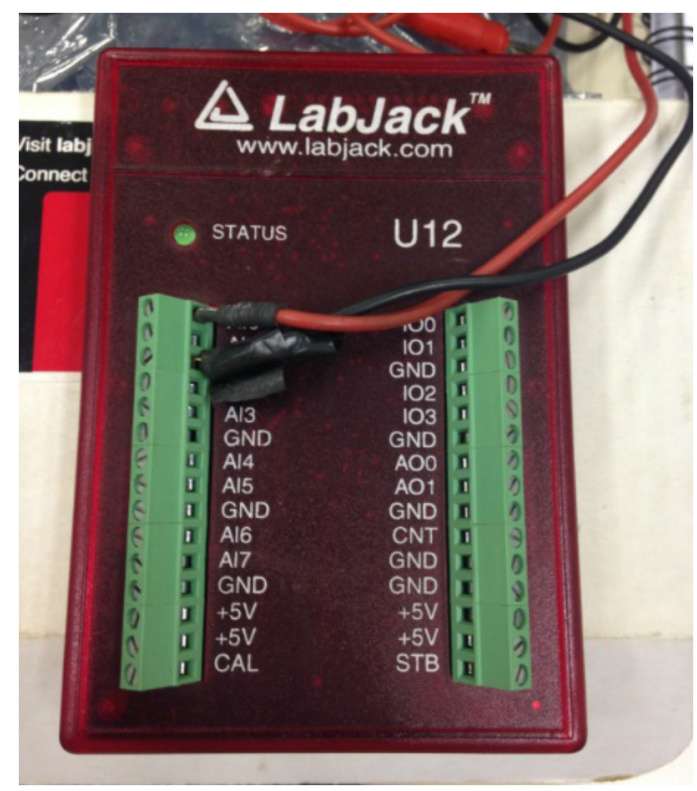

Figura 4.4: LabJack

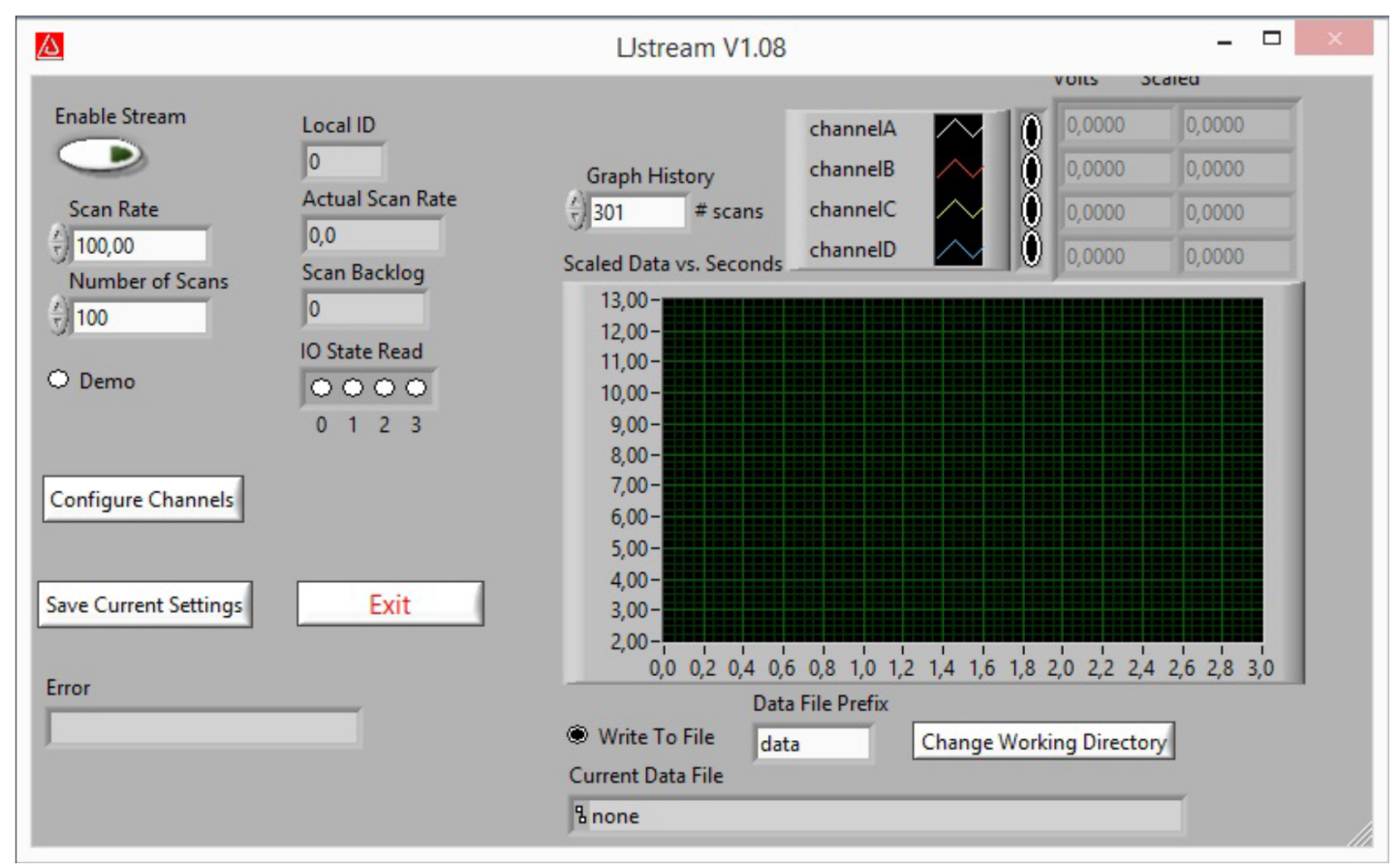

Figura 4.5: Software LJstream

O programa LJstream recebe a informação sobre potência em volts, e para que se obtenham os sinais em dBm observados no analisador de espectro, é preciso determinar uma equação de calibração que associe a potência em $\mathrm{dBm}$ com a potência observada em volts. A equação obtida experimentalmente a partir de comparações dos valores exibidos no analisador de espectro e valores recebidos pelo computador conectado ao LabJack é dada por 


$$
V_{d B m}(V)=78,06471 V-75,4476
$$

\subsubsection{Analisador de Rede FieldFox}

Para realizar as medições, é necessária a geração de sinais nas frequências estudadas. Para este fim, foi usado o analisador de rede FieldFox mostrado na Figura 4.6. Ele é capaz de gerar os sinais na frequência de $450 \mathrm{MHz}$ e possui a vantagem de ser portátil, ou seja, não precisa de alimentação direta. O modelo utilizado foi o Agilent N9912A FieldFox RF Analyzer [37].

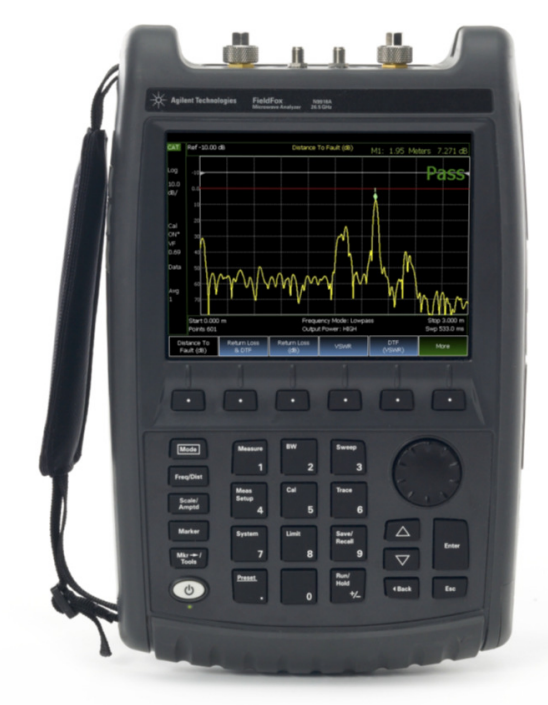

Figura 4.6: Analisador de Rede FieldFox

\subsubsection{Antenas}

As antenas foram escolhidas para melhor atender as frequências utilizadas nas medições. Na recepção foi utilizada uma antena omnidirecional da Aquário, modelo M 300C [38] de $131 \mathrm{MHz}$ a $900 \mathrm{MHz}$ que possui a base imantada para fixação. Ela é mostrada na Figura 4.7.

Para transmissão em $450 \mathrm{MHz}$ foi utilizado uma antena omnidirecional da marca Diamond, modelo RH-799 [39] para a faixa de frequência de $70 \mathrm{MHz}$ a $1000 \mathrm{MHz}$. Para a 
frequência configurada na transmissão, o comprimento da antena foi ajustado de acordo com especificações do fabricante. A Figura 4.8 mostra a antena utilizada.

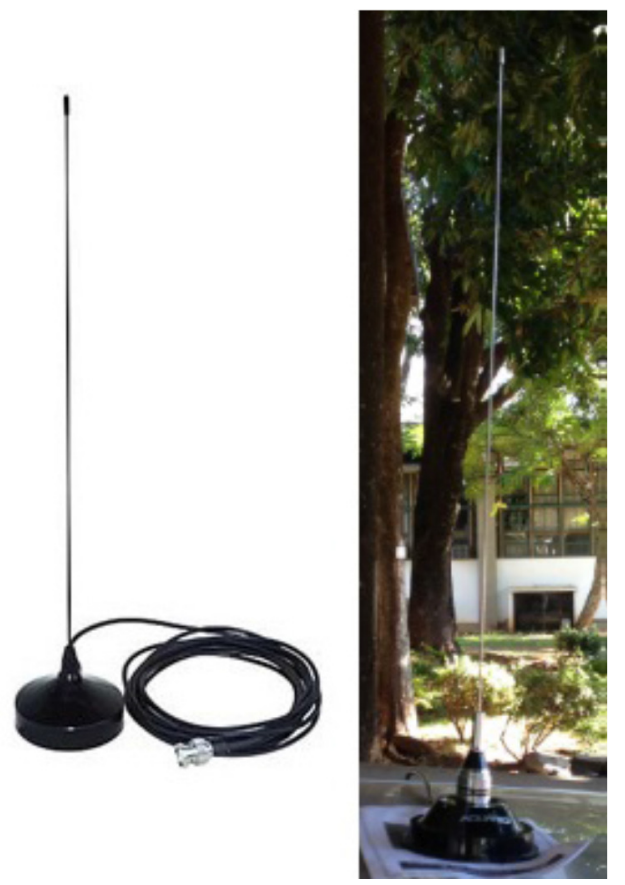

Figura 4.7: Antena Omnidirecional utilizada na recepção.

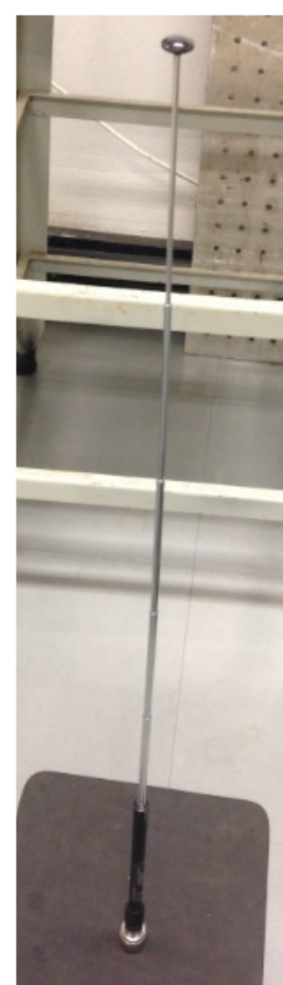

Figura 4.8: Antena Omnidirecional utilizada na transmissão. 


\subsubsection{Amplificador}

Fora o uso do amplificador de baixo ruído (LNA), foi utilizado um amplificador de $20 \mathrm{~dB}$ na transmissão. Este amplificador é mostrado na Figura 4.9, o modelo dele é o HP 8447D Amplifier 0.1 $1300 \mathrm{MHz}$ [40].

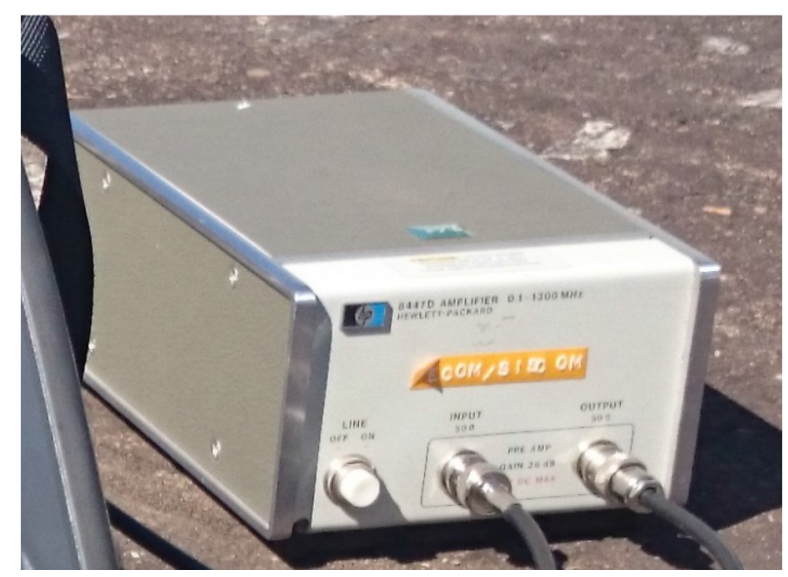

Figura 4.9: Amplificador utilizado na transmissão.

\subsubsection{Montagem}

A disposição dos equipamentos em todas as medições seguiu um modelo com o transmissor parado e o receptor em movimento. A transmissão foi montada no telhado do prédio do SG 11 (na Universidade de Brasília - UnB), enquanto que a recepção se deslocava pelos percursos que serão mencionados na próxima seção.

Para as medições, os equipamentos na recepção foram dispostos como mostra a Figura 4.10. $\mathrm{O}$ analisador de espectro foi ajustado para a faixa central de transmissão da onda em $450 \mathrm{MHz}$, para a visualização da potência recebida ao longo do percurso, e os demais parâmetros de configuração foram: Sweep Time $=20 \mathrm{~ms}$; VBW $=30 \mathrm{~Hz} ; \mathrm{RBW}=10 \mathrm{kHz}$; Span $=0$. Em que o sweep time é o tempo de aquisição, $V B W$ é a largura de banda de vídeo do analisador, $R B W$ é a largura de banda de resolução do analisador e span é a largura de banda visualizada. A recepção foi montada em um carro, como mostra a Figura 4.11.

Após configurar o analisador de espectro, a bateria de 12 volts que irá alimentar o LNA foi conectada a um inversor de corrente contínua para corrente alternada, esta bateria é própria do carro e também foi utilizada para alimentar o analisador de espectro. A entrada do LNA foi conectada ao cabo receptor da antena e a saída do LNA foi conectada ao analisador de espectro. 


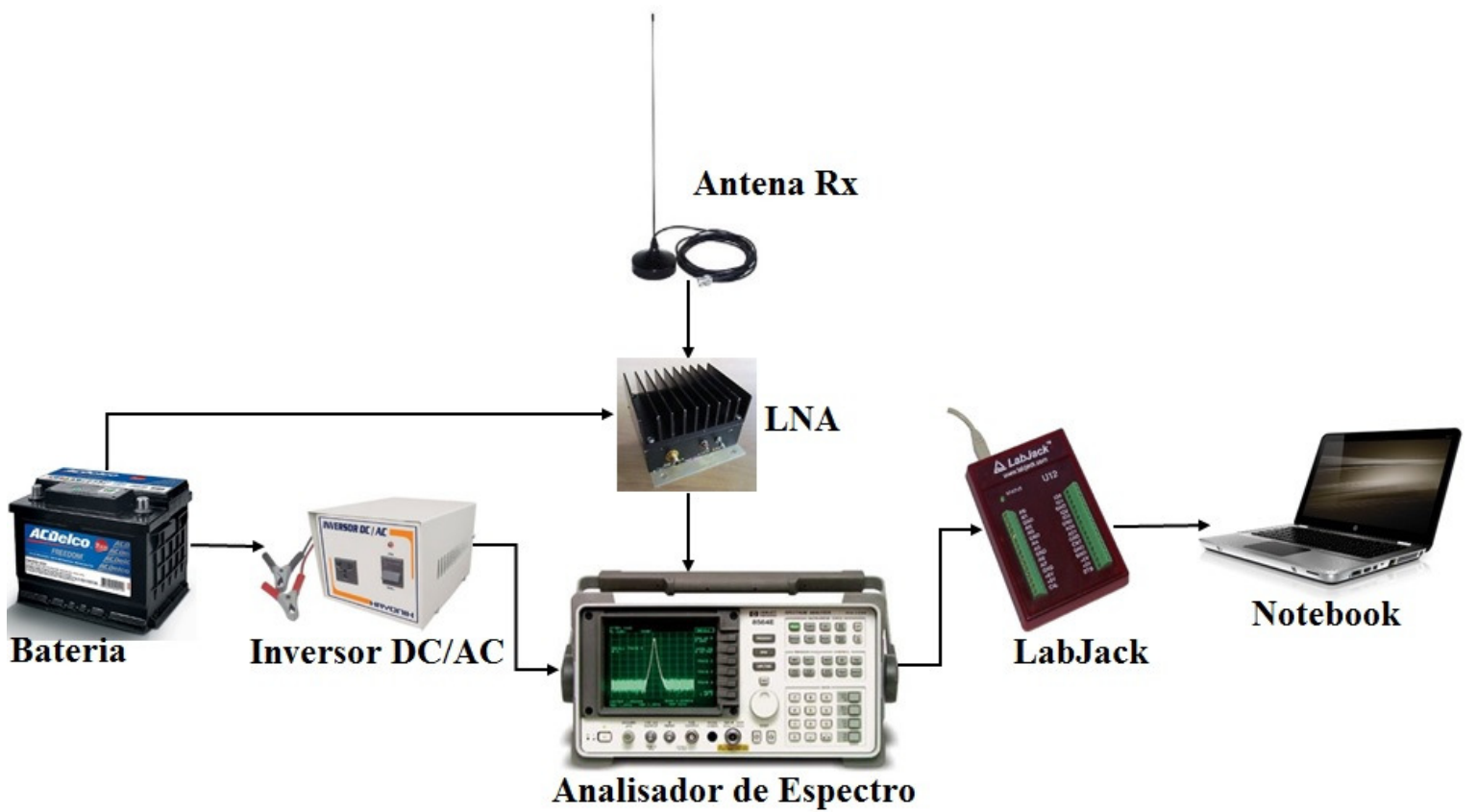

Figura 4.10: Diagrama de equipamentos na recepção.

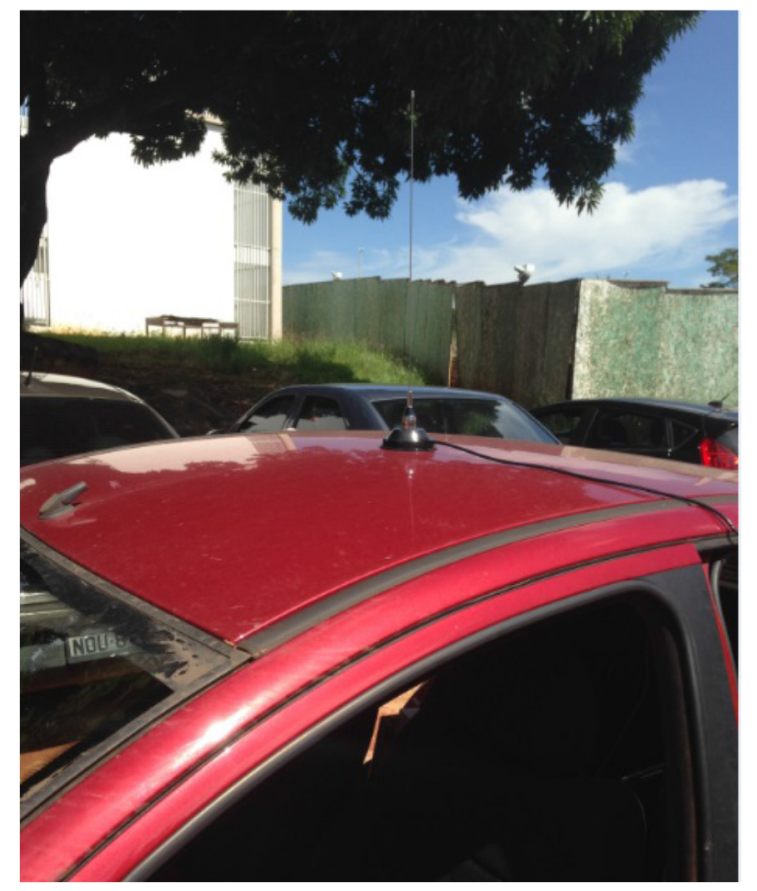

Figura 4.11: Antena acoplada ao carro.

O conversor A/D LabJack foi conectado ao computador com o software LJstream instalado, responsável pela geração dos arquivos com os dados obtidos na medição. 
Para a transmissão, uma antena omnidirecional ajustada com 48 centímetros para transmitir em $450 \mathrm{MHz}$ foi instalada com auxílio de um tripé, e o analisador FieldFox foi conectado para geração do sinal. Esta antena foi colocada no alto do prédio do SG 11, de uma altura de aproximadamente 10 metros. A Figura 4.12 mostra a montagem na transmissão e a Figura 4.13 mostra o sistema de transmissão das medições.

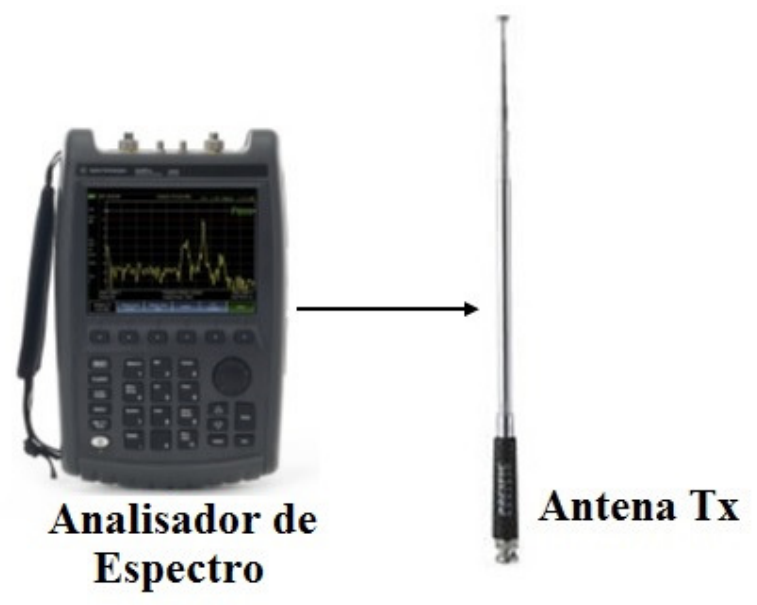

Figura 4.12: Diagrama de equipamentos na transmissão.

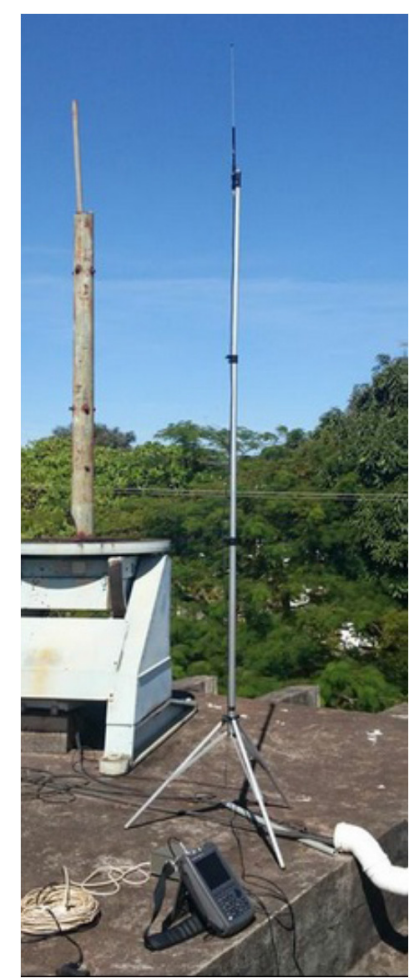

Figura 4.13: Sistema de transmissão 


\subsection{Medições em Campo}

Uma série de medições de campo foi realizada na Universidade de Brasília (UnB), Brasil, com o objetivo de se obter, na prática, a caracterização estatística de funções de primeira e de segunda ordens do canal sem fio na frequência de $450 \mathrm{MHz}$, tais como PDF, CDF e função de autocorrelação, assim como investigar os modelos teóricos de desvanecimento $\alpha-\mu$, Nakagami- $m$, Rice e Rayleigh quanto os seus respectivos ajustes aos dados experimentais.

\subsubsection{Local das Medições}

Com a finalidade de se realizar as medições, o conjunto transmissor foi instalado no terraço de um dos prédios da UnB, conforme Figura 4.14, e o receptor o receptor móvel percorreu diversas rotas em ambientes externos do campus que caracterizam ambientes suburbanos e rurais. As Figuras 4.15 e 4.16 mostram alguns ambientes medidos.

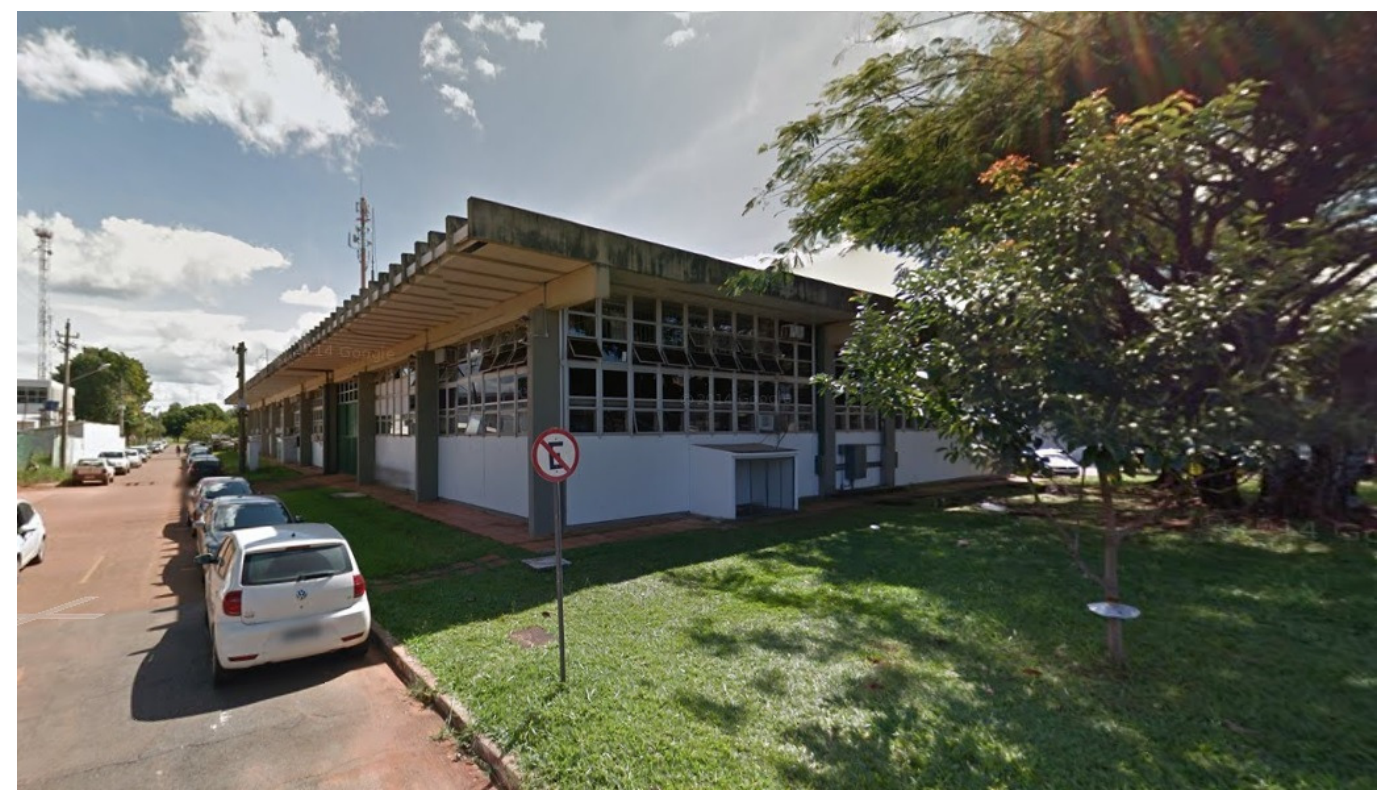

Figura 4.14 Prédio SG-11 UnB. Transmissor instalado no terraço. 


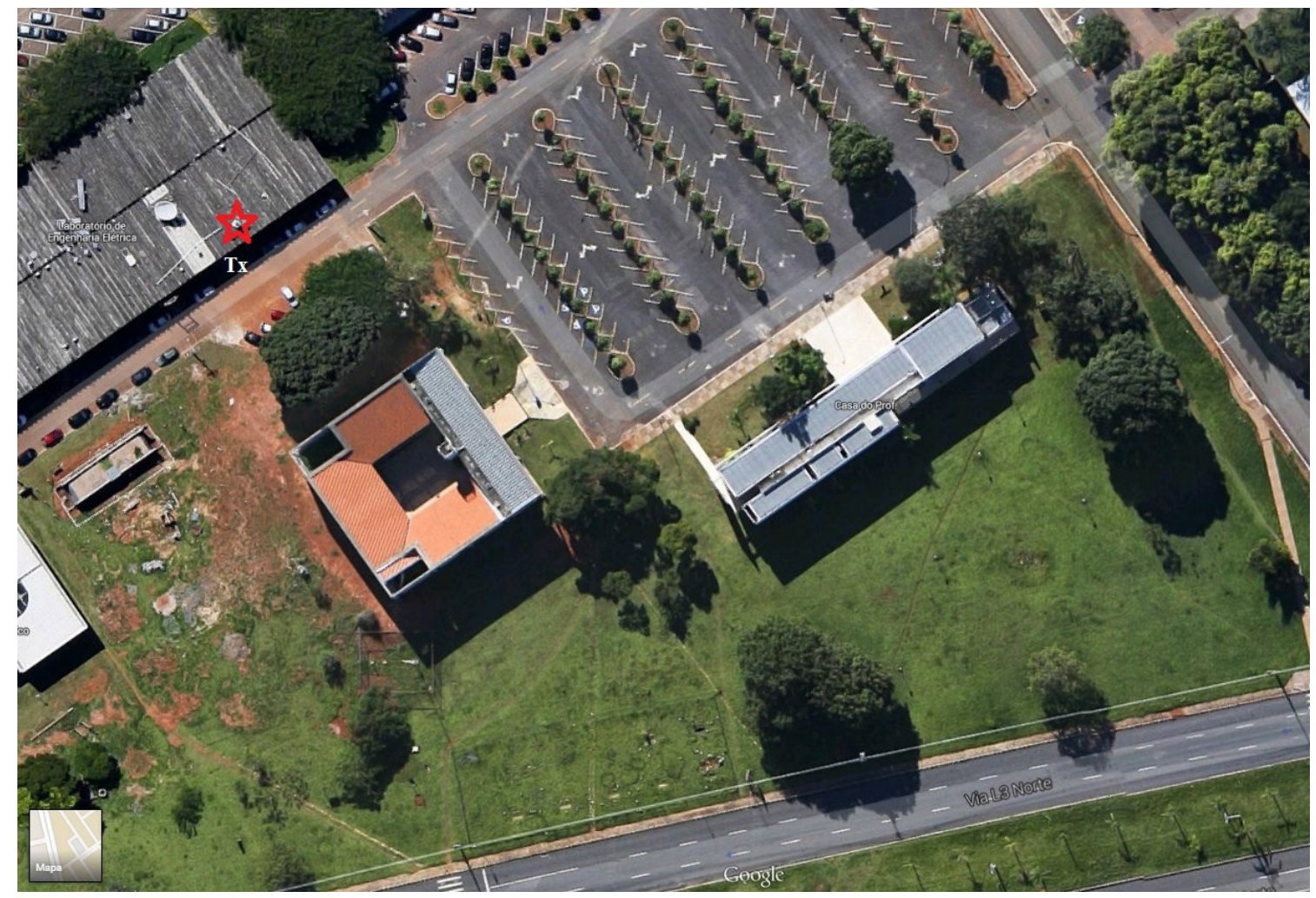

Figura 4.15: Vista aérea de um dos ambientes medidos

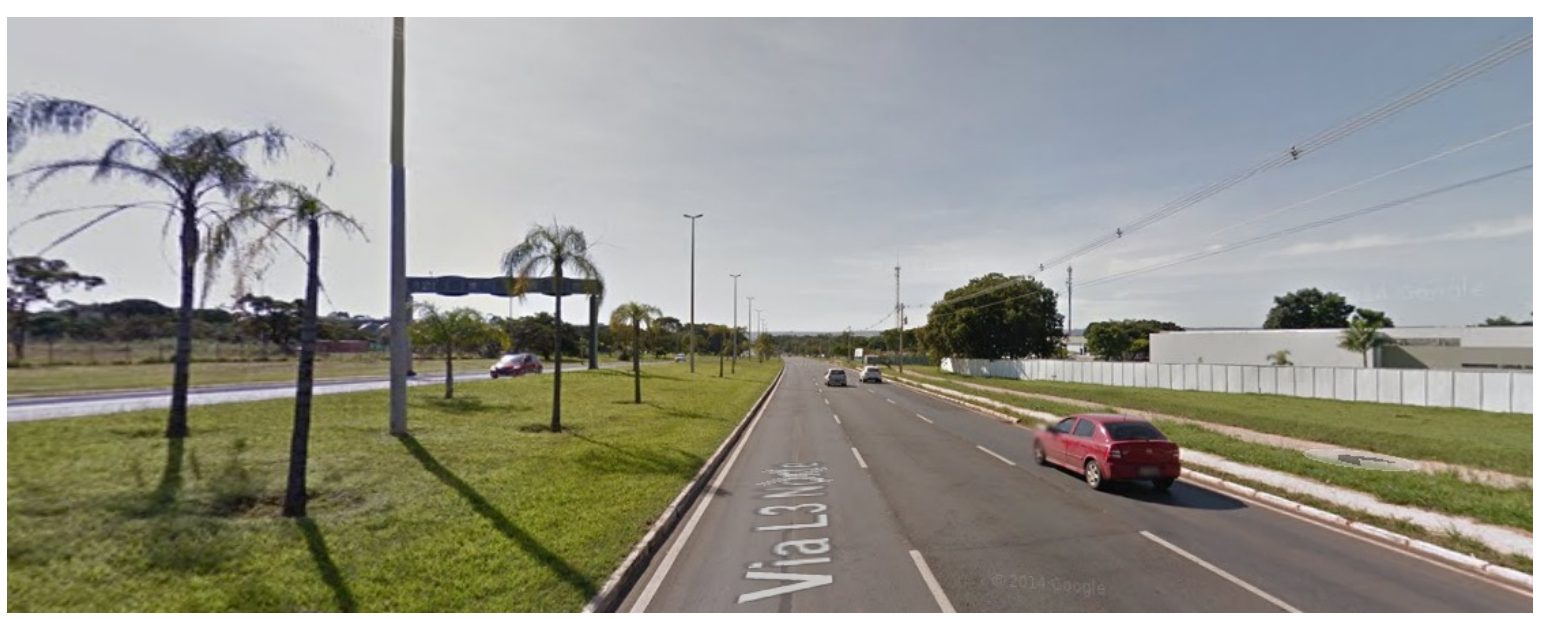

Figura 4.16: Via L3 


\subsection{Resultados Experimentais}

O equipamento de recepção móvel foi montado especialmente para a finalidade deste trabalho. Basicamente, a configuração consistia de uma antena receptora omnidirecional polarizada verticalmente, um amplificador de baixo ruído (LNA), um analisador de espectro, dispositivos de aquisição de dados, um notebook, e um veículo controlado espacialmente. $\mathrm{O}$ diagrama esquemático do receptor foi mostrado na seção anterior, conforme Figura 4.10. O transmissor consistia de um rádio com um tom de onda contínua $(\mathrm{CW})$ em $450 \mathrm{MHz}$. O analisador de espectro foi configurado em zero span e centrado na frequência desejada, e sua saída de vídeo foi usada como entrada do equipamento de aquisição de dados com um intervalo de amostragem de $\lambda / 14$ [41]. A média local foi estimada por meio do método de média móvel, com tamanho ótimo de janelas de $45 \lambda$ a $60 \lambda$ [42], equivalente a 630 e 830 amostras de envoltórias medidas, respectivamente. A partir dos dados coletados, o desvanecimento de larga escala foi filtrado e, consequentemente, os parâmetros de desvanecimento $\alpha, \mu, m e k$, conforme definidos anteriormente, foram estimados, assim como os parâmetros de anisotropia $\zeta, \varphi e \mathrm{~b}$.

A autocorrelação empírica normalizada foi computada de acordo com

$$
\hat{A}_{R}(\Delta)=\frac{\sum_{i=1}^{N-\Delta} r_{i} r_{i}+\Delta}{\sum_{i=1}^{N-\Delta} r_{i}^{2}}
$$

em que $r_{i}$ é a i-ésima amostra da sequência de amplitude sample, $\mathrm{N}$ é o número total de amostras, $\Delta$ é a diferença relativa à distância, e $\hat{A}_{R}(\cdot)$ denota um estimador empírico de $A_{R}(\cdot)$. O coeficiente de autocorrelação empírico foi computado como

$$
\hat{\rho}(\Delta)=\frac{\hat{A}_{R}(\Delta)-\hat{E}^{2}(R)}{\hat{V}\left(R^{2}\right)},
$$

em que $\hat{E}(\cdot)$ e $\widehat{V}(\cdot)$ denotam os estimadores de média e de variância, respectivamente. Finalmente, os parâmetros anisotrópicos puderam ser estimados para todas as medições. 
Todas as estatísticas obtidas empiricamente foram confrontadas com suas correspondentes formulações teóricas, com os mesmos parâmetros estimados em campo. Ademais, o erro médio ${ }^{3}, \epsilon$, foi calculado para cada caso.

As Figuras 4.17 a 4.19, correspondem, respectivamente, a intensidade do sinal de uma das amostras coletas; o desvanecimento de longo prazo; e, o desvanecimento de curto prazo.

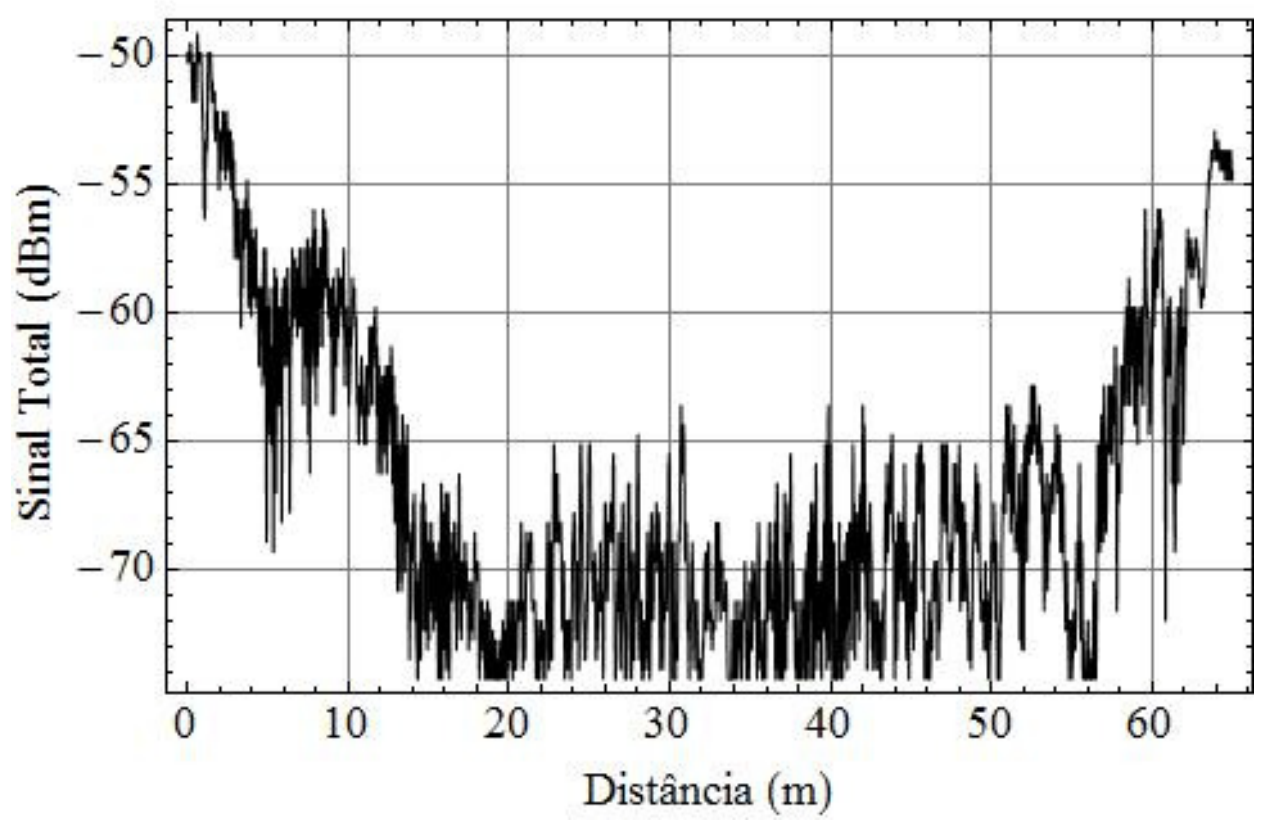

Figura 4.17: Sinal total obtido a partir de uma das amostras coletadas

${ }^{3} \mathrm{O}$ desvio médio entre os dados medidos $x_{i}$ e os valores teóricos $y_{i}$ é definido como $\epsilon=\frac{1}{N} \sum_{i=1}^{N} \frac{\left|y_{i}-x_{i}\right|}{x_{i}}$, em que $\mathrm{N}$ é o número total de pontos. Para os cálculos aqui apresentados, os erros foram estimados para pontos no intervalo $[0,1.4 \lambda]$, onde os maiores desvios ocorrem. 


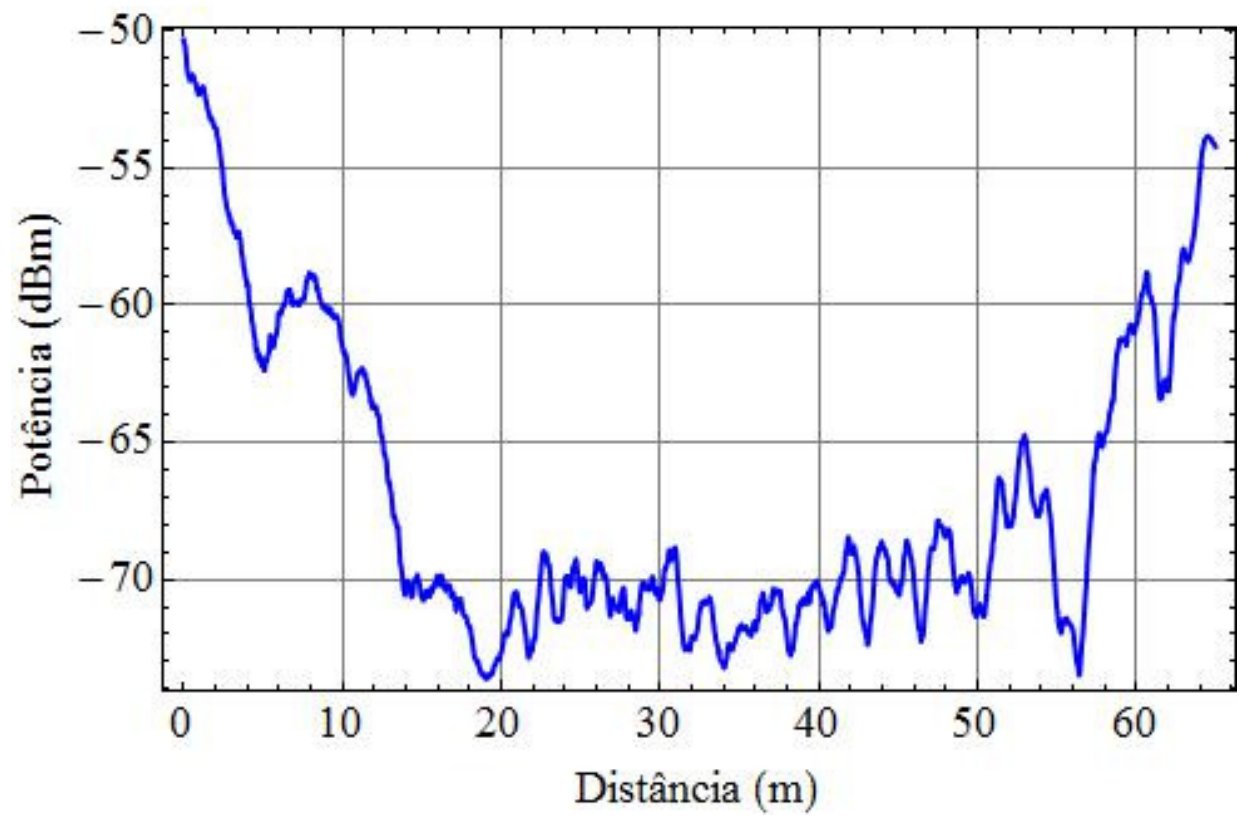

Figura 4.18: Desvanecimento de longo prazo obtido a partir de uma das amostras coletadas

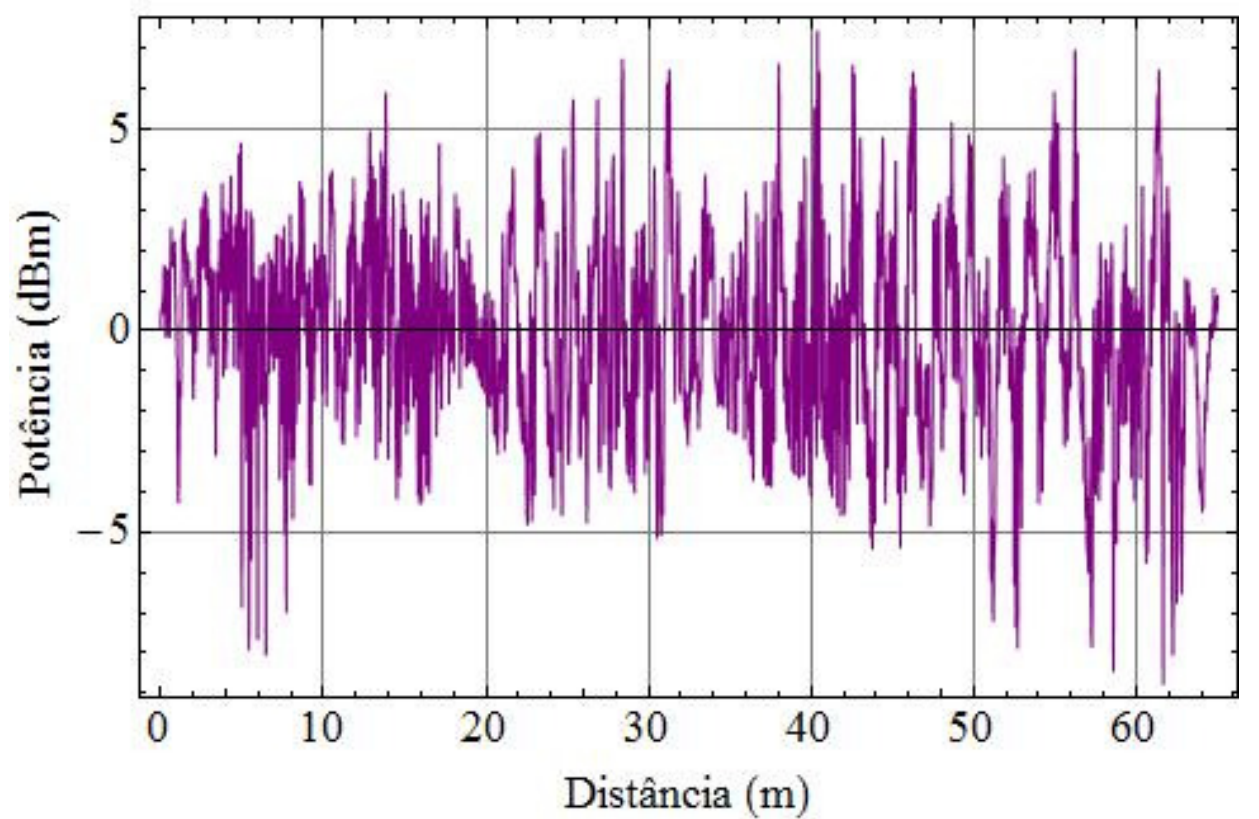

Figura 4.19: Desvanecimento de curto prazo obtido a partir de uma das amostras coletadas 
As Figuras 4.20 a 4.27 mostram os resultados de algumas das diversas medições realizadas em ambientes típicos suburbanos e rurais da Universidade de Brasília. Os parâmetros de desvanecimento obtidos para cada percurso são mostrados na Tabela 4.1 e a Tabela 4.2 apresenta os erros médios calculados para cada medição. A caracterização estatística de primeira ordem, dada por PDFs e CDFs estão apresentadas nas Figuras 4.20 a 4.22 e 4.23 a 4.25 , respectivamente.

Notadamente, a distribuição $\alpha-\mu$ apresentou excelentes ajustes em todos as rotas e cenários medidos, obtendo erros médios sempre menores do que qualquer outro modelo investigado, tanto em ambientes mais determinísticos (Figuras 4.20, 4.22, 4.23 e 4.25) quanto em ambientes mais aleatórios (Figuras 4.21 e 4.24). Sabe-se que a flexibilidade da distribuição generalizada $\alpha-\mu$ é maior do que os modelos tradicionais devido a $\alpha-\mu$ possuir um grau de liberdade a mais. Entretanto, é interessante ressaltar que, apesar de todos os cenários possuírem condições LOS, que é a situação contemplada na concepção do modelo físico de Rice, o modelo $\alpha-\mu$ superou este último principalmente por estimar as nãolinearidades do meio de propagação. As Figuras 4.26 e 4.27 apresentam a função de autocorrelação $\alpha-\mu$ confrontada com a autocorrelação empírica obtida em campo. Observe, novamente, o excelente ajuste da distribuição $\alpha-\mu$ e como as curvas teóricas tendem a acompanhar as mudanças da concavidade dos dados empíricos.

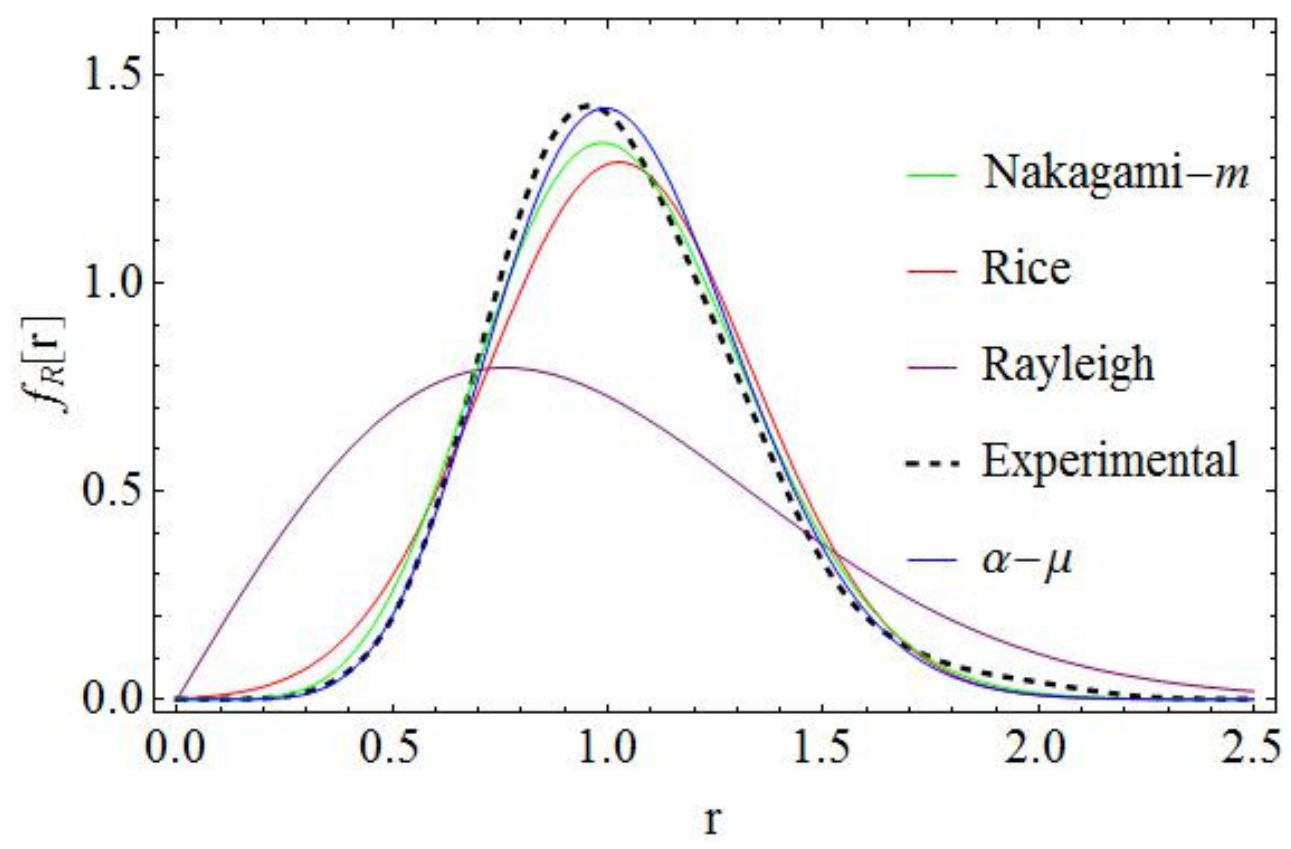

Figura 4.20: PDFs teórica vs. experimental em ambiente LOS rural 


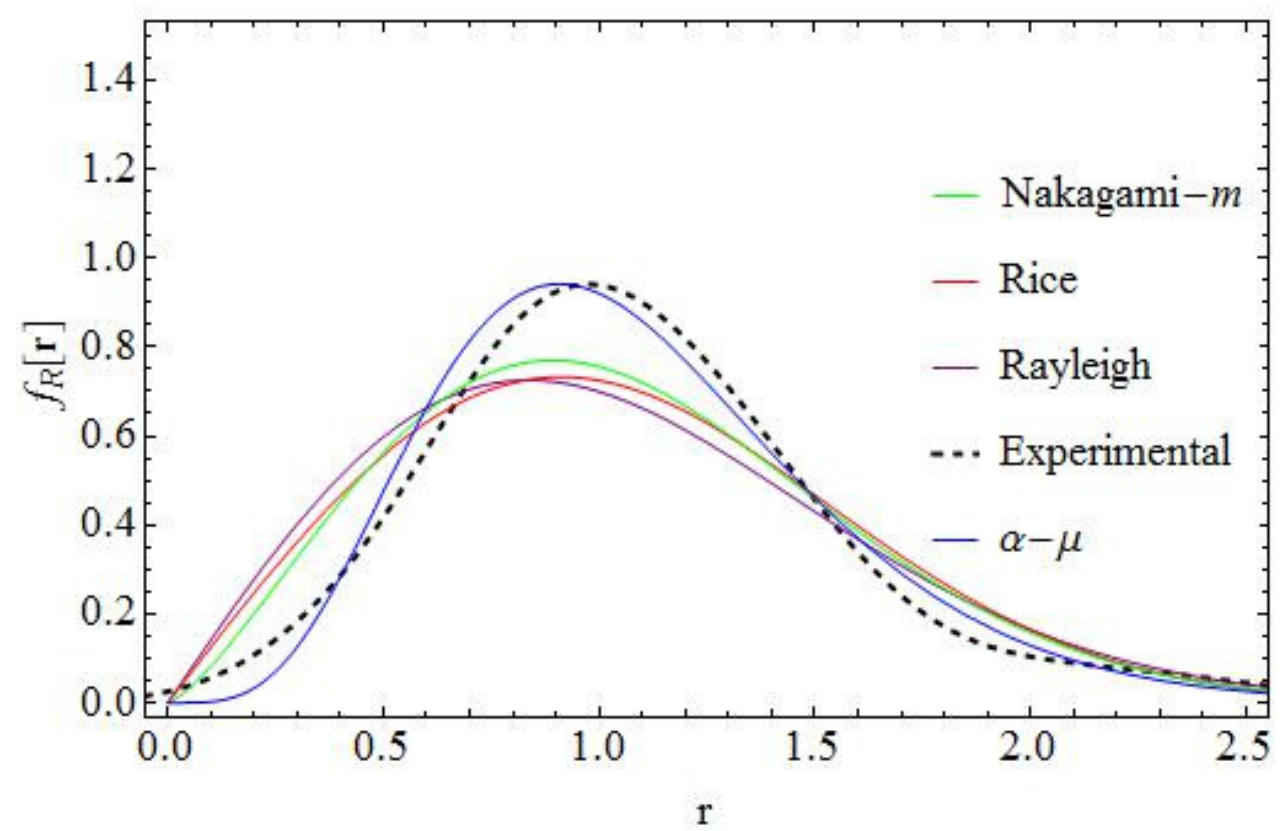

Figura 4.21: PDFs teórica vs. experimental em ambiente LOS suburbano

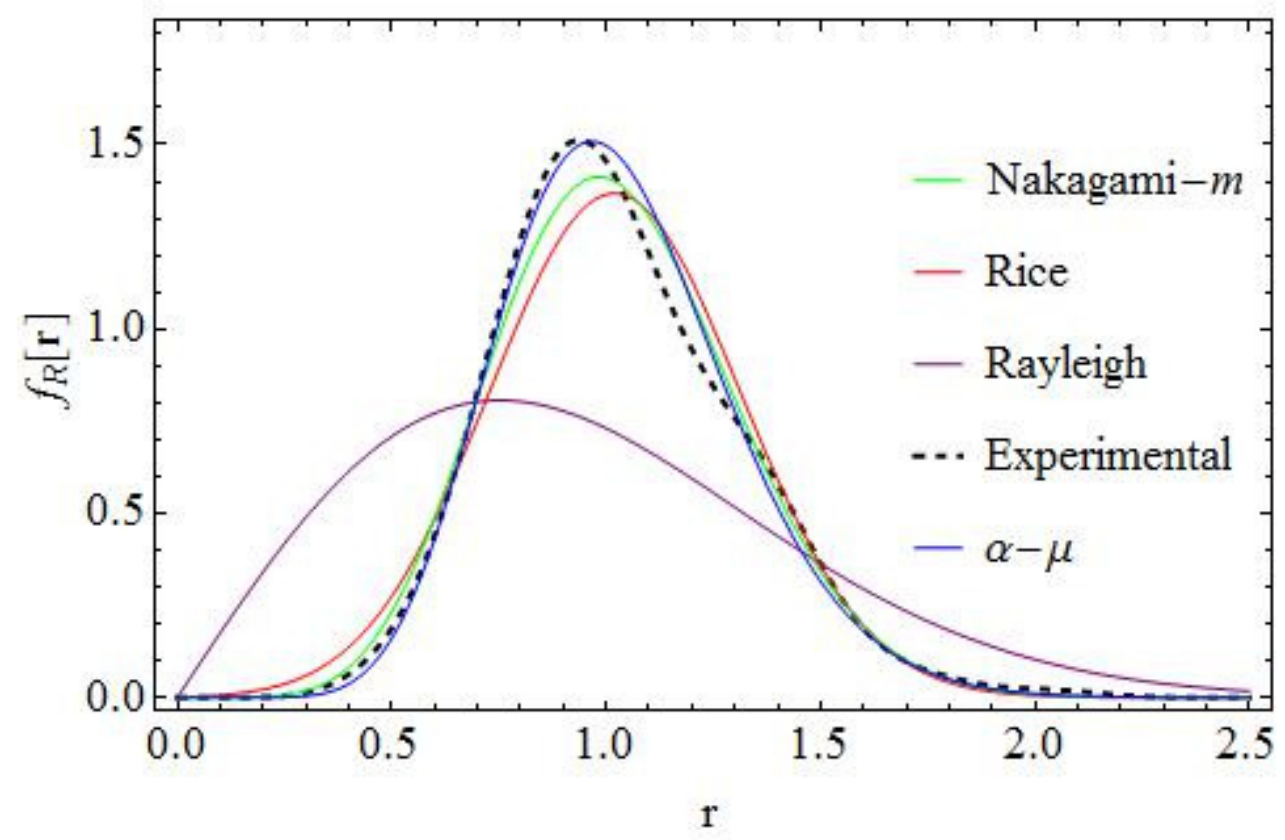

Figura 4.22: PDFs teórica vs. experimental em ambiente LOS com predominância de vegetações baixas 


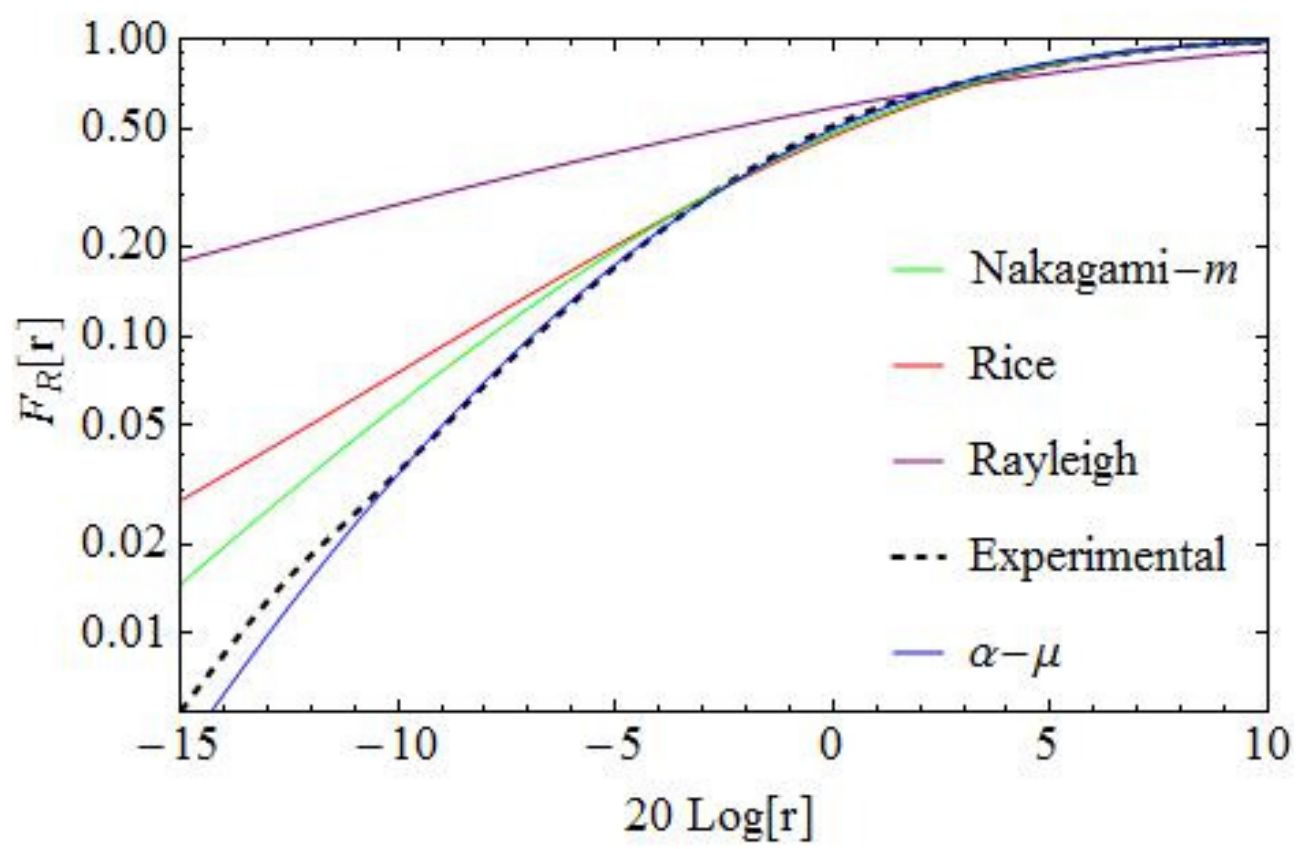

Figura 4.23: CDFs teórica vs. experimental em ambiente LOS rural

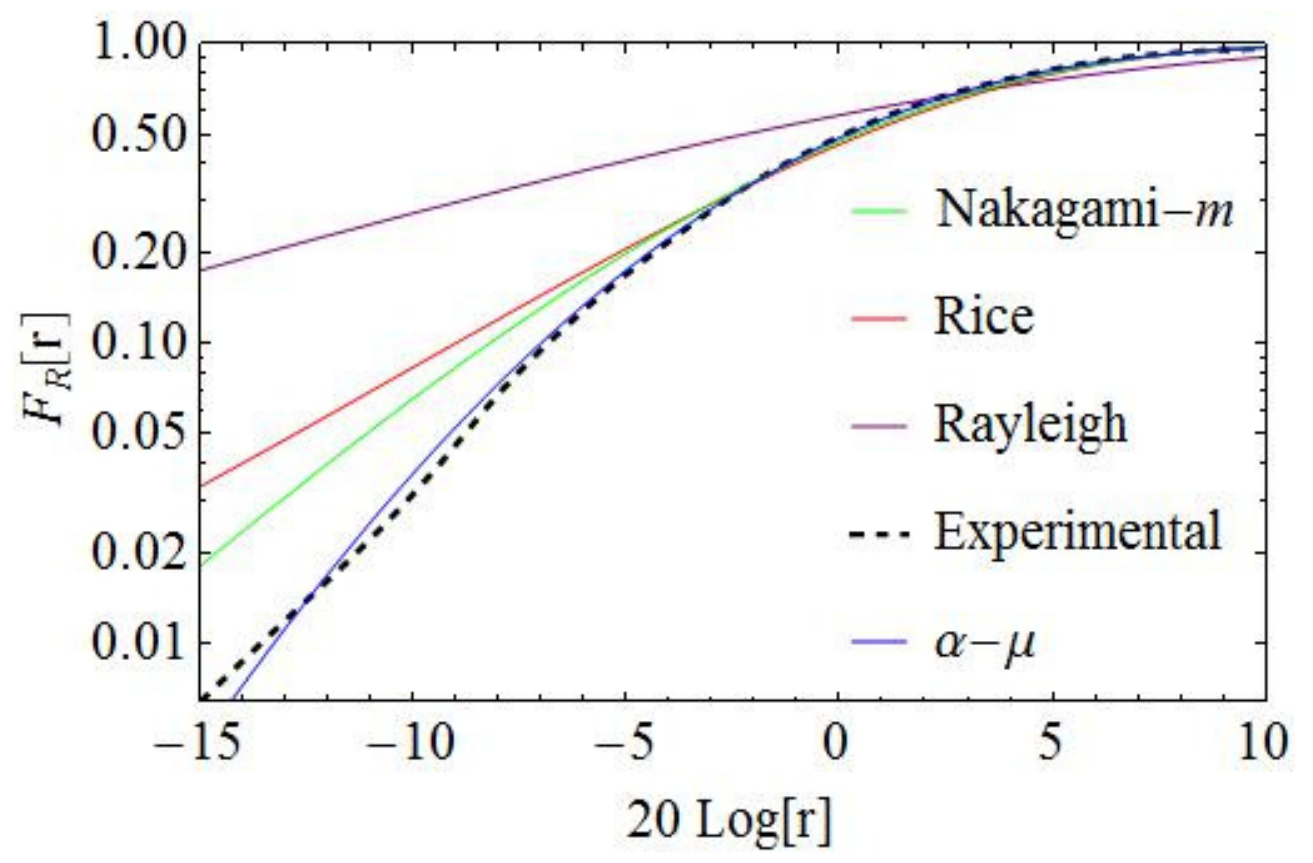

Figura 4.24: CDFs teórica vs. experimental em ambiente LOS suburbano 


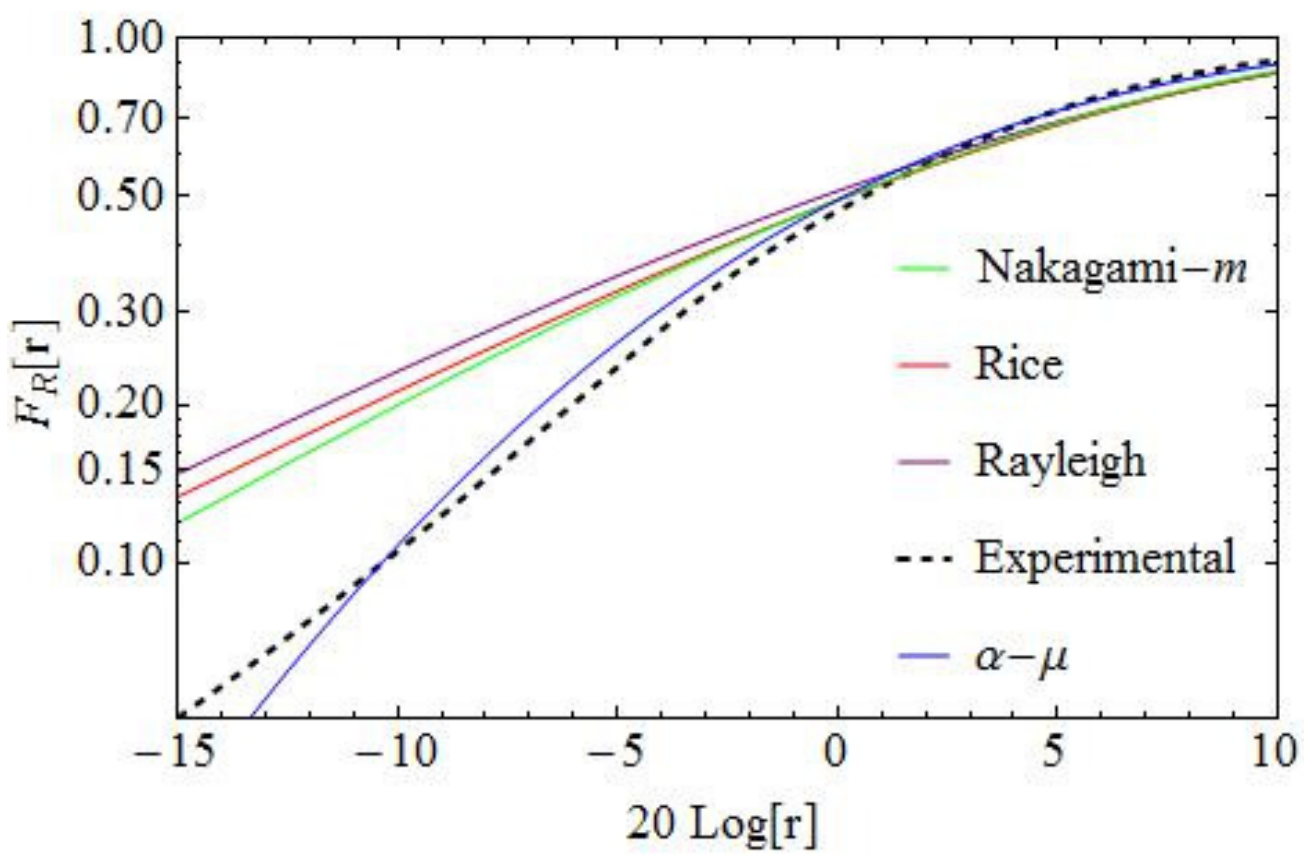

Figura 4.25: CDFs teórica vs. experimental em ambiente LOS com predominância de vegetações baixas

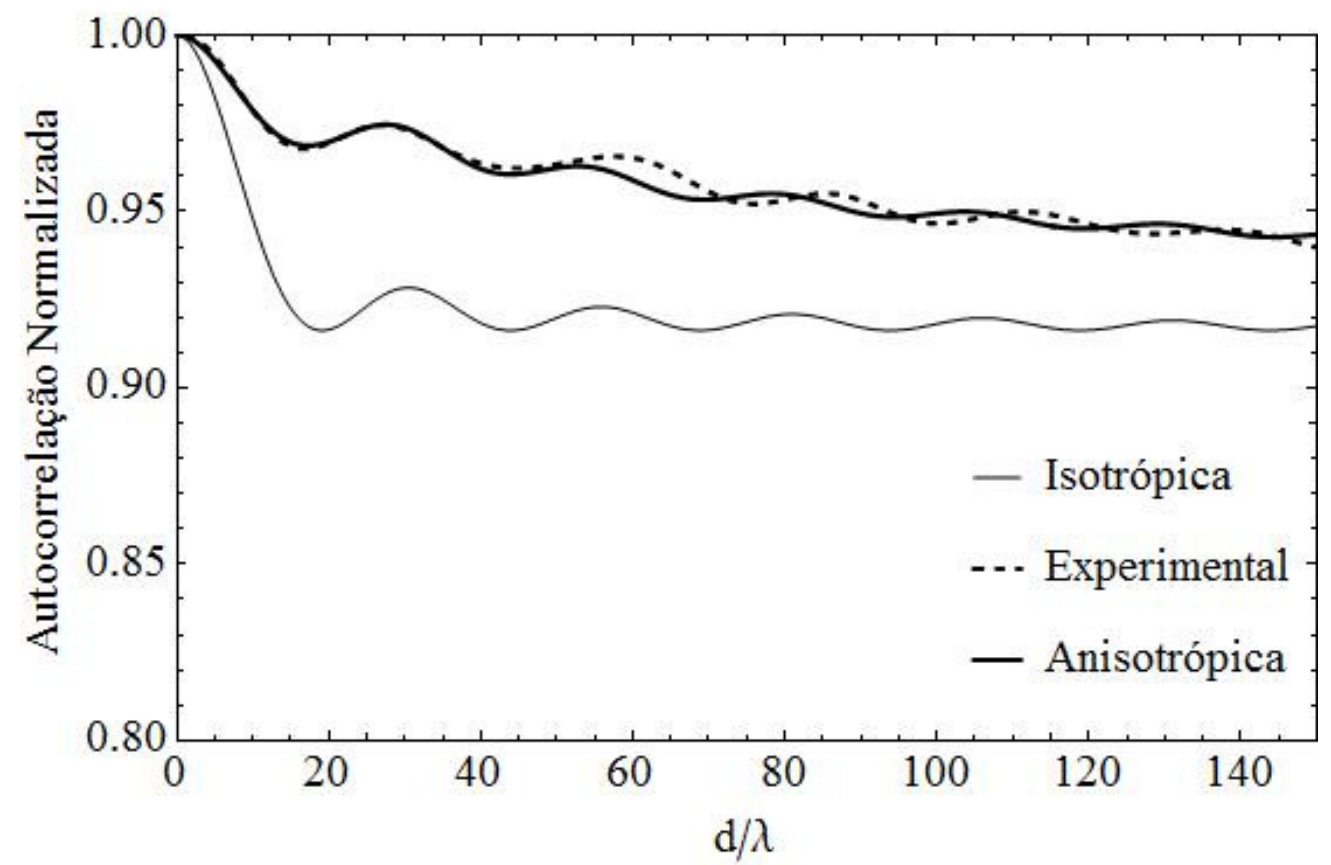

Figura 4.26: Funções de autocorrelação teóricas vs. experimental em ambiente LOS suburbano 


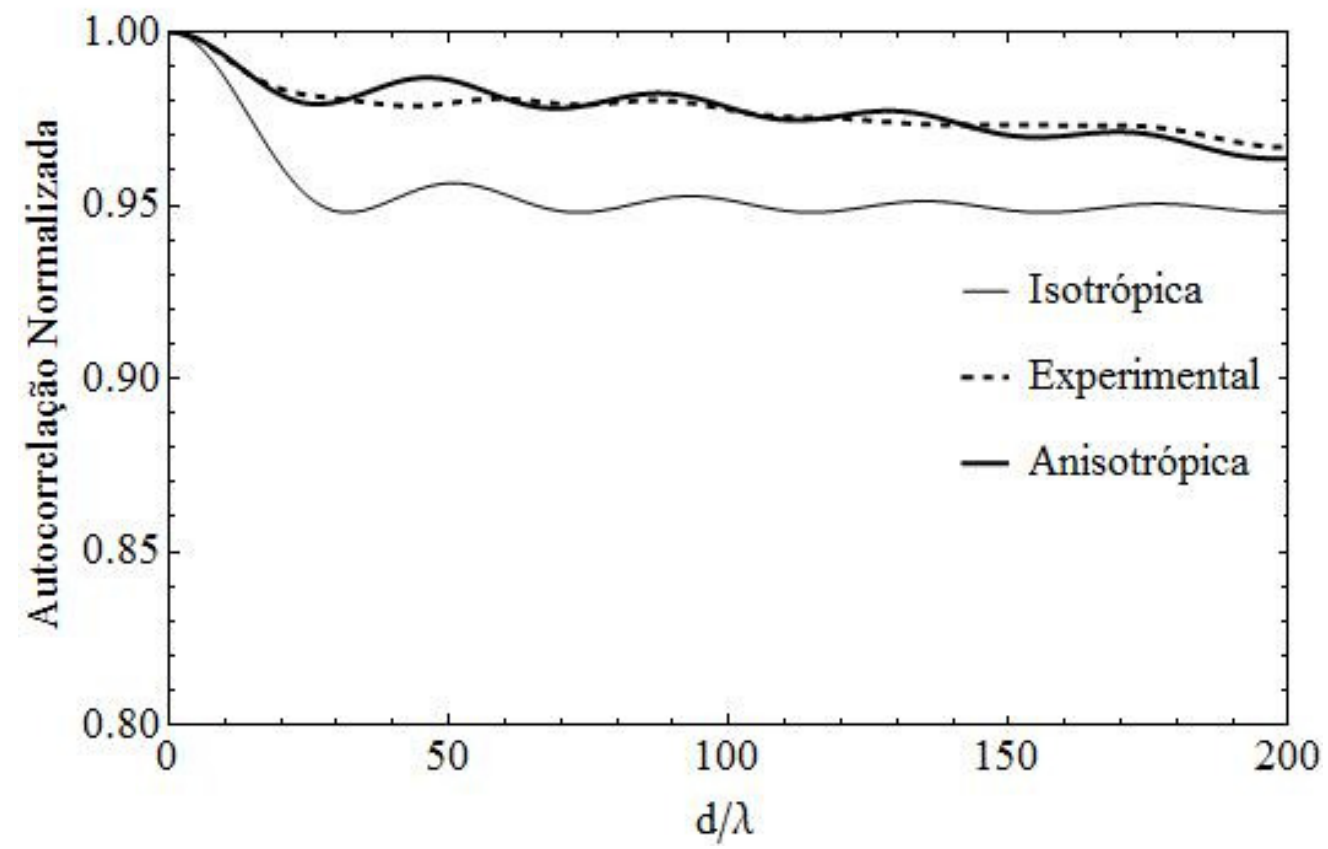

Figura 4.27: Funções de autocorrelação teóricas vs. experimental em ambiente LOS rural

Tabela 4.1: Parâmetros de Desvanecimento

\begin{tabular}{|c|c|c|c|c|}
\hline & $\alpha$ & $\mu$ & $\mathrm{m}$ & $\mathrm{k}_{\text {Rice }}$ \\
\hline Figura 4.17 & 1,884660 & 3,96954 & 3,15433 & 4,76114 \\
\hline Figura 4.18 & 1,07845 & 4,97423 & 1,16030 & 0,59157 \\
\hline Figura 4.19 & 1,27457 & 9,01460 & 3,44733 & 5,35195 \\
\hline
\end{tabular}

Tabela 4.2: Erros médios calculados

\begin{tabular}{|c|c|c|c|c|}
\hline & $\epsilon_{\text {Rayleigh }}$ & $\epsilon_{\text {Rice }}$ & $\epsilon_{\text {Nakagami- } m}$ & $\epsilon_{\alpha-\mu}$ \\
\hline Figura 4.17 & $26,6358 \%$ & $6,5098 \%$ & $3,4927 \%$ & $2,47303 \%$ \\
\hline Figura 4.18 & $10,2512 \%$ & $9,0185 \%$ & $7,6694 \%$ & $3,75271 \%$ \\
\hline Figura 4.19 & $27,7093 \%$ & $6,33008 \%$ & $3,77446 \%$ & $2,91934 \%$ \\
\hline
\end{tabular}




\subsection{Conclusão}

Neste capítulo foram apresentados o sistema de medição e discutido os resultados das medições de campo. As estatísticas exploradas, foram PDF, CDF e função de autocorrelação dos modelos de desvanecimento $\alpha-\mu$, Nakagami- $m$, Rice e Rayleigh. Excelentes ajustes foram encontrados entre os dados empíricos e teóricos da distribuição $\alpha-\mu$, considerando todas as rotas e cenários medidos em ambientes LOS típicos das aplicações esperadas para LTE 450. Desta forma, recomenda-se a utilização do modelo generalizado $\alpha-\mu$ no planejamento de futuras redes sem fio operando na faixa de $450 \mathrm{MHz}$. 


\section{Predição de Cobertura LTE 450MHz}

O planejamento de redes celulares consiste no desenvolvimento e otimização de diversos fatores: o local de implantação de novas estações rádio base, a determinação da área de cobertura desejada, a capacidade da rede, o reuso de frequência, a qualidade do serviço, entre outros. Para isso, deve ser realizado um estudo considerando a morfologia e a topografia do local, assim como os diversos parâmetros sistêmicos.

$\mathrm{Na}$ estimativa da área de cobertura devem ser utilizados modelos de propagação adequados a cada situação, já vistos no Capítulo 3. Fundamentalmente, tais modelos estão associados ao posicionamento e altura da ERB.

Além disso, é válido observar que a altura da antena constitui um importante parâmetro de ajuste, permitindo modificar o raio de cobertura da célula e, consequentemente, a capacidade de tráfego e a distância de reuso. Há ainda outros parâmetros que devem ser avaliados, como, por exemplo, a potência de transmissão e o ganho das antenas, parâmetros que dependem das especificações fixadas pelos fabricantes de equipamento.

Ainda não foi possível de se estabelecer um relacionamento entre cobertura, capacidade e reuso de frequência que permita realizar o planejamento seguindo um único procedimento direto que envolva todos os parâmetros de sistema que devem ser levados em conta.

Com base em parâmetros de sistema definidos previamente, faz-se o cálculo da cobertura de cada célula. A seguir, com os dados de tráfego disponíveis procura-se estruturar uma distribuição preliminar das células na área em estudo. Esta fase do planejamento inclui a definição do fator de reuso a ser utilizado, estimado a partir do número de canais previsto para cada célula. Em geral, supõe-se inicialmente uma distribuição uniforme de células. Verifica-se, então, se o fator de reuso previsto atende ao valor mínimo da relação portadorainterferência especificada para o padrão celular a ser utilizado no planejamento. Caso as condições fixadas nesta análise preliminar não permitam que seja atendido o critério de interferência, o cálculo deve ser refeito, reajustando-se os parâmetros mais sensíveis. Se o critério for atendido, passa-se ao planejamento definitivo, onde condições mais aderentes à realidade sejam consideradas (distribuição de células não uniforme, modelo de propagação mais preciso em função das características topográficas e morfológicas da área, etc.). 


\subsection{Balanceamento de Enlace}

O balanceamento de enlace em um sistema de telecomunicações é o cálculo de todos os ganhos e perdas a partir do transmissor, passando pelo meio de propagação, até o receptor.

Em sistemas de comunicação com fio, a transmissão é feita utilizando-se um meio físico, como um cabeamento metálico ou de fibra óptica que é responsável guiar o sinal entre o transmissor e o receptor. Nos sistemas sem fio, métodos complexos e avançados são responsáveis por garantir que a viabilidade da comunicação. Ondulações de terreno, movimentos relativos entre transmissor e receptor, interferências causadas por outros sistemas, ruídos e diversos outros fatores podem ser responsáveis pelo enfraquecimento, atraso e distorção do sinal, de forma não previsível e variável com o tempo. Considera-se um desafio o balanceamento de enlaces sob tais condições.

Este balanceamento avalia fatores como: a atenuação do sinal transmitido pela propagação no meio, assim como ganhos de antena, linhas de transmissão e perdas variadas. Ganhos aleatórios de canal como desvanecimento também são contabilizados. A equação para um balanceamento de enlace simples pode ser escrita como

Potência recebida $(\mathrm{dBm})=$ Potência transmitida $(\mathrm{dBm})+$ ganhos $(\mathrm{dB})-$ perdas $(\mathrm{dB})[43]$.

Os modelos de perda por propagação e as distribuições de desvanecimento considerados no cálculo do balanceamento de enlace foram abordados no Capítulo 3.

\subsection{CelPlanner: Programa de Simulação}

O CelPlanner é uma ferramenta computacional que permite uma solução completa para projetos de sistemas sem fio. Ele possibilita a execução de estudos de predição de cobertura e de interferência sobre conjuntos de estações rádio bases, além de simular/calcular tráfego, interferências e handover, entre outros aspectos. O CelPlanner possibilita a utilização de bases de dados topográficas, morfológicas, de imagens de alta resolução, de vetores de apoio e referência e de antenas e elimina o trabalho exaustivo e empírico de geração dos parâmetros de propagação, para uma determinada área de interesse.

O software opera vários modelos de predição, entre eles: linha de visada, Lee, Korowajczuk, microcélulas, SUI Erceg, Cost231/HATA, que foi utilizado nas simulações que veremos a seguir. 
Através das informações de topografia e morfologia, cada ponto existente no caminho de propagação entre ERB e estação móvel é analisado com intuito de verificar a existência de obstrução à passagem de sinal, determinação do ponto de reflexão no solo e obtenção da altura efetiva da antena da ERB.

Devido à proximidade da antena do terminal de usuário ao solo e às grandes distâncias que percorrem as ondas de RF, todos os obstáculos presentes sobre o terreno contribuem de forma específica na atenuação do sinal. Assim, cada ponto de terreno da área sob estudo necessita, também, de atributo que identifique o tipo de cobertura sobre o terreno, como, por exemplo, árvores, edifícios, água, avenidas, praças, etc. O conjunto de pontos com esse tipo de atributo forma a base de dados de morfologia.

Além disso, devido a necessidade de que todo sistema de comunicação bidirecional seja balanceado, o CelPlanner possibilita configurações ajustadas conforme o cenário de interesse, levando em consideração inclusive, a potência de transmissão adequada da ERB e do terminal de usuário, que depende, entre outros fatores, da sensibilidade dos receptores dos equipamentos.

Dessa forma, é preciso inserir parâmetros como a tecnologia a ser utilizada; a modulação escolhida; a frequência de operação; a localização da estação rádio base, assim como sua potência, altura, azimute, tilt, ganho e modelo de suas antenas; a potência do equipamento móvel, assim como a altura de seu receptor; as perdas envolvidas para cada tipo de ambiente, além das perdas por cabos e conectores; e os modelos de propagação a ser utilizados.

\subsubsection{Configurações realizadas para a simulação do LTE $450 \mathrm{MHz}$}

Em um primeiro momento, determina-se a tecnologia a ser utilizada na simulação para uma cobertura celular de quarta geração, no caso LTE como sistema. Depois, realizase a configuração do rádio, que tem como principais parâmetros os padronizados já pelo sistema, a Figura 5.1 exemplifica os parâmetros escolhidos. O LTE possui largura de banda flexível, entre $1,25 \mathrm{MHz}$ a $20 \mathrm{MHz}$, sendo escolhido para esta simulação a largura de 10 MHz; os esquemas de modulação utilizados pelo LTE são o QPSK, 16-QAM e 64-QAM, tanto no enlace direto como no enlace reverso; a flexibilidade do LTE permite utilizar duplexação do tipo TDD ou FDD [44], neste trabalho escolhemos o FDD. 


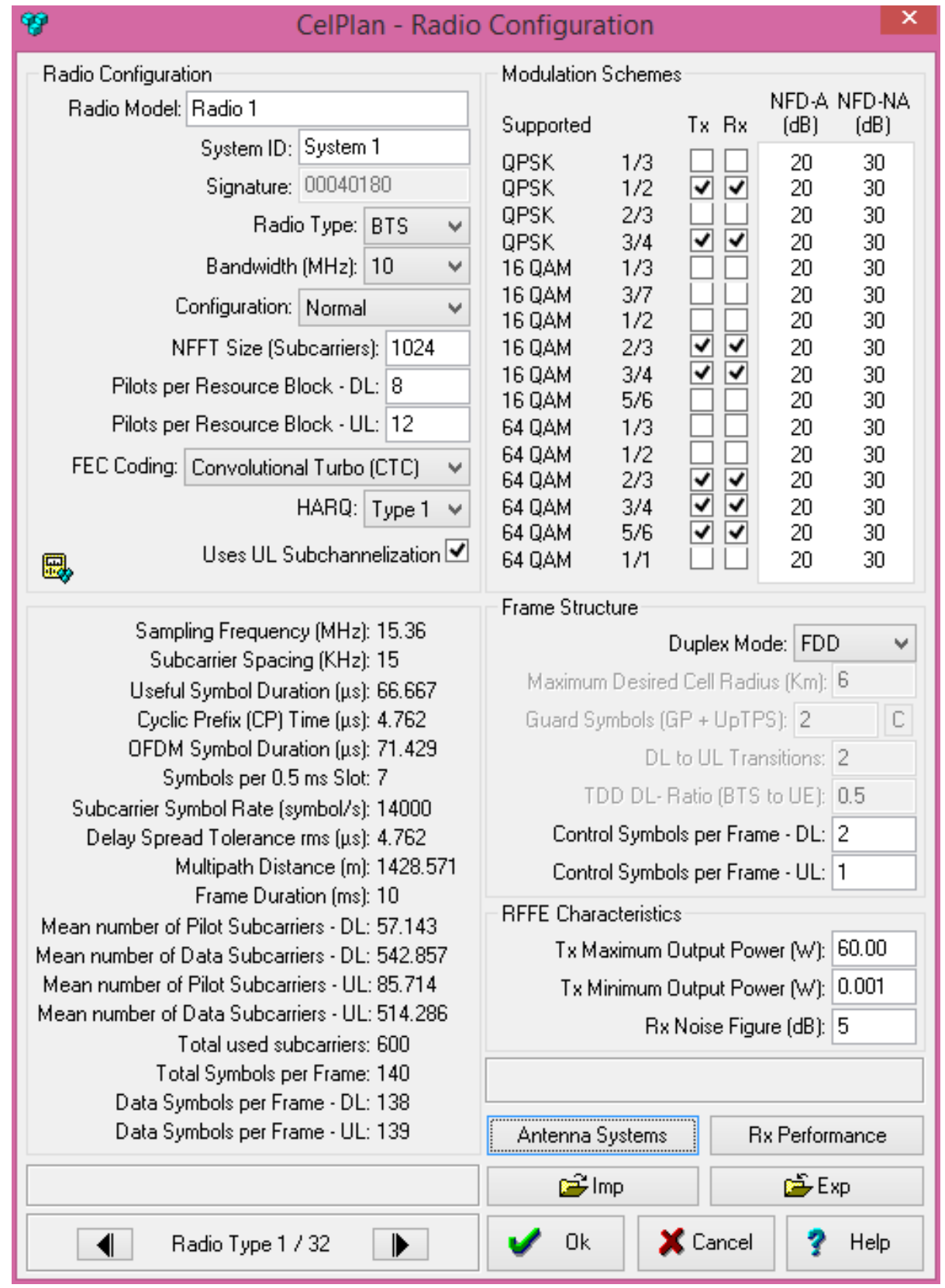

Figura 5.1 Configurações do Rádio 
Após ser determinada a tecnologia e as configurações de rádio, são configurados o tipo de ambiente e o tipo de usuário que serão englobados, conforme ilustrado nas Figuras 5.2 e 5.3, respectivamente. Para ambientes rurais, consideram-se dois cenários principais:

- Cenário Outdoor: atenuação devido ao corpo humano de $3 \mathrm{~dB}$, atenuação por penetração de $0 \mathrm{~dB}$ e usuário com a antena a uma altura de 6 metros acima do solo;

- Cenário Indoor: atenuação devido ao corpo humano de $3 \mathrm{~dB}$, atenuação por penetração de $10 \mathrm{~dB}$ e usuário com a antena a uma altura de 1,5 metro acima do solo.

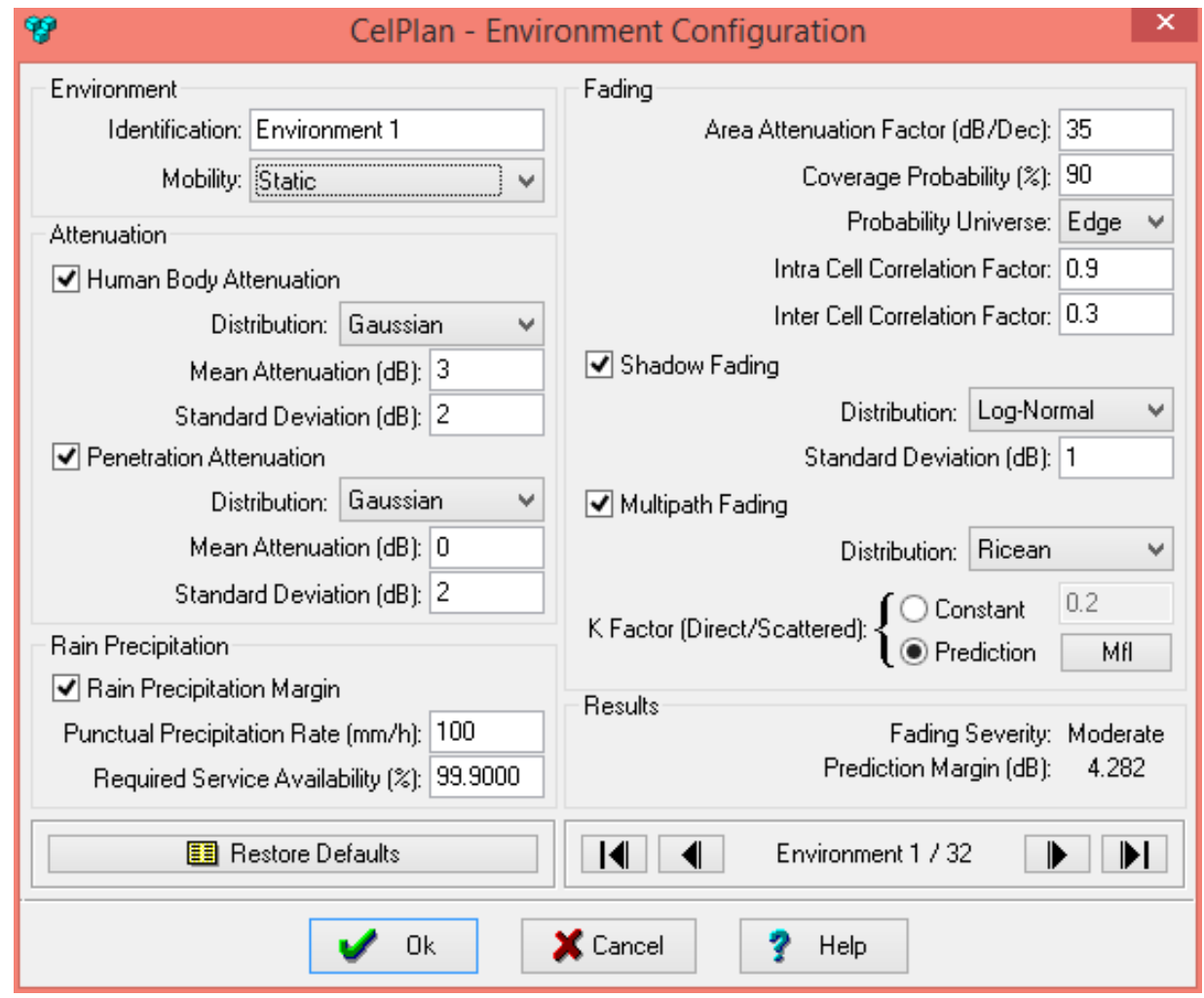

Figura 5.2: Configurações de ambiente para o cenário Outdoor

As estações rádio base são cadastradas em seguida. As ERBs foram localizadas de forma a prover a melhor cobertura para as áreas rurais de interesse. A Figura 5.4 ilustra os parâmetros a serem configurados neste caso. Os principais dados a serem preenchidos, relacionados a ERB, são: nome; posição geográfica - latitude e longitude; modelo por perda de propagação, neste trabalho, todas as ERBs utilizaram o modelo Cost 231/Hata; azimute, tilt, altura, foram escolhidos de forma a melhorar a cobertura fornecida pela ERB; a frequência utilizada foi de $450 \mathrm{MHz}$; e a antena LPD 3805/2 foi a escolhida para este trabalho, seu diagrama de irradiação está ilustrado na Figura 5.5. 


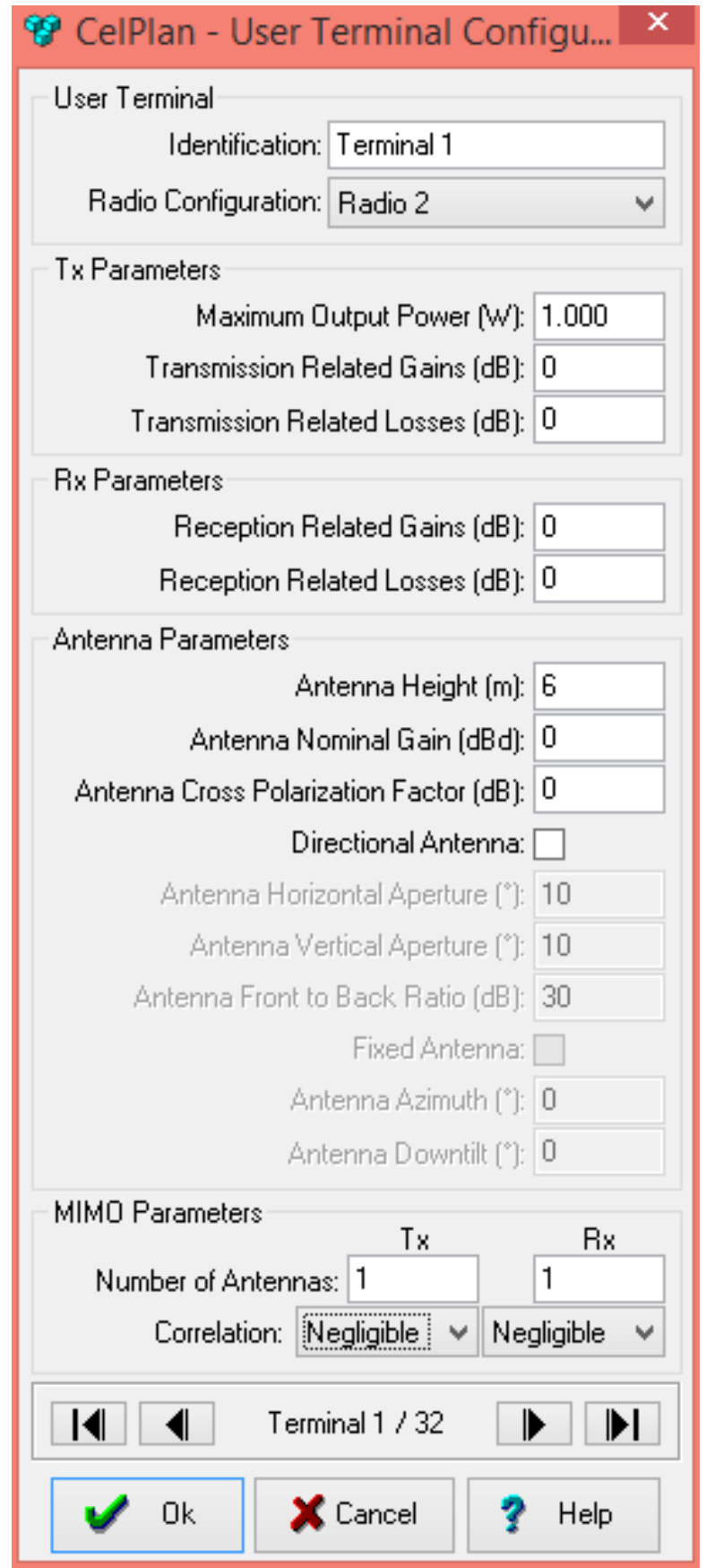

Figura 5.3: Configurações do terminal para o cenário Outdoor. 


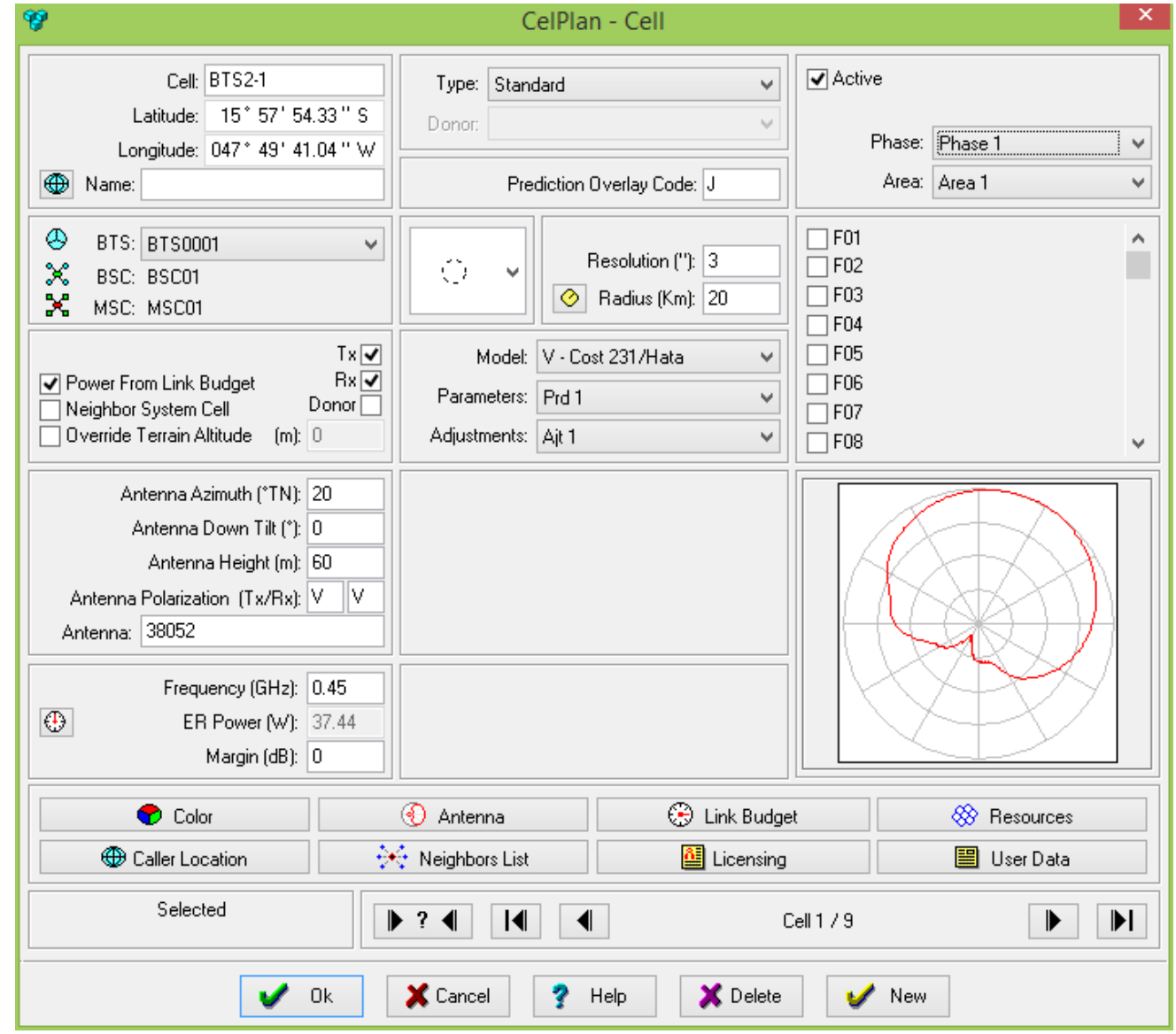

Figura 5.4: Cadastro das ERBs para o LTE $450 \mathrm{MHz}$ no software CelPlanner.

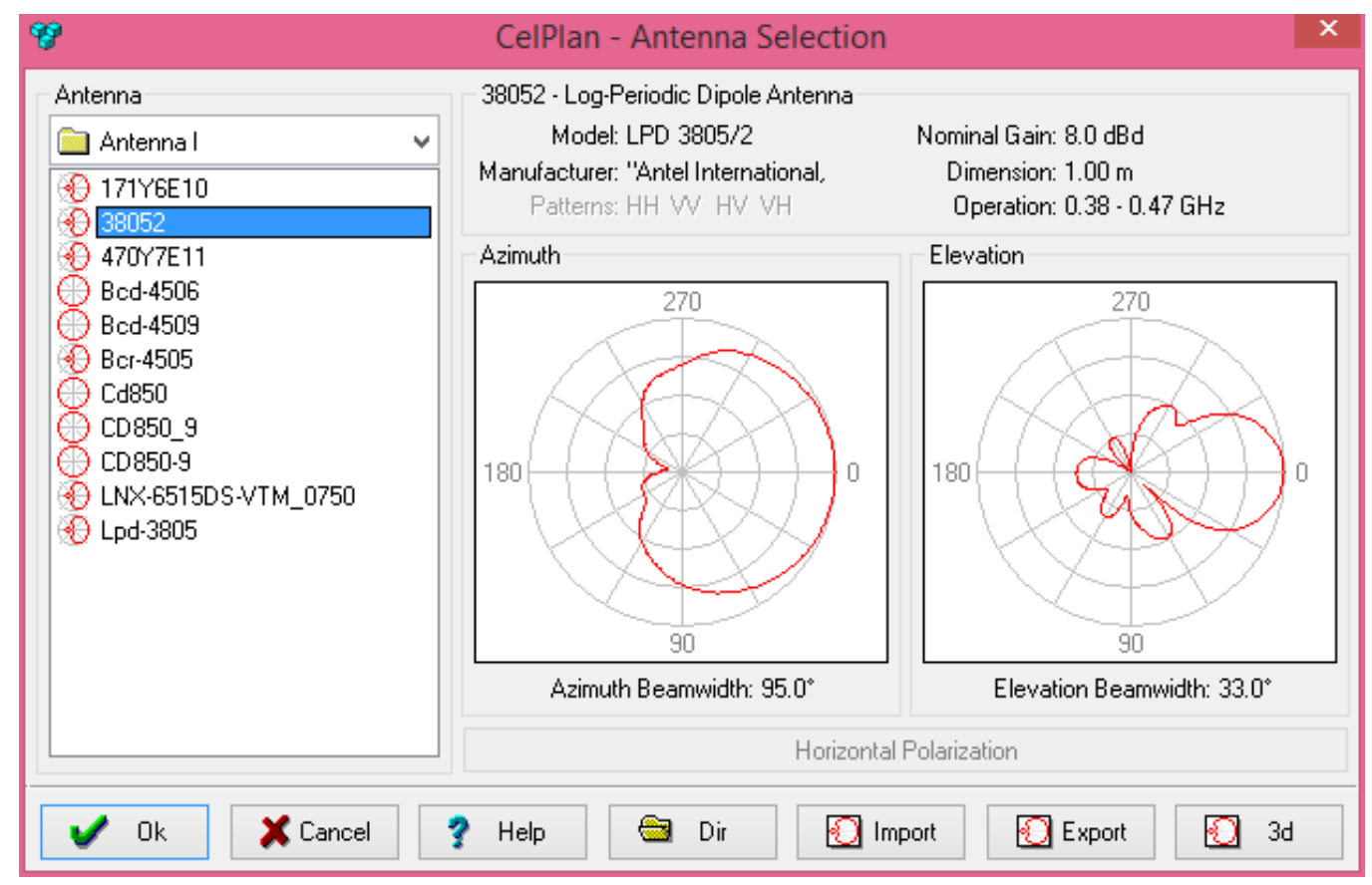

Figura 5.5: Diagrama de irradiação da antena LPD 3805/2 
Para a configuração do balanceamento de enlace de cada ERB, a Figura 5.6 exemplifica os dados que devem ser introduzidos no software para que seja realizado o cálculo da predição de cobertura. Os principais dados a serem preenchidos são: Potência de transmissão, que neste trabalho foi utilizada a solução do fabricante WxBR que oferece eNodeB para o LTE na faixa de $450 \mathrm{MHz}$ com uma potência de $10 \mathrm{~W}$ (40 dBm), conforme Tabela 5.1; Perda por cabos, o cabo escolhido, LMR-400, para a faixa de frequência desejada apresenta atenuação no valor de 8,9 dB/100m [45]; Comprimento dos cabos; Perda por conectores; Número de conectores; Ganho de antena, a antena escolhida possui ganho de 8dBd tanto para a transmissão quanto para a recepção; Potência de recepção, foi considerada como $1 \mathrm{~W}$ (30 dBm), conforme Tabela 5.1. A Figura 5.7 ilustra a sensibilidade do receptor para o caso LTE $450 \mathrm{MHz}$ simulado.

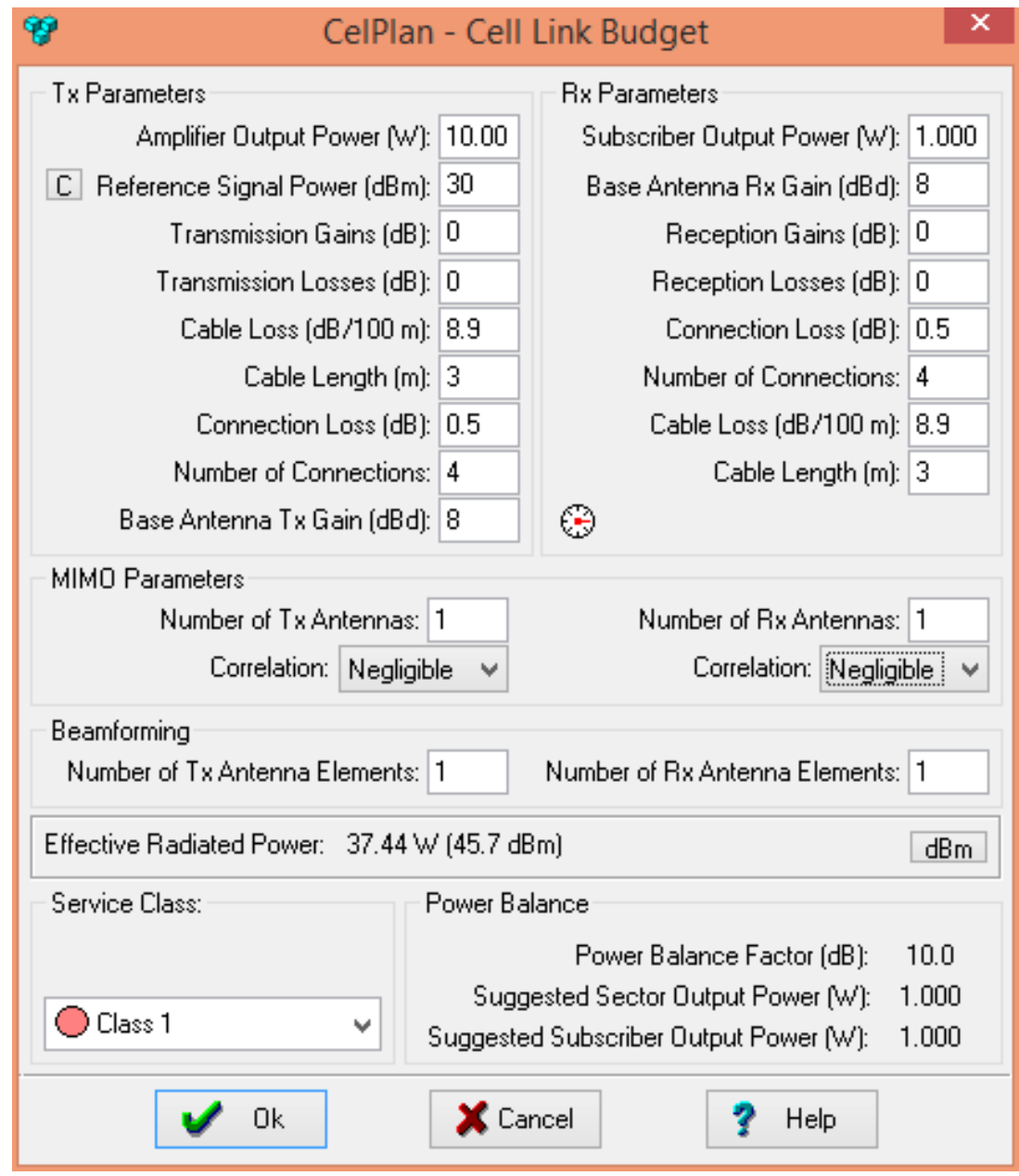

Figura 5.6: Balanceamento de enlace do LTE $450 \mathrm{MHz}$ pelo software CelPlanner. 
Tabela 5.1: Solução do fabricante WxBR para a tecnologia LTE 450 MHz.

\begin{tabular}{|c|c|c|}
\hline \multirow{5}{*}{$\begin{array}{c}\text { CPE LTE } \\
450 \mathrm{MHz} \\
\text { OUTDOOR }\end{array}$} & Potência de Transmissão & $30 \mathrm{dBm}$ \\
\hline & Largura de Banda & $5 \mathrm{MHz}$ \\
\hline & Faixa de Frequência & 450 a $470 \mathrm{MHz}$ (Anatel 558/2010) \\
\hline & Fonte de Alimentação & AC 110-220V / VIA PoE \\
\hline & Taxas PHY & $25 \mathrm{Mbps}$ (DL) $12 \mathrm{Mbps}$ (UL) \\
\hline \multirow{5}{*}{$\begin{array}{l}\text { CPE LTE } \\
450 \mathrm{MHz} \\
\text { INDOOR }\end{array}$} & Potência de Transmissão & $23 \mathrm{dBm}$ \\
\hline & Largura de Banda & $5 \mathrm{MHz}$ \\
\hline & Faixa de Frequência & 450 a $470 \mathrm{MHz}$ (Anatel 558/2010) \\
\hline & Fonte de Alimentação & AC $110-220 \mathrm{~V}$ \\
\hline & Taxas PHY & $25 \mathrm{Mbps}$ (DL) $12 \mathrm{Mbps}(\mathrm{UL})$ \\
\hline \multirow{5}{*}{$\begin{array}{c}\text { eNodeB } \\
\text { LTE 450 } \\
\text { MHz } \\
\text { OUTDOOR }\end{array}$} & Potência de Transmissão & $30-40 \mathrm{dBm}$ \\
\hline & Largura de Banda & $5 \mathrm{MHz}$ \\
\hline & Faixa de Frequência & 450 a $470 \mathrm{MHz}$ (Anatel 558/2010) \\
\hline & Fonte de Alimentação & AC $110-220 \mathrm{~V} / \mathrm{DC} 48 \mathrm{~V}$ \\
\hline & Taxas PHY & $25 \mathrm{Mbps}(\mathrm{DL}) 16 \mathrm{Mbps}(\mathrm{UL})$ \\
\hline
\end{tabular}

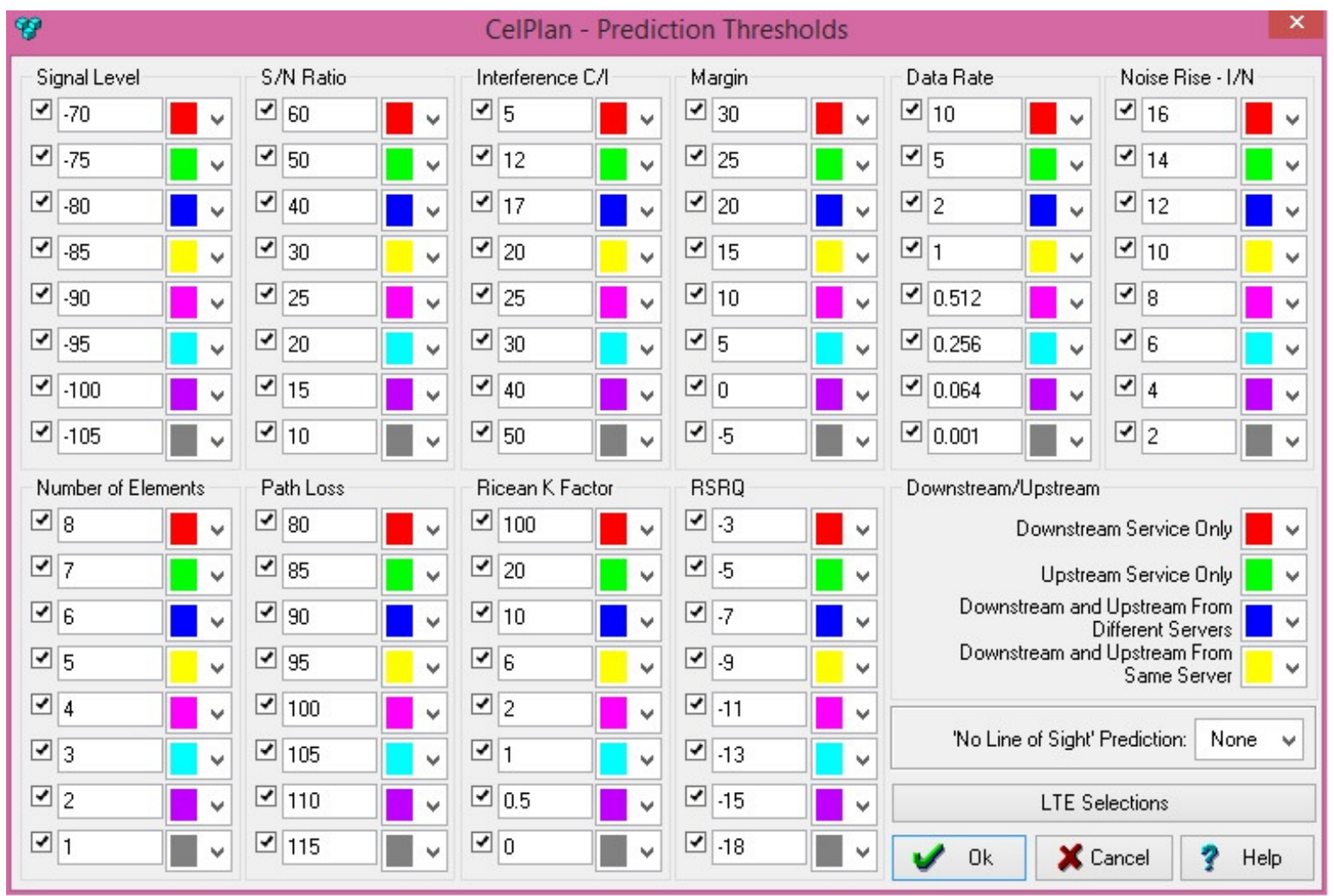

Figura 5.7: Sensibilidade no receptor LTE $450 \mathrm{MHz}$ 


\subsection{Resultados e Análises das simulações do LTE 450 MHz em áreas rurais do Distrito}

Federal.

A utilização da tecnologia LTE na faixa de frequência de $450 \mathrm{MHz}$ é propícia para levar acesso à internet móvel de qualidade a áreas rurais do país. Foram escolhidos alguns núcleos rurais do Distrito Federal para simular a predição de cobertura desta tecnologia:

- Núcleo 1: engloba o Núcleo Rural Santos Dumont localizado na região administrativa de Planaltina - DF;

- Núcleo 2: engloba a Cooperativa Agropecuária de São Sebastião (COPAS) e o Setor Habitacional Tororó (SHTO), localizados próximos a região administrativa de São Sebastião - DF;

- Núcleo 3: Núcleo Rural Lago Oeste, localizado na região administrativa de Sobradinho - DF.

A predição de cobertura foi realizada após a escolha dos locais - núcleos - que serão analisados e feita a configuração dos parâmetros no software Celplanner, conforme já explicado na seção acima.

\subsubsection{Núcleo 1}

As Figuras 5.8 a 5.11 exibem os resultados para o Núcleo 1. Pode-se perceber que tanto para o cenário Outdoor quanto para o cenário Indoor, a cobertura é significativamente maior no caso do enlace direto (sentido estação rádio base para o terminal do usuário downstream) se comparado ao enlace inverso (sentido terminal do usuário para a estação rádio base - upstream). Isto acontece principalmente devido às diferenças de configuração no balanceamento de enlace, em que a potência de transmissão da ERB é bem maior que a potência do terminal do usuário, cenário típico de operação de redes celulares comerciais.

Para o cenário Outdoor, a cobertura é boa em praticamente toda a região. Os níveis de sinal mais baixos são atingidos no enlace reverso e chegam a ter valores entre $-85 \mathrm{dBm}$ a -90 dBm, o que ainda é aceitável. Entretanto, ainda é possível visualizar algumas áreas de sombra. Caso seja de interesse, para aumentar o nível de sinal a longas distâncias e aumentar a área de cobertura, é sugerido algumas soluções, tais como instalar novas estações rádio base na região, aumentar a altura da antena da ERB proposta ou aumentar a altura do terminal do usuário caso seja do tipo CPE. As duas primeiras opções são soluções desinteressantes 
economicamente. A última opção é economicamente viável e interessante principalmente para os usuários que estão localizados nos pontos onde há buracos.

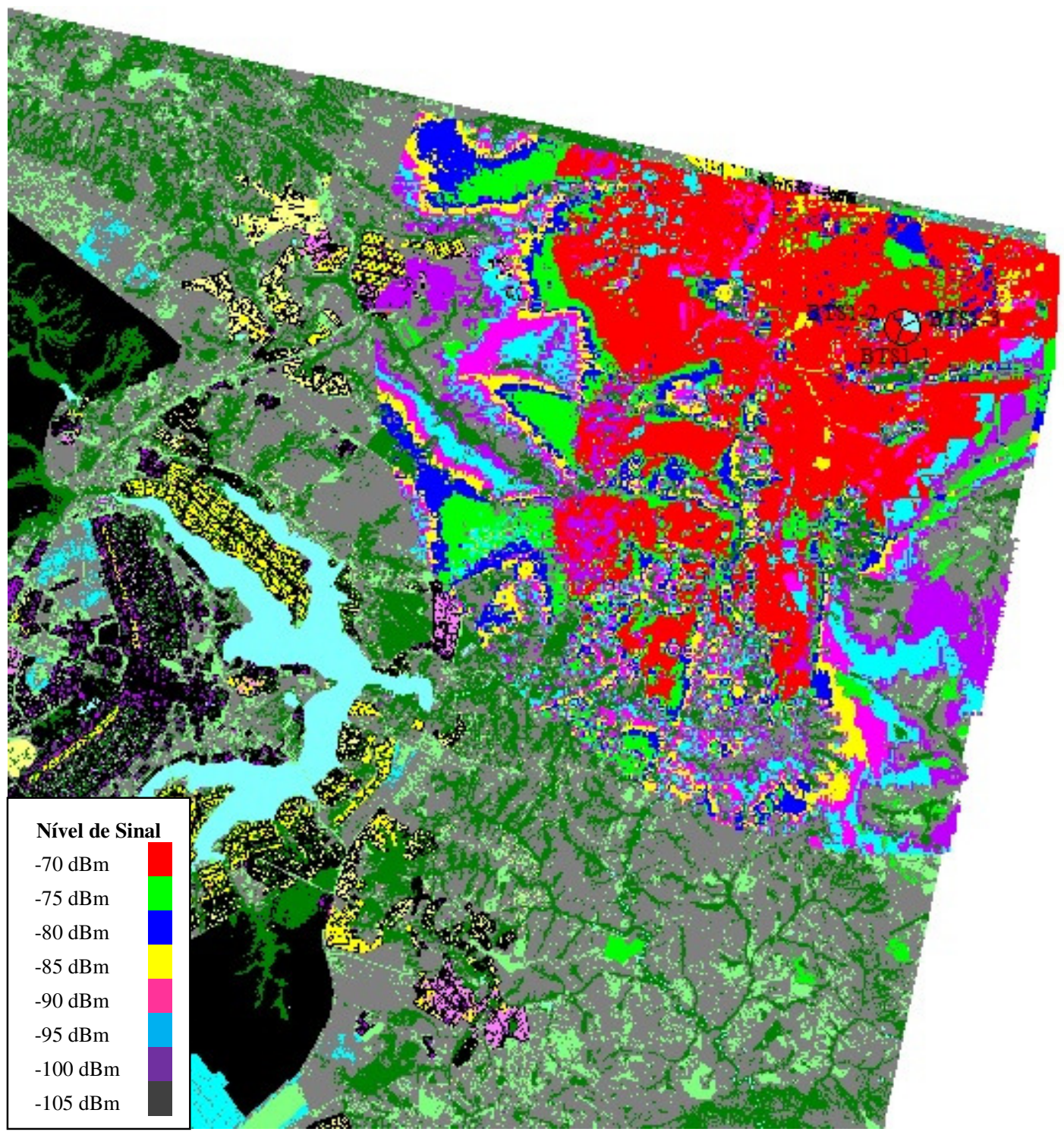

Figura 5.8: Cobertura no sentido downstream para ambientes outdoors - Núcleo 1. 


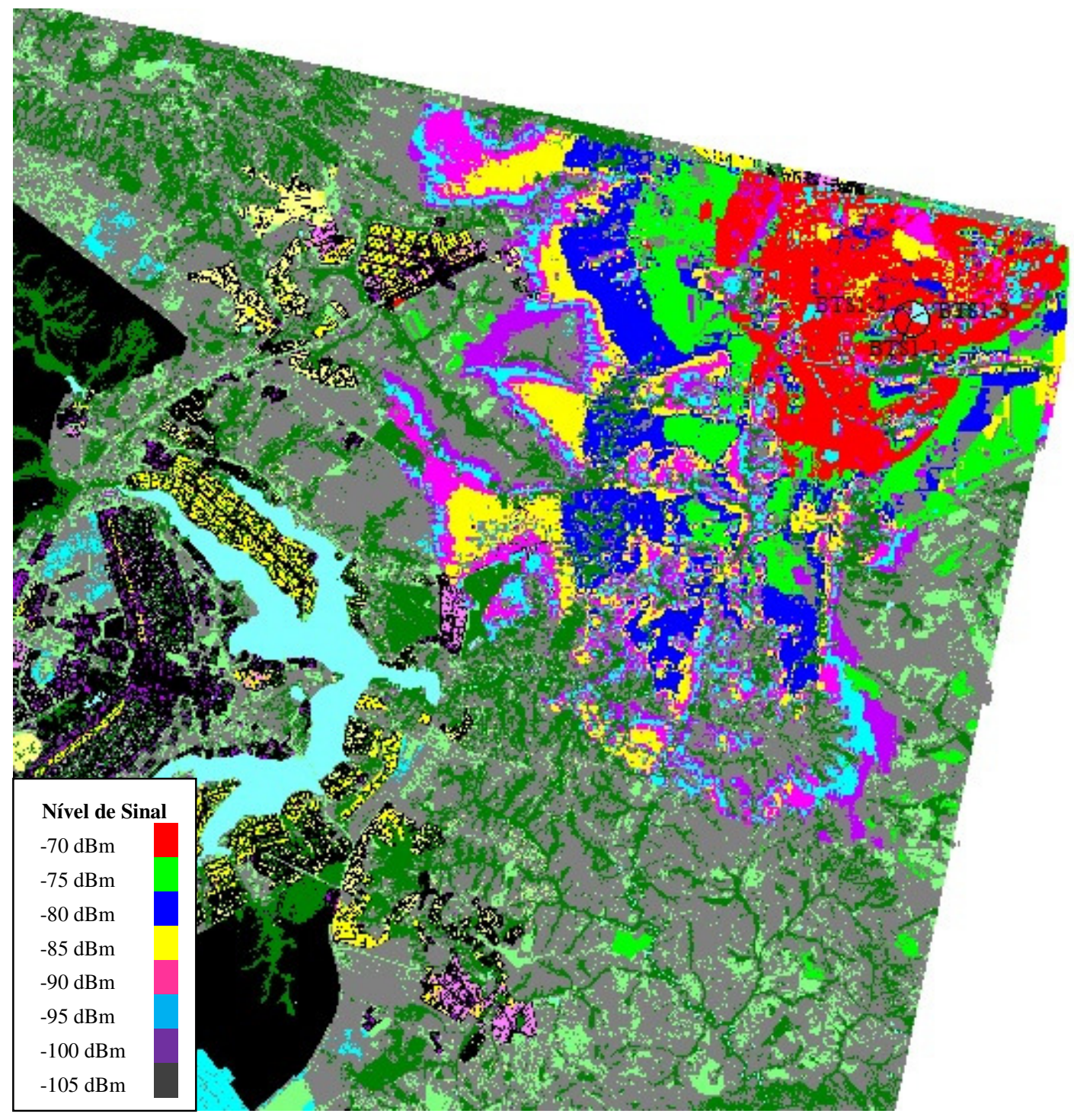

Figura 5.9: Cobertura no sentido upstream para ambientes outdoors - Núcleo 1.

Para o cenário Indoor, a cobertura é visivelmente prejudicada, principalmente no sentido upstream. Isso se deve às perdas por estar em ambiente fechado e à altura mais baixa do terminal do usuário. Dessa forma, a ERB foi posicionada de maneira a conseguir cobrir principalmente as áreas de maior densidade de residências em detrimentos a áreas com grandes espaços abertos. Levando em consideração este fato, a cobertura neste cenário é satisfatória por exibir níveis de sinal bons na região interna desejada. Para melhorar o alcance da cobertura no cenário Indoor, a solução proposta é aumentar a altura da antena da ERB ou instalar outras estações. 


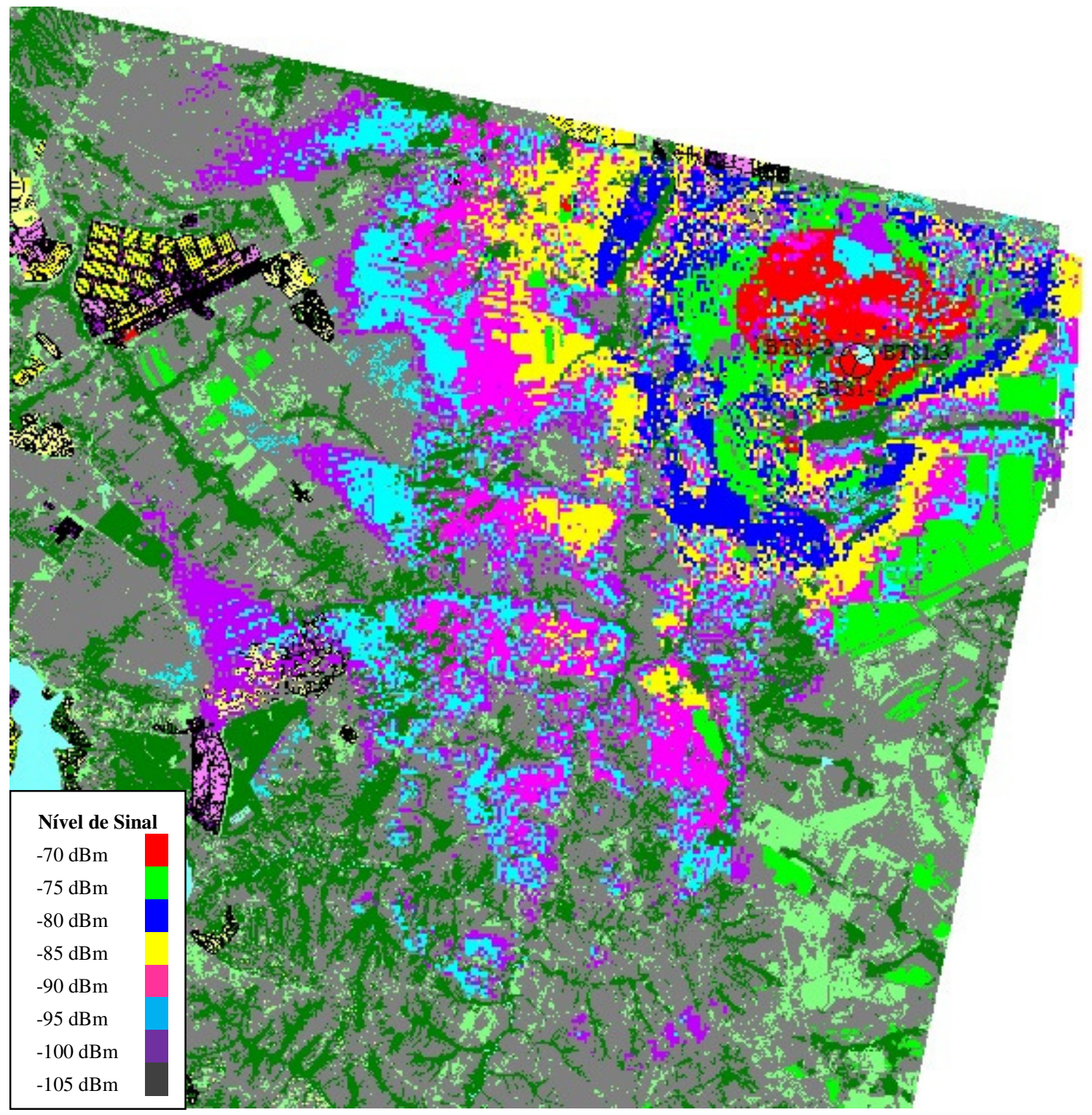

Figura 5.10: Cobertura no sentido downstream para ambientes indoors - Núcleo 1. 


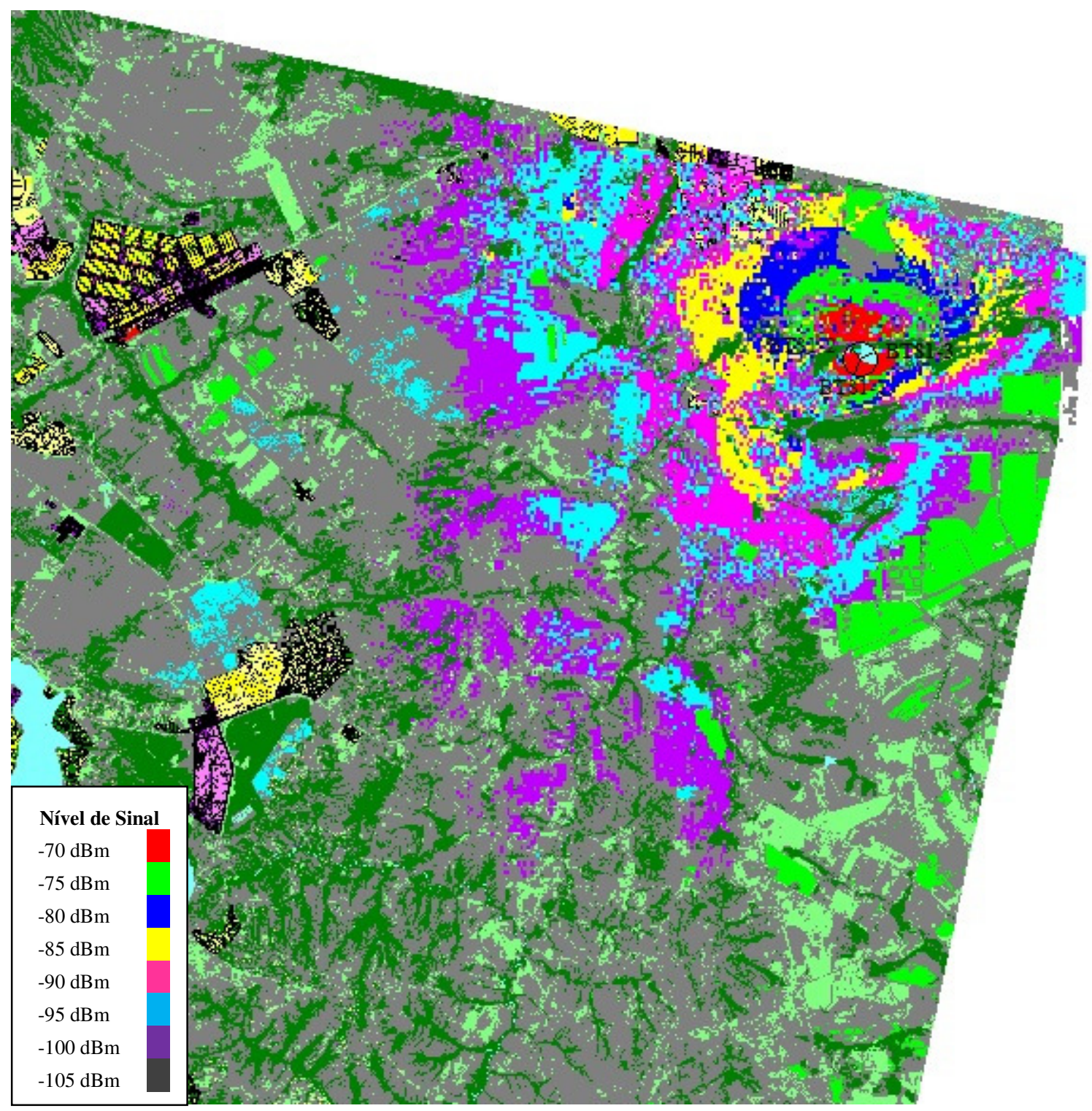

Figura 5.11: Cobertura no sentido upstream para ambientes indoors - Núcleo 1.

\subsubsection{Núcleo 2}

As Figuras 5.12 a 5.15 exibem os resultados para o Núcleo 2. Como visto anteriormente, a cobertura para o enlace direto é melhor que a cobertura para o enlace reverso, tanto para o cenário Outdoor quanto para o cenário Indoor, devido as diferentes configurações no enlace. 
Para o cenário Outdoor, a cobertura da área desejada é totalmente satisfatória. Tanto para o enlace direto como para o enlace reverso, os níveis de sinal de $-70 \mathrm{dBm}$ que chegam a toda a região é suficiente para servir os usuários.

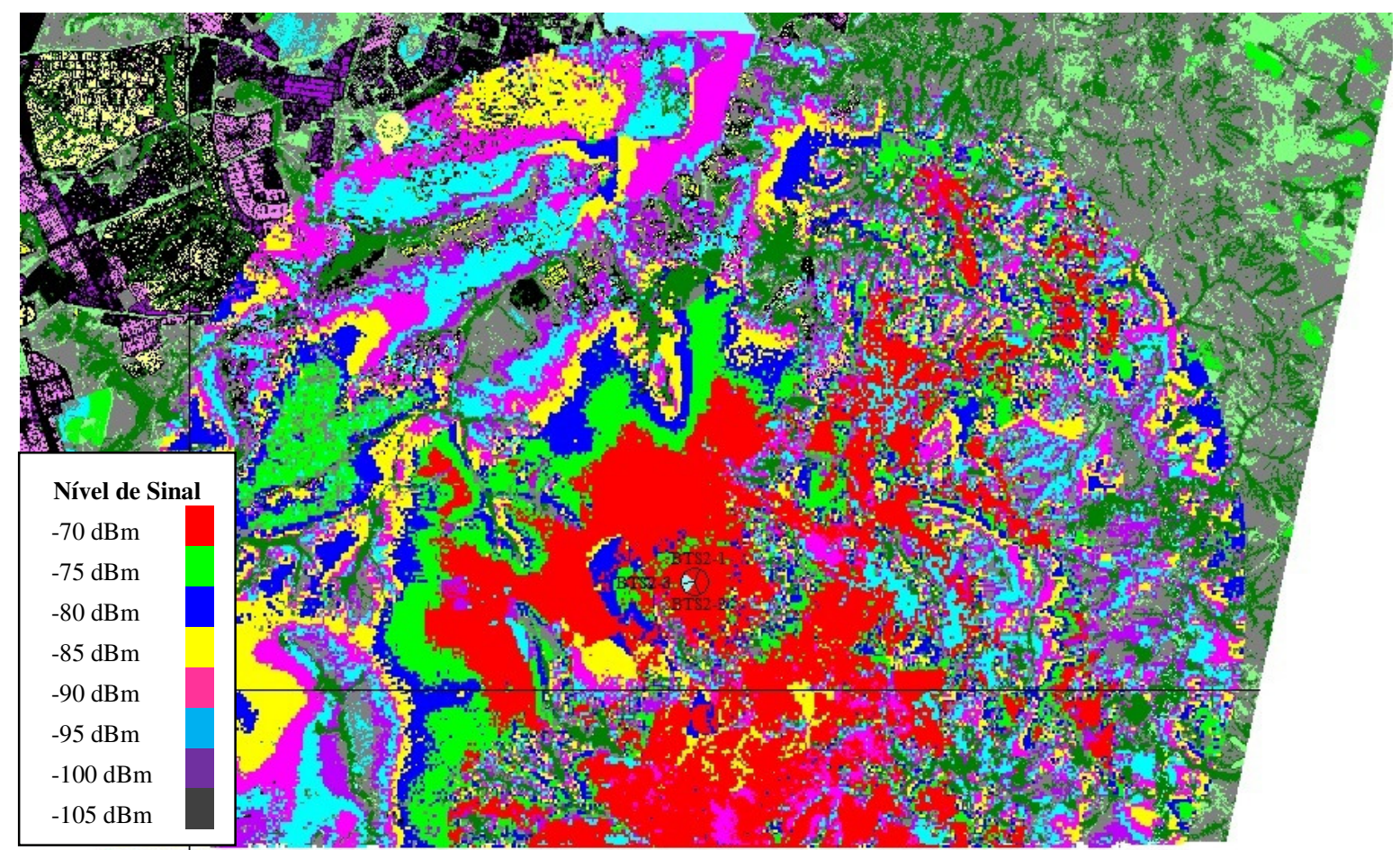

Figura 5.12: Cobertura no sentido downstream para ambientes outdoors - Núcleo 2.

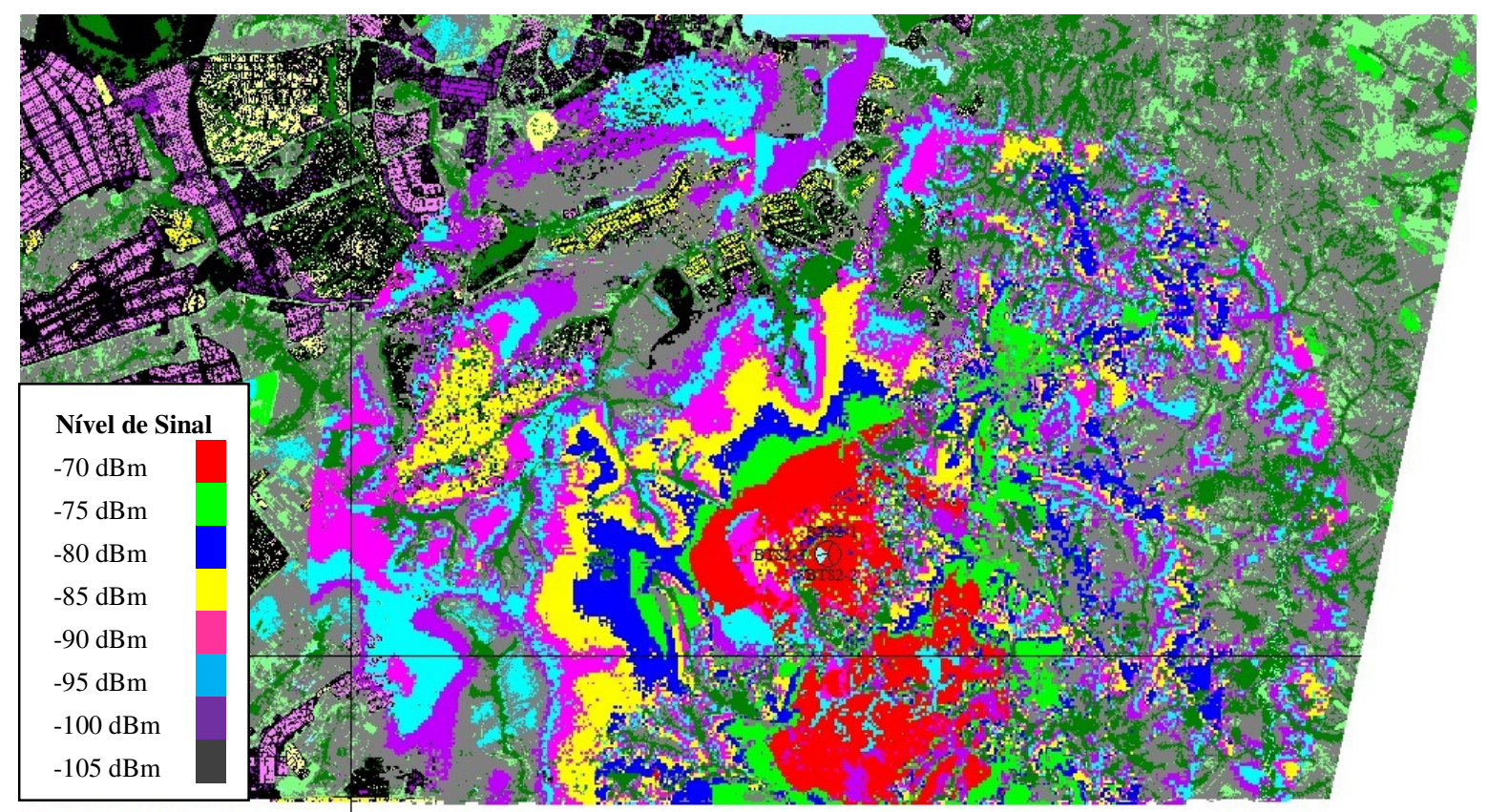

Figura 5.13: Cobertura no sentido upstream para ambientes outdoors - Núcleo 2. 
Para o cenário Indoor, apesar das perdas por penetração, a cobertura ainda é satisfatória não somente para ambientes fechados como para toda a região. Os locais onde os níveis de sinal são mais baixos, atingindo $-90 \mathrm{dBm}$, ainda conseguem conexão para alguns serviços que não exigem tanta confiabilidade da rede ou ordem na entrega de pacotes, como os serviços baseados em TCP que possui tecnologia de retransmissão.

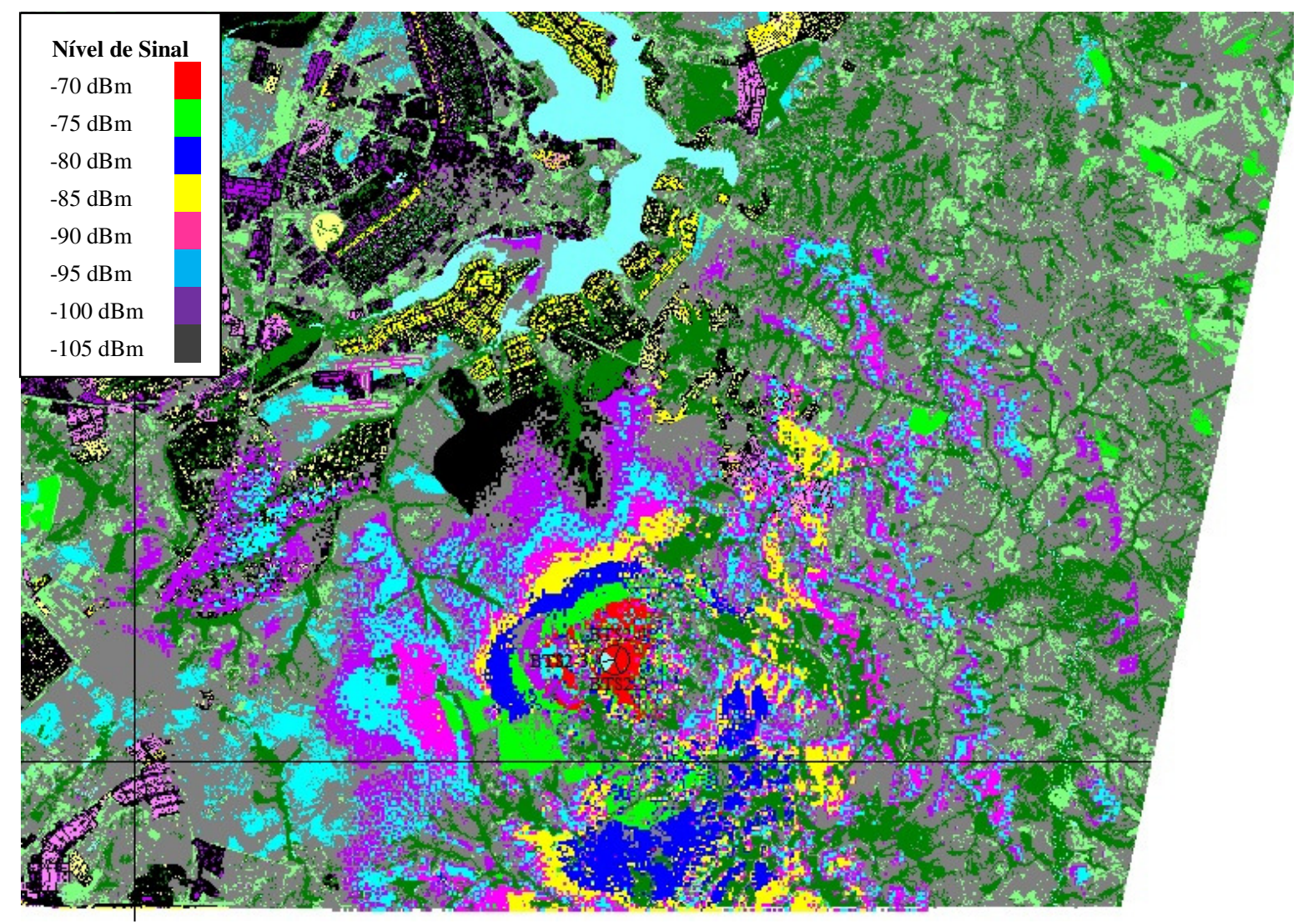

Figura 5.14: Cobertura no sentido downstream para ambientes indoors - Núcleo 2. 


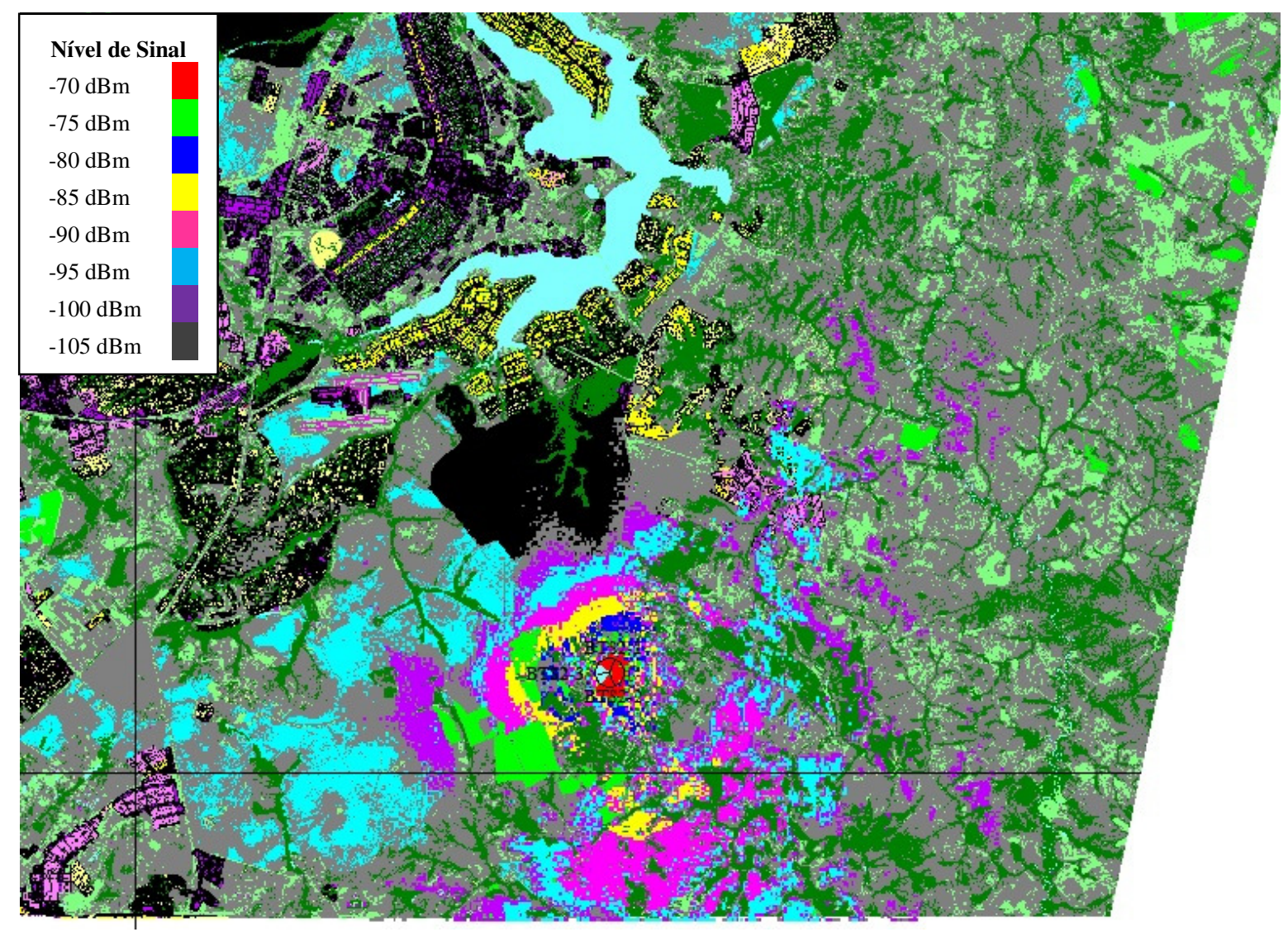

Figura 5.15: Cobertura no sentido upstream para ambientes indoors - Núcleo 2.

\subsubsection{Núcleo 3}

As Figuras 5.16 a 5.19 exibem os resultados para o Núcleo 3. A área definida pelo núcleo 3 possui uma topologia irregular, com altos relevos cercando a região e alguns vales dentro dela. Isto dificulta a predição de cobertura: para os altos relevos a zona de Fresnel é obstruída e o sinal é interrompido, e para os vales o sinal não alcança o solo. Assim como para as outras regiões, o sinal para o enlace direto possui diferença significativa em relação ao enlace direto para ambos os cenários.

Para o cenário Outdoor, no enlace direto, toda a região é coberta com ótimos níveis de sinal. Já no enlace reverso os níveis de sinal são reduzidos, mas aceitáveis, chegando até 
a -85 dBm, e deixando sem cobertura apenas as regiões de vales profundos. Para solucionar o problema das áreas de sombra sem que seja adicionada uma nova ERB é possível aumentar a altura da antena na estação sugerida ou aumentar a altura do terminal do usuário, caso ele esteja dentro de uma destas áreas.

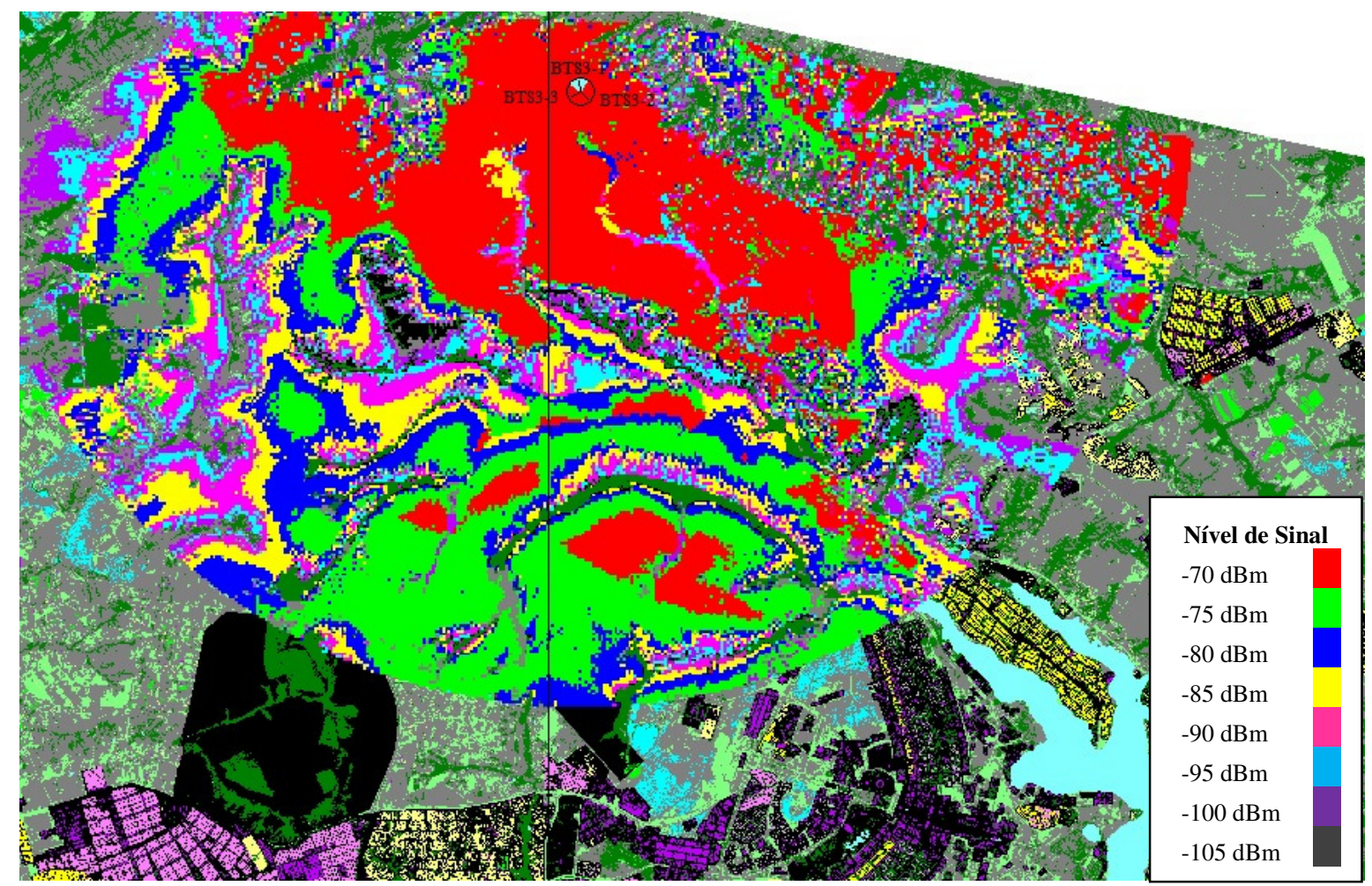

Figura 5.16: Cobertura no sentido downstream para ambientes outdoors - Núcleo 3. 


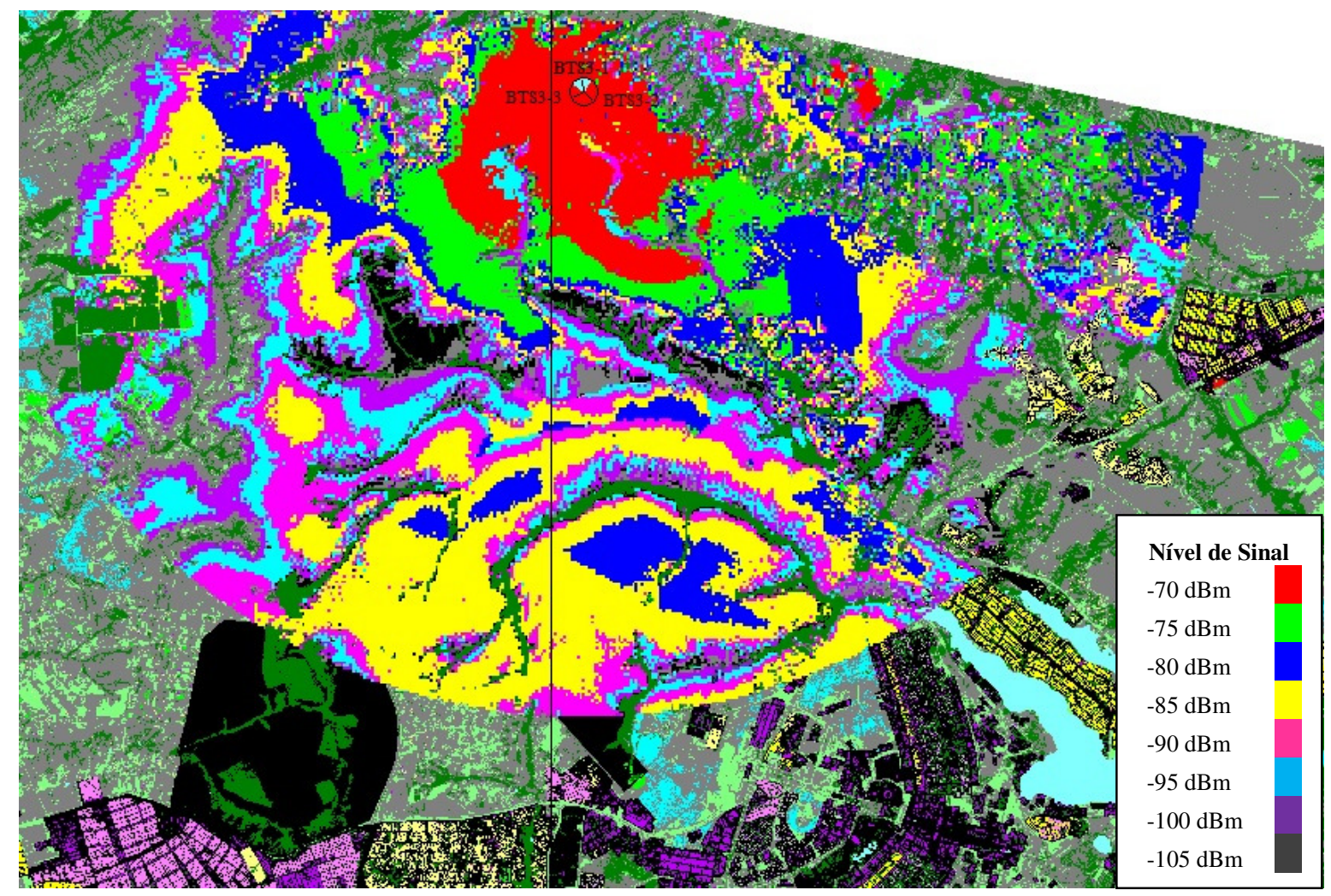

Figura 5.17: Cobertura no sentido upstream para ambientes outdoors - Núcleo 3.

Já para o cenário Indoor, a penetração em ambientes fechados não é boa. Além das dificuldades de topografia, o terminal do usuário está a um nível mais baixo e existem muitos obstáculos que acarretam o desvanecimento. Os níveis de sinal até -85 dBm em que o usuário conseguiria uma cobertura aceitável estão concentrados em uma área pequena. Para todo o resto da região, os níveis de sinal são bastante ruins tanto para o enlace direto quanto para o enlace reverso. Entretanto, esta região é praticamente toda rural, sem centros ou concentrações urbanas consideráveis, tornando a princípio o cenário Indoor desnecessário para este núcleo. Caso surja o interesse de cobrir este tipo de cenário, seria necessário introduzir novas ERBs e realizar um cálculo preciso para o balanceamento de enlace. 


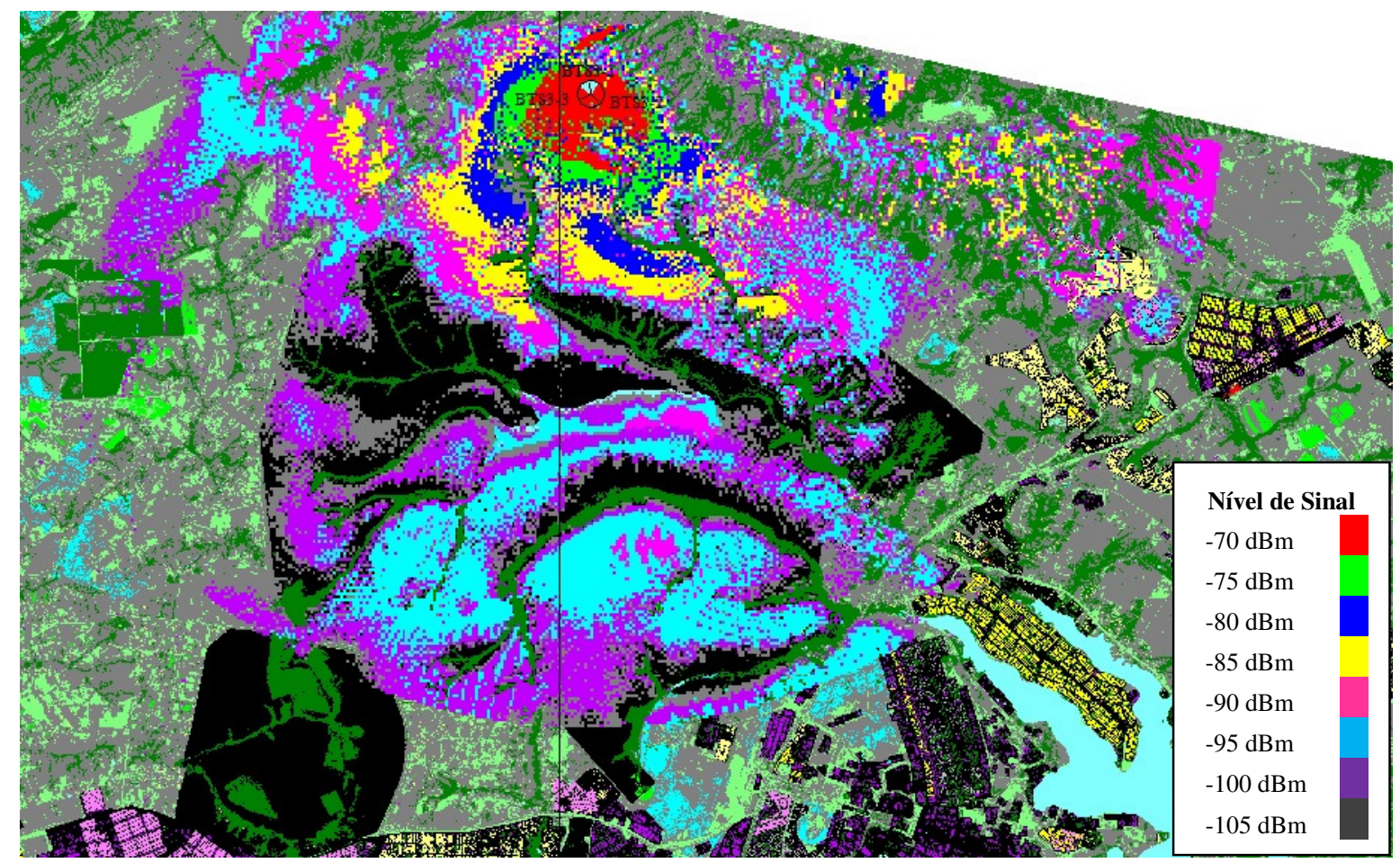

Figura 5.18: Cobertura no sentido downstream para ambientes indoors - Núcleo 3.

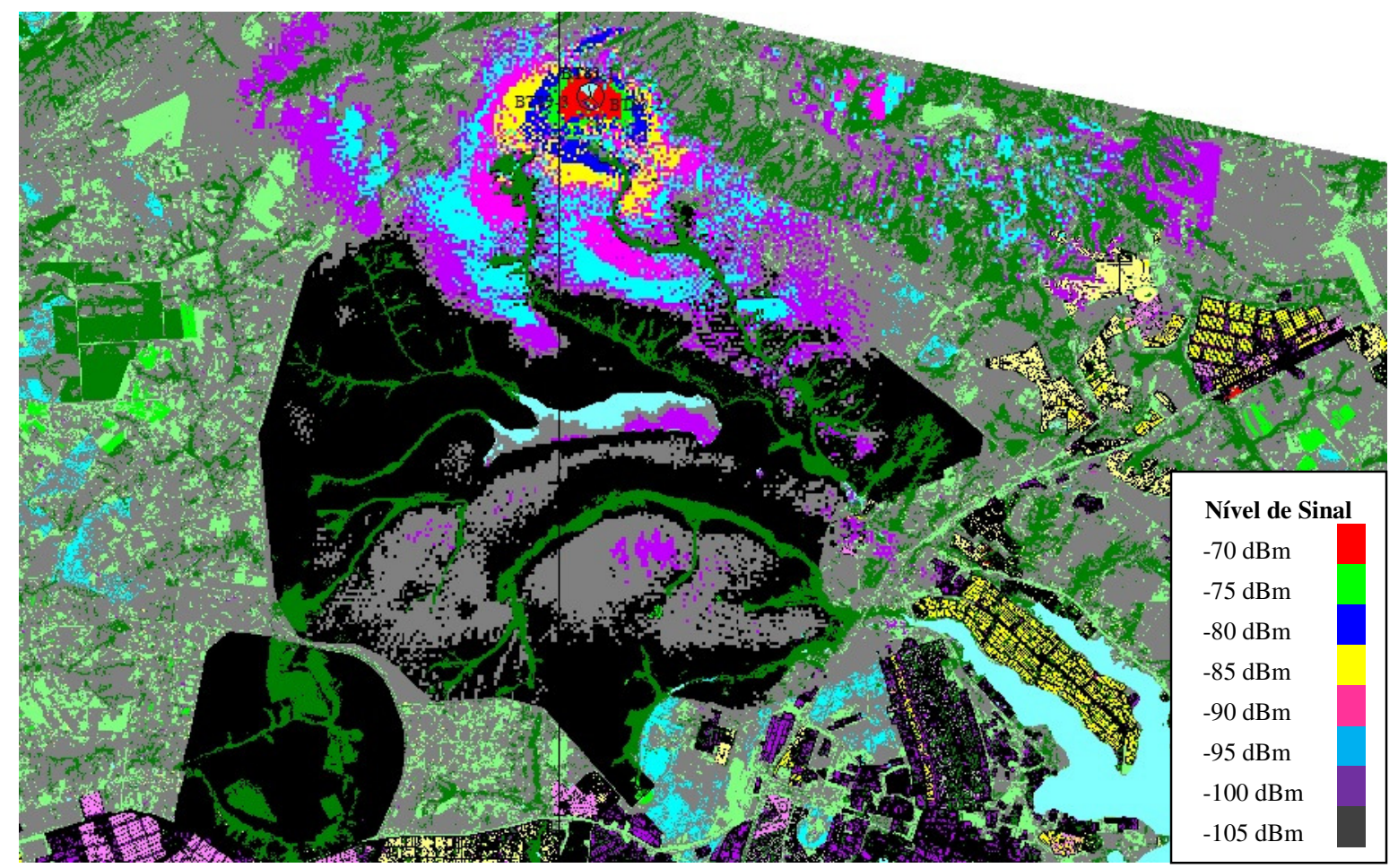

Figura 5.19: Cobertura no sentido upstream para ambientes indoors - Núcleo 3. 


\subsection{Conclusão}

Neste capítulo foram apresentadas e justificadas as configurações de parâmetros para as simulações realizadas no CelPlanner, bem como os resultados obtidos nas simulações computacionais e suas respectivas análises. 


\section{Considerações Finais}

Este trabalho apresentou e fez analise com dados práticos os canais sem fio em ambientes externos na faixa de frequência de $450 \mathrm{MHz}$ e, ainda, apresentou a predição de cobertura nesta faixa de frequência em algumas áreas rurais do Distrito Federal. Tal frequência foi disponibilizada para a rede 4G brasileira, com uso da tecnologia LTE.

Na primeira parte do projeto, foram obtidos dados experimentais de transmissões na frequência estudada com a finalidade de investigar estatísticas de primeira e de segunda ordens do canal sem fio em ambientes abertos, tais como funções densidades de probabilidades (PDF), função de distribuição acumulada (CDF) e funções de autocorrelação para os modelos de desvanecimento $\alpha-\mu$, Nakagami- $m$, Rice e Rayleigh. Para este fim, um sistema de medição foi especificamente montado e os dados experimentais foram coletados com a finalidade de se obter, na prática, as estatísticas em análise. Comparações realizadas entre os modelos investigados e os dados experimentais. Por fim, os desvios médios são obtidos com a finalidade de sugerir o modelo que obteve o melhor desempenho de caracterização estatística na faixa de $450 \mathrm{MHz}$ considerando os ambientes medidos.

Excelentes ajustes foram encontrados entre os dados empíricos e teóricos da distribuição $\alpha-\mu$, considerando todos as rotas e cenários medidos em ambientes LOS típicos das aplicações esperadas para LTE 450. Desta forma, recomenda-se a utilização do modelo generalizado $\alpha-\mu$ no planejamento de futuras redes sem fio operando na faixa de $450 \mathrm{MHz}$.

$\mathrm{Na}$ segunda parte do trabalho, através do programa computacional de simulação CelPlanner foi possível realizar a predição de cobertura para o sistema 4G LTE na faixa de $450 \mathrm{MHz}$ para ambientes externos e internos em áreas rurais do Distrito Federal com a finalidade de investigar a utilização desta tecnologia na faixa de frequência de $450 \mathrm{MHz}$ para estas áreas.

A ferramenta computacional CelPlanner foi utilizada para se configurar as ERBs e ajustar os parâmetros para o cálculo do balanceamento de enlace. Os resultados mostraram que utilizar ao LTE em $450 \mathrm{MHz}$ é possível cobrir maiores áreas geográficas utilizando um menor número de estações rádio base. Foi conseguido bons níveis de sinal na cobertura para distâncias de até $20 \mathrm{~km}$ como apenas uma ERB por núcleo de interesse neste trabalho. Dessa forma, nesta faixa de frequência mais baixa, pode-se cobrir uma área maior ou a mesma área com menos ERBs, o que permite reduzir consideravelmente despesas com implantação deste 
sistema. O principal benefício e justificativa do uso do LTE 450, seria poder levar banda larga móvel a regiões menos populosas, como áreas rurais e suburbanas, e assim, possibilitar uma maior integração tecnológica ao país.

\subsection{Investigações Futuras}

Finalmente, podem ser sugeridos alguns tópicos para trabalhos futuros que deem continuidade ao estudo desenvolvido neste projeto. São eles:

- Investigar os fenômenos e efeitos do sombreamento e da perda de percurso;

- Realizar campanhas de medição em novas áreas rurais;

- Otimizar o sistema de medição, de modo a ter um controle espacial com maior precisão;

- Realizar investigações comparativas com as faixas de $700 \mathrm{MHz}$ e $2500 \mathrm{MHz}$;

- Investigar a capacidade de redes LTE $450 \mathrm{MHz}$ nas áreas rurais medidas. 


\section{Referências Bibliográficas}

[1] RAPPAPORT, T. S. Comunicações sem fio: princípios e práticas. 2ed. São Paulo: Pearson Prentice Hall, 2009. ISBN 978-85-7605-198-5

[2] STALlingS, W. Wireless Communications and Networks. 2ed. Upper Saddle River: Pearson Prentice Hall, 2005. ISBN 0-13-191835-4

[3] Global Mobile Data Traffic Forecast Update. White Paper. CISCO VNI, February 2014

[4] 2013: The Year of the Smartphone in Latin America. Disponível em: <http://www. emarketer.com/Article/2013-Year-of-Smartphone-Latin-America/ 1010545>. Acesso em 29 de julho de 2015.

[5] SANTANA, H. Qualidade de Serviço (QoS) em Redes IP: Princípios Básicos, Parâmetros e Mecanismos. Universidade Santa Cecília. s.d.

[6] Resolução no 558/2010, "Regulamento sobre Canalização e Condições de Uso de Radiofrequências na Faixa de 450 MHz a 470 MHz." ANATEL, Tech. Rep., Dezembro2010.

[7] ITU, "Final acts," in World Radiocommunication Conference (WRC-07), Geneva, 2007.

[8] ITU Radio Communication Study Groups, "Contribution to technical requirements for IMTAdvanced systems D7," ITU, Tech. Rep., 2007.

[9] TECNOLOGIAS de Celular. Disponível em: <http://www.teleco.com.br/ tecnocel.asp>. Acesso em 29 de julho de 2015.

[10] STEFANIA, S.; ISSAM, T.; MATTHEW, B. LTE - The UMTS Long Term Evolution: from theory to practice. A John Wiley and Sons, Ltd, v. 6, p. 136_144, 2009. 
[11] HOLMA, H.; TOSKALA, A. LTE for UMTS: OFDMA and SC-FDMA Based Radio Access. 1.ed. West Sussex: John Wiley \& Sons Ltd, 2009. ISBN 978-0-470-99401-6

[12] Long Term Evolution (LTE): A Technical Overview. White Paper. MOTOROLA INC, 2007. Disponível em http://goo.gl/chXXot. Acesso em 29 de julho de 2015.

[13] EDITAL LICITAÇÃO No 004/2012/PVCP/SPV - ANATEL. Disponível em: $<$ http://sistemas.anatel.gov.br/SAE/Edital/Download/Tela.asp? SISQSmodulo=6376>. Acesso em 29 de julho de 2015.

[14] ATRIBUIÇÃO de Faixas de Frequências no Brasil. Disponível em: <http://migre.me/ kbWDg >. Acesso em 29 de julho de 2015.

[15] LTE 450 MHz: uma solução para a universalização do acesso em banda larga para áreas rurais e suburbanas. CpQD. Disponível em: http://www.cpqd.com.br/pesquisadesenvolvimento/lte-450mhz. Acesso em 29 de julho de 2015.

[16] LEÓN, O. de. La banda de $450 \mathrm{MHz}$ para LTE en América Latina: situación actual y recomendaciones de política. CEPAL, October 2013. 12 f.

[17] J.A. de O. NETO, Bridging the digital gap by Universal MBB Service. HUAWEI, May 2013.

[18] LTE $450 \mathrm{MHz}$ in Brazil Work Item Technical Report. Technical Report. 3GPP, September 2013. Disponível em: <http://www.3gpp.org/DynaReport/36840.htm>. Acesso em 29 de julho de 2015.

[19] Edital de Licitação das Faixas de 450 MHz e de 2,5 GHz: Proposta. ANATEL, January 2012.

[20] SAUNDERS, S. R.; ZAVALA, A. A. Antennas and Propagation for Wireless Communication Systems. 2nd. ed. [S.1.]: John Wiley \& Sons, Ltd, 2007. 
[21] SEYBOLD, J. S. Introduction to RF Propagation. 3rd. ed. Hoboken, New Jersey: John Wiley \& Sons, Inc., 2005.

[22] JESZENSKY, P. J. E. Sistemas telefônicos. [S.1.]: Editora Manole Ltda, 2004.

[23] GOLDSMITH, A. Wireless communications. [S.1.]: Cambridge university press, 2005.

[24] M. D. Yacoub, “The $\alpha-\mu$ Distribution: A Physical Fading Model for the Stacy Distribution," IEEE Trans. Veh. Technol., vol. 56, no. 1, pp. 27-34, Jan. 2007.

[25] M. Abramowitz and I. A. Stegun, Handbook of Mathematical Functions with Formulas, Graphs, and Mathematical Tables. New York: Dover, 1972.

[26] U. S. Dias and M. D. Yacoub, “On the $\alpha-\mu$ Autocorrelation and Power Spectrum Functions: Field Trials and Validation," in IEEE Global Communications Conference (GLOBECOM), Honolulu, USA, Nov.- Dec. 2009.

[27] R. Von Mises, "Uber die 'Ganzzahligkeit' der Atomgewicht und verwandte Fragen," Phys. Z., vol. 19, pp. 490-500, 1918.

[28] M. Nakagami, The m-Distribution - A General Formula of Intensity Distribution of Rapid Fading, ser. Statistical Methods in Radio Wave Propagation. W. C. Hoffman, Ed. Elmsford, NY: Pergamon, 1960, pp. 3-36.

[29] R. H. Clarke, “A statistical theory of mobile-radio reception,” Bell Syst. Tech. J., vol. 47, pp. 957-1000, Jul.-Aug. 1968.

[30] S. O. Rice, "Mathematical analysis of random noise," Bell Syst. Tech. J., vol. 23, no. 3, pp. 282-332, Jul. 1944.

[31] _ _ "Mathematical analysis of random noise," Bell Syst. Tech. J., vol. 24, no. 1, pp. 46156, Jan. 1945. 
[32] FRIIS, H. T. Noise figures of radio receivers. Proceedings of the IRE, IEEE, v. 32, n. 7, p. 419_422, 1944.

[33] LOW Noise Amplifier ZHL-1724HLN. Disponível em: <http://www.minicircuits.com/ pdfs/ZHL-1724HLN.pdf>. Acesso em 29 de julho de 2015.

[34] HP E363xA - Series Programmable Power Supplies. Disponível em: <https://d3fdwrtpsinh7j.cloudfront.net/Docs/datasheet/hp_e363xa.pdf>. Acesso em 29 de julho de 2015.

[35] HP 8590 E-Series Portable Spectrum Analyzers. Disponível em: <http://www. buy17.com/hp/pdf/hp8590e.pdf>. Acesso em 29 de julho de 2015.

[36] U12 LabJack User's Guide. Disponível em: <http://labjack.com/support/u12/users-guide>. Acesso em 29 de julho de 2015.

[37] AGILENT N9912A FieldFox RF Analyzer. Disponível em: <http://cp.literature. agilent.com/litweb/pdf/N9912-90006.pdf>. Acesso em 29 de julho de 2015.

[38] ANTENA Móvel VHF 1/4 de Onda 131 a 900 MHz. Disponível em: <http://www.aquario .com.br/?action $=$ downloads $\&$ categoria $=4 \&$ subcategoria $=22 \&$ produto $=43>$. Acesso em 29 de julho de 2015.

[39] RH799: 70 to 1000MHz Wide-band antenna. Disponível em: <http://www.diamondant.co.jp/english/amateur/antenna/ante_3hand/ante_hand1.html>. Acesso em 29 de julho de 2015.

[40] HP 8447D Amplifier. Disponível em: <http://www.artisantg.com/info/PDF 48505F3834343746.pdf>. Acesso em 29 de julho de 2015.

[41] B. Davis and R. Bogner, "Propagation at $500 \mathrm{MHz}$ for mobile radio," IEE Proc., vol. 132, pp. 307-320, Aug. 1985. 
[42] L. Rubio, J. Reig, and N. Cardona, "Evaluation of nakagami fading behavior based on measurements in urban scenarios," AEU - International Journal of Electronics and Communications, vol. 61, no. 2, pp. 135 - 138, 2007.

[43] Wikipedia, Free Encyclopedia."Link budget". Disponível em: <http://en.wikipedia.org/ wiki/Link_budget>. Acesso em 29 de julho de 2015.

[44] L. G. de C. Ferraz; R. R.G. Garcia; D. Nunes. Estudo comparativo entre sistemas propostos para 4G: LTE e WiMAX móvel. INCITEL, 2012.

[45] Coaxial Cable Attenuation Charts. RF Elektronik, November 2012. Disponível em: $<$ http://rfelektronik.se/manuals/Datasheets/Coaxial_Cable_Attenuation_CChart.pdf $>$. Acesso em 29 de julho de 2015. 